Marley Fagundes Tavares

\title{
Utilização dos Modelos ARX e ARMAX em Plantas Industriais Ruidosas
}

Dissertação apresentada à Escola de Engenharia de São Carlos, da Universidade de São Paulo, como parte dos requisitos para obtenção obtenção do título de Mestre em Ciências, Programa de Engenharia Elétrica ${ }^{1}$.

Área de Concentração: Sistemas Dinâmicos.

Orientador: Prof. Dr. Dennis Brandão

São Carlos

2012

\footnotetext{
${ }^{1}$ Trata-se da versão corrigida da dissertação. A versão original encontra-se disponível na EESC/USP que aloja o Programa de Pós-Graduação de Engenharia Elétrica.
} 
AUTORIZO A REPRODUÇÃO E DIVULGAÇÃO TOTAL OU PARCIAL DESTE TRABALHO, POR QUALQUER MEIO CONVENCIONAL OU ELETRÔNICO, PARA FINS DE ESTUDO E PESQUISA, DESDE QUE CITADA A FONTE.

Ficha catalográfica preparada pela Seção de Tratamento da Informação do Serviço de Biblioteca - EESC/USP

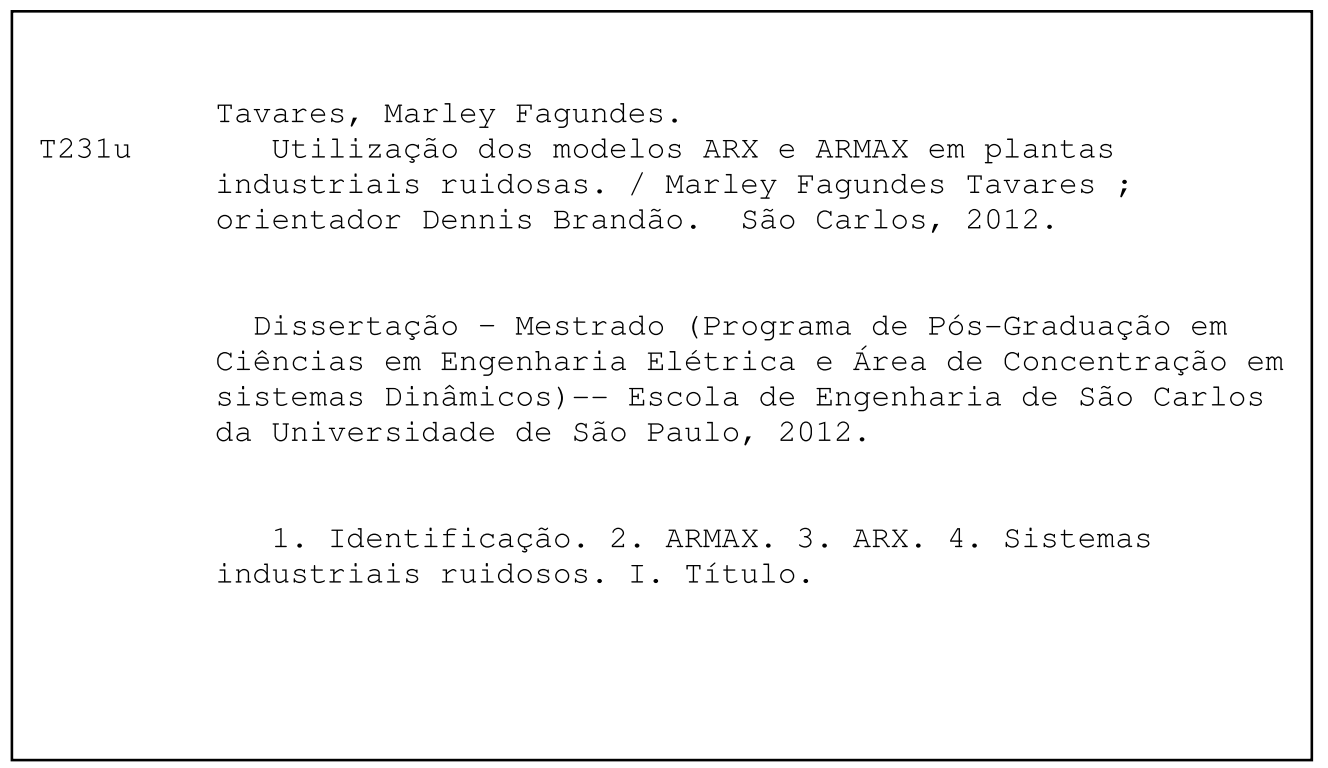


FOLHA DE JULGAMENTO

Candidato: Engenheiro MÁRLEY FAGUNDES TAVARES.

Título da dissertação: "Utilização dos modelos ARX e ARMAX em plantas industriais ruidosas".

Data da defesa: 23/05/2012

Comissão Julgadora:

Resultado:

Prof. Dr. Dennis Brandão (Orientador)

Aprovada

(Escola de Engenharia de São Carlos/EESC)

Prof. Dr. Manoel Luís de Aguiar

(Escola de Engenharia de São Carlos/EESC)

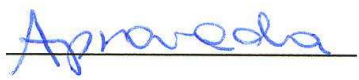

Prof. Dr. Wu Hong Kwong

(Universidade Federal de São Carlos/UFSCar)

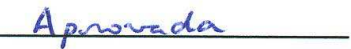

Coordenador do Programa de Pós-Graduação em Engenharia Elétrica:

Prof. Titular Denis Vinicius Coury

Presidente da Comissão de Pós-Graduação:

Prof. Associado Paulo Cesar Lima Segantine 

Às pessoas que conheci e tive a oportunidade de estar próximo e poder contar durante algumas ou todas as etapas deste Mestrado, sabem o quanto foram importantes e que devo muito as agradecer.

Houve pessoas que contribuíram estando próximos, trazendo momentos de alegrias, fazendo-me relaxar e esquecer o quão era difícil. Houve pessoas que estavam empenhadas em me fazer cumprir os prazos, mesmo quando pareciam tão apertados... Houve pessoas que contribuíram com a parte técnica e pessoas as quais a simples presença era suficiente para dar ânimo para prosseguir e terminar. Houve, também, aquelas pessoas que mesmo longe pareciam estar tão próximas que só em pensar me dava força em continuar.

Gostaria de agradecer de forma especial ao meu orientador e amigo Dennis Brandão, fonte de conhecimento, quem junto comigo acreditou e na realização deste projeto.

Aos meus pais e irmã alicerces em minha vida e faz-me seguir cada vez mais longe, amo vocês.

A minha sempre amiga e parceira de muitas, muitas conversas, no barzinho ou mesmo por telefone, quando estávamos para "estourar" seja por questões do Mestrado ou mesmo por assuntos pessoais, né Tatizinha (ou como todos a conhecem Tatiana Giorgenon Bonifácio)?!

Aos amigos que fiz (ou descobri) em São Carlos: Marcel Cezare (mais que amigo um verdadeiro irmão, mesmo longe nunca deixou de apoiar de cobrar, você é muito especial cara; se deu mal vai carregar me por resto da vida), Marcelo Marques, Lilian Gambi. A toda república da Gaiola (e suas versões): Renato Monaro, Marcelo Suetake, Almicar Querubini, Giovani Guarienti Pozzebon; Moussa, Giovanna, ao anjinho Debby (sempre 
linda), aos goianos Alexandre e Dudu, pessoas muito especiais. E claro, a república que me acolheu e me ajudou muito: Carol Ribeiro Rodrigues (mais que uma colega de república, uma verdadeira amiga que me ajudava até a falar com a Lua cheia, mesmo quando ela não aparecia, rs), Lie, Nane e Maria Clara.

Aos mais que professores e sim aos amigos Rodrigo com seus conselhos, contribuições, orientações, incentivos meu enorme agaradecimento, você foi muito importante para concretização deste projeto; ao Manoel e José Roberto.

Aos amigos que mesmo longe sempre estão comigo José Vitor, Sarah Moreno, Carolzinha, e Juliana Ambrozim.

Ao grupo e amigos do SENAI CIMATEC que viu a importância dessa conquista e, como pôde, me concedeu momentos para que eu pudesse terminá-la.

À Larissa Nou pelo sempre apoio e amor de irmã.

A Deus pela força, inspiração, capacidade e determinação para o desenvolvimento deste projeto.

À todas essas pessoas, super especiais, meu MUITO OBRIGADA. 


\section{Sumário}

Lista de Figuras v

Lista de Tabelas

Lista de Abreviaturas e Siglas xiii

$\begin{array}{ll}\text { Resumo } & \text { Xv }\end{array}$

Abstract $\quad$ xvii

1 Introdução 1

1.1 Motivação . . . . . . . . . . . . . . . . . . . . 3

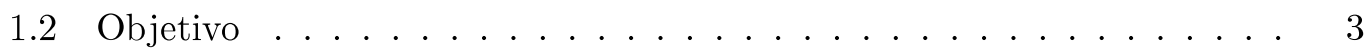

1.3 Organização da Dissertação . . . . . . . . . . . . . . . . . . . 4

2 Contextualização $\quad 5$

2.1 Nível de Chão de Fábrica . . . . . . . . . . . . . . . . . . . 6

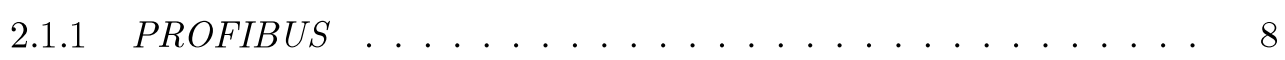

2.1.2 FIELDBUS FOUNDATION $(\mathrm{FF}) \ldots \ldots \ldots$

2.2 Nível de Supervisão . . . . . . . . . . . . . . . . . . . . . . . . 12

2.2.1 Object Linking and Embedding for Process Control (OPC) . . . 14

2.2.2 Sintonia das Malhas de Controle . . . . . . . . . . . . . . . 17

2.2 .3 Identificação de Sistemas . . . . . . . . . . . . . . . . . 26

3 Modelagem Empírica ou Identificação de Sistemas 29

3.1 Testes dinâmicos e coletas de dados . . . . . . . . . . . . . . 31

3.2 Escolha da representação matemática a ser utilizada e determinação da estrutura do modelo . . . . . . . . . . . . . . . . 34

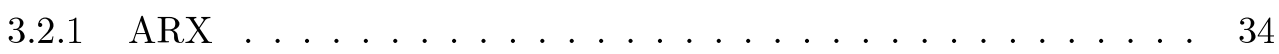

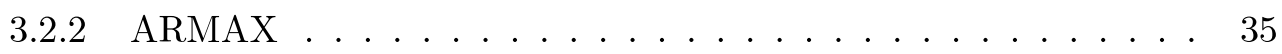


3.3 Estimação de parâmetros . . . . . . . . . . . . . . . . . . . 35

3.3.1 Mínimos Quadrados . . . . . . . . . . . . . . . . . . 35

3.4 Validação do Modelo Matemático Proposto . . . . . . . . . . . . . . . 38

4 Descrição de Teste e Resultados 41

4.1 Testes Simulados . . . . . . . . . . . . . . . . . . . . . . . . . . . 41

4.1.1 Testes Simulados em Malha Aberta . . . . . . . . . . . . . . . . 42

4.1.2 Testes Simulados em Malha Fechada . . . . . . . . . . . . . . . 52

4.1.3 Resultado da Identificação com dados reais da Usina Ipiranga . 62

$\begin{array}{llr}5 & \text { Conclusão } & 77\end{array}$

$\begin{array}{lr}\text { A Modelo OSI } & \mathbf{7 9}\end{array}$

A.1 Modelo OSI e as Redes Fieldbuses . . . . . . . . . . . . . . . . . 83

B Método de Ziegler e Nichols $\quad 85$

B.1 Primeiro Método ZN - Método Gráfico . . . . . . . . . . . . . . 85

$\begin{array}{lr}\text { Referências Bibliográficas } & 87\end{array}$ 


\section{Lista de Figuras}

FIGURA 2.1 Arquitetura de Sistema de Automação Industrial $\ldots . . \ldots$

FIGURA 2.2 Subdivisão da rede PROFIBUS em nível de chão de fábrica. . 8

FIGURA 2.3 Fluxo de informação do processo com uso de Blocos Funcionais. 9

FIGURA 2.4 Subdivisão da rede PROFIBUS em nível de chão de fábrica. . 10

FIGURA 2.5 Diagrama Geral de um Bloco Funcional. . . . . . . . . . . . . 11

FIGURA 2.6 Arquitetura do Sistema Supervisão e Controle. . . . . . . . . . . 13

FIGURA 2.7 Comunicação entre os dispositivos de campo e supervisórios

(a) através de drivers de dispositivos e (b) usando sistema OPC. . . . . 15

FIGURA 2.8 Arquitetura Cliente-Servidor. . . . . . . . . . . . 15

FIGURA 2.9 Diagrama de Blocos representando controlador Proporcional Integral Derivativo (PID) . . . . . . . . . . . . . . . . . 17

FIGURA 3.1 Diagrama de Blocos demonstrativo de um processo de mode-

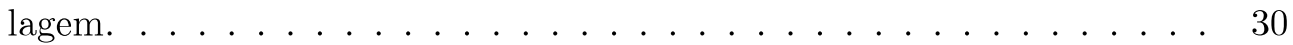

FIGURA 3.2 Fluxograma de um processo de Identificação. . . . . . . . . . 31

FIGURA 3.3 Sistema linear com n parâmetros $\ldots \ldots \ldots$. . . . . . . 36

FIGURA 4.1 Resultado simulação do sistema 1, Malha Aberta, com densidade de potência do ruído branco igual a $0,005 \ldots$. . . . . . . . . 43

FIGURA 4.2 Resultado simulação do sistema 1, Malha Aberta, com densidade de potência do ruído branco igual a $0,05 \ldots \ldots$. . . . . . . 43 
FIGURA 4.3 Resultado simulação do sistema 1, Malha Aberta, com densidade de potência do ruído branco igual a $0,5 \ldots$. . . . . . . . . . 44

FIGURA 4.4 Resultado simulação do sistema 2, Malha Aberta, com densidade de potência do ruído branco igual a $0,005 \ldots$. . . . . . . . . . 44

FIGURA 4.5 Resultado simulação do sistema 2, Malha Aberta, com densidade de potência do ruído branco igual a 0,05.

FIGURA 4.6 Resultado simulação do sistema 2, Malha Aberta, com densidade de potência do ruído branco igual a $0,5 \ldots \ldots$. . . . . . . 45

FIGURA 4.7 Resultado simulação do sistema 3, Malha Aberta, com densidade de potência do ruído branco igual a $0,005 \ldots$. . . . . . . . . . 46

FIGURA 4.8 Resultado simulação do sistema 3, Malha Aberta, com densidade de potência do ruído branco igual a $0,05 \ldots \ldots$. . . . . . . 46

FIGURA 4.9 Resultado simulação do sistema 3, Malha Aberta, com densidade de potência do ruído branco igual a $0,5 \ldots \ldots$. . . . . . . . . 47

FIGURA 4.10 Resultado simulação do sistema 4, Malha Aberta, com densidade de potência do ruído branco igual a $0,005 \ldots \ldots$. . . . . . . 47

FIGURA 4.11 Resultado simulação do sistema 4, Malha Aberta, com densidade de potência do ruído branco igual a $0,05 . \ldots \ldots$. . . . . . . . 48

FIGURA 4.12 Resultado simulação do sistema 4, Malha Aberta, com densidade de potência do ruído branco igual a $0,5 \ldots \ldots$. . . . . . . . 48

FIGURA 4.13 Resultado simulação do sistema 5, Malha Aberta, com densidade de potência do ruído branco igual a $0,005 \ldots$. . . . . . . . . . . . 49

FIGURA 4.14 Resultado simulação do sistema 5, Malha Aberta, com densidade de potência do ruído branco igual a $0,05 \ldots$. . . . . . . . . . 49

FIGURA 4.15 Resultado simulação do sistema 5, Malha Aberta, com densidade de potência do ruído branco igual a $0,5 \ldots \ldots$. . . . . . . . 50

FIGURA 4.16 Resultado simulação do sistema 6, Malha Aberta, com densidade de potência do ruído branco igual a $0,005 \ldots$. . . . . . . . . 50 
FIGURA 4.17 Resultado simulação do sistema 6, Malha Aberta, com densidade de potência do ruído branco igual a $0,05 \ldots$. . . . . . . . . . . 51

FIGURA 4.18 Resultado simulação do sistema 6, Malha Aberta, com densidade de potência do ruído branco igual a $0,5 \ldots \ldots \ldots$. . . . . . 51

FIGURA 4.19 Diagrama de Bloco do Sistema Simulado. . . . . . . . . . . . 52

FIGURA 4.20 Resultado simulação do sistema 1, Malha Fechada, com densidade de potência do ruído branco igual a $0,005 \ldots \ldots$. . . . . . . 53

FIGURA 4.21 Resultado simulação do sistema 1, Malha Fechada, com densidade de potência do ruído branco igual a $0,05 \ldots \ldots \ldots \ldots$

FIGURA 4.22 Resultado simulação do sistema 1, Malha Fechada, com densidade de potência do ruído branco igual a $0,5 \ldots \ldots$. . . . . . . 54

FIGURA 4.23 Resultado simulação do sistema 2, Malha Fechada, com densidade de potência do ruído branco igual a $0,005 \ldots$. . . . . . . . . . 54

FIGURA 4.24 Resultado simulação do sistema 2, Malha Fechada, com densidade de potência do ruído branco igual a $0,05 \ldots$. . . . . . . . . . 55

FIGURA 4.25 Resultado simulação do sistema 2, Malha Fechada, com densidade de potência do ruído branco igual a $0,5 \ldots \ldots \ldots$

FIGURA 4.26 Resultado simulação do sistema 3, Malha Fechada, com densidade de potência do ruído branco igual a $0,005 \ldots \ldots \ldots$

FIGURA 4.27 Resultado simulação do sistema 3, Malha Fechada, com densidade de potência do ruído branco igual a $0,05 \ldots \ldots \ldots$

FIGURA 4.28 Resultado simulação do sistema 3, Malha Fechada, com densidade de potência do ruído branco igual a $0,5 \ldots \ldots \ldots$. . . . . . 57

FIGURA 4.29 Resultado simulação do sistema 4, Malha Fechada, com densidade de potência do ruído branco igual a $0,005 \ldots$. . . . . . . . . . 57

FIGURA 4.30 Resultado simulação do sistema 4, Malha Fechada, com densidade de potência do ruído branco igual a $0,05 \ldots$. . . . . . . . . 58

FIGURA 4.31 Resultado simulação do sistema 4, Malha Fechada, com densidade de potência do ruído branco igual a $0,5 \ldots \ldots \ldots$ 
FIGURA 4.32 Resultado simulação do sistema 5, Malha Fechada, com densidade de potência do ruído branco igual a $0,005 \ldots$. . . . . . . . . . . 59

FIGURA 4.33 Resultado simulação do sistema 5, Malha Fechada, com densidade de potência do ruído branco igual a $0,05 \ldots \ldots \ldots$. . . . . . 59

FIGURA 4.34 Resultado simulação do sistema 5, Malha Fechada, com densidade de potência do ruído branco igual a $0,5 \ldots \ldots \ldots$. . . . . .

FIGURA 4.35 Resultado simulação do sistema 6, Malha Fechada, com densidade de potência do ruído branco igual a $0,005 \ldots$. . . . . . . . . . 60

FIGURA 4.36 Resultado simulação do sistema 6, Malha Fechada, com densidade de potência do ruído branco igual a $0,05 \ldots$. . . . . . . . . .

FIGURA 4.37 Resultado simulação do sistema 6, Malha Fechada, com densidade de potência do ruído branco igual a $0,5 \ldots \ldots$. . . . . . . . . 61

FIGURA 4.38 Conjunto de dados utilizado na identificação. Sinal de saída (superior) e entrada (inferior) de identificação referente à temperatura no processo de Aquecimento. . . . . . . . . . . . . . . .

FIGURA 4.39 Gráfico Comparativo entre diferentes estruturas de modelo, referente à temperatura do caldo de cana no processo de Aquecimento. .

FIGURA 4.40 Conjunto de dados utilizado do sistema de identificação até 2200 segundos.

FIGURA 4.41 Resultado da Validação até 2200 segundos. . . . . . . . . . . . 66

FIGURA 4.42 Conjunto de dados utilizado na identificação. Sinal de entrada, inferior, saída, superior, filtrados com Butterworth de primeira ordem e frequência de corte de $0,1 \ldots \ldots \ldots \ldots \ldots$

FIGURA 4.43 Sinais de validação da identificação com a utilização de filtro de primeira ordem e frequência de corte $0,1 \ldots \ldots \ldots$. . . . . . 68

FIGURA 4.44 Sinais de validação da identificação com a utilização de filtro de primeira ordem e frequência de corte $0,5 \ldots \ldots \ldots \ldots$. . . . . .

FIGURA 4.45 Sinais de validação da identificação com a utilização de filtro de segunda ordem e frequência de corte 0,1 . 
FIGURA 4.46 Sinais de validação da identificação com a utilização de filtro de segunda ordem e frequência de corte $0,5 \ldots \ldots$. . . . . . . . .

FIGURA 4.47 Sinais de validação da identificação com a utilização de filtro de segunda ordem e frequência de corte $0,5 \ldots \ldots$. . . . . . . 70

FIGURA 4.48 Conjunto de dados do sistema utilizados na identificação. . . . 71

FIGURA 4.49 Gráfico Comparativo entre diferentes estruturas de modelo. Dado real aferido em preto, identificado com modelo ARMAX, em verde, e com modelo ARX, em laranja. . . . . . . . . . . . . . . . . . . .

FIGURA 4.50 Gráfico Comparativo, entre diferentes estruturas de modelo, resultante da validação da modelagem utilizando filtro de primeira ordem

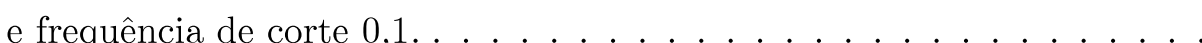

FIGURA 4.51 Gráfico Comparativo, entre diferentes estruturas de modelo, resultante da validação da modelagem utilizando filtro de primeira ordem e frequência de corte $0,5 \ldots \ldots \ldots$. . . . . . . . . . . 73

FIGURA 4.52 Gráfico Comparativo, entre diferentes estruturas de modelo, resultante da validação da modelagem utilizando filtro de segunda ordem e frequência de corte $0,1 \ldots \ldots$. . . . . . . . . . . . . . . . . . 74

FIGURA 4.53 Gráfico Comparativo, entre diferentes estruturas de modelo, resultante da validação da modelagem utilizando filtro de segunda ordem e frequência de corte $0,5 \ldots \ldots \ldots \ldots$. . . . . . . . . . . 74

FIGURA 4.54 Conjunto de dados utilizados para identificação, com uso do filtro de segunda ordem e frequência de corte $0,5 \ldots \ldots \ldots$. . . . . 75

FIGURA 4.55 Gráfico Comparativo, entre diferentes estruturas de modelo, resultante da validação da modelagem utilizando filtro de segunda ordem e frequência de corte 0,5 e cojunto de dados de validação de 944 segundos. 76

FIGURA A.1 Modelo de referência OSI. . . . . . . . . . . . . . . 79

FIGURA A.2 Modelo detalhado OSI. . . . . . . . . . . . . . . . . . 82

FIGURA A.3 Modelo OSI para Redes Fieldbuses. . . . . . . . . . . . . . . 83

FIGURA B.1 Curva de resposta ao degrau em forma de S. (OGATA, 2003) 86 


\section{Lista de Tabelas}

TABELA 2.1 Principais Softwares de Sintonia PID comercial (ANG et al., 2005)

TABELA 3.1 Resumo: resposta em Frequência x Ordem do filtro Butterworth . . . . . . . . . . . . . . . . . 33

TABELA 4.1 Sistemas simulados em ambiente Matlab. . . . . . . . . . . 42

TABELA 4.2 Índice FPE, para os modelos ARX e ARMAX, dos sistemas simulados em Malha Aberta. . . . . . . . . . . . . . 52

TABELA 4.3 Índice FPE, para os modelos ARX e ARMAX, dos sistemas simulados em Malha Fechada. . . . . . . . . . . . . . 62

TABELA 4.4 Comparação dos índices FPE para diferentes representações matemáticas. ........................ 65

TABELA 4.5 Comparação dos índices FPE para diferentes representações matemáticas, referente à temperatura do caldo de cana no processo de Aquecimento com até 2200 segundos. . . . . . . . . . . . . . . 66

TABELA 4.6 Índices FPE de diferentes representações matemáticas, com a utilização de filtro Butterworth de primeira e segunda ordem. . . . . . . 70

TABELA 4.7 Comparação dos índices FPE para diferentes representações

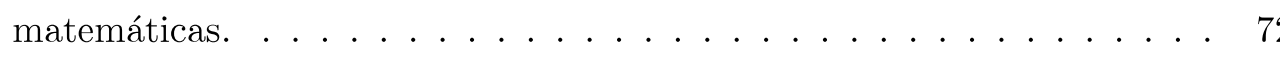

TABELA 4.8 Índices FPE de diferentes representações matemáticas, com a utilização de filtro Butterworth de primeira e segunda ordem. 
TABELA 4.9 Índices FPE de diferentes representações matemáticas, com conjunto de dados de modelagem reduzido para 944 dados. . . . . . . . 76

TABELA B.1 Regra Sintonia de Ziegler e Nichols baseado na resposta ao degrau da planta - Primeiro Método. (OGATA, 2003) . . . . . . . 86 


\section{Lista de Abreviaturas e Siglas}

AR Auto Regressive - Auto Regressivo

ARX Auto Regressive with External Input - Auto Regressivo com entrada exógena

ARMAX Auto Regressive Moving Average with Exogeneous Input- Auto Regressivo com média móvel e entrada exógena

CLP Controlador Lógico Programável

DDE Dynamic Data Exchange

FF Fieldbus Foundation

FPE Akaike's Final Prediction Error - Critério do Erro Final de Akaike

HTTP Hyper Text Transfer Protocol

IAE Integrated Absolute Error - Integral do valor Absoluto do Erro

IE Integrated Error - Integral do Erro

IMC Internal Model Control

ISE Integrated Square Error - Integral do Erro Quadrático

ISO International Organization for Standardization

ITAE Integrated of the Time Multiplied by Absolute Error - Integral do Erro Absoluto Multiplicado pelo Tempo

ITSE Integrated of the Time Multiplied by Square Error - Integral do Erro Quadrático Multiplicado pelo Tempo

MQ Mínimos Quadrados 
NARMAX Non-Linear Auto Regressive Moving Average with Exogeneous Input Auto Regressivo com média móvel e entrada exógena não Linear

OPC Object Linking and Embedding for Process Control

OSI Open Systems Interconnection

PID Proporcional Integral Derivativo

SCADA Supervisory Control and Data Acquisition

SD Síntese Direta

SISO Single input Single Output - Única Entrada e Única Saída

TITO Two Input Two Output - Duas Entradas e Duas Saídas

WWW World Wide Web 


\section{Resumo}

Tavares, M. F. (2011). Identificação em Plantas Industriais Ruídosas. São Carlos, 2011. Qualificação (Mestrado) - Escola de Engenharia de São Carlos, Universidade de São Paulo.

Técnicas experimentais de Identificação de Sistemas de controle têm despertado interesse na indústria devido a sua facilidade em ajustar modelos matemáticos, simplificando a formulação e a resolução de problemas de sintonia de controle de processos. Essa sintonia possibilita, também, a conservação das características de desempenho do processo industrial durante o ciclo de produção. Dessa forma, é proposto, no presente trabalho, o uso de uma técnica experimental de Identificação de Sistemas aplicados a dados coletados em ambientes industriais ruidosos, utilizando a estrutura matemática linear ARX e ARMAX. Os parâmetros dessas estruturas matemáticas são estimados por meio do algoritmo dos Mínimos Quadrados (LS).

Palavras-chave: Identificação, ARMAX, ARX, sistemas industriais. 


\section{Abstract}

Tavares, M. F. Identificação em Plantas Industriais Ruídosas São Carlos, 2011. M. Sc. Qualification - Escola de Engenharia de Sãoo Carlos, Universidade de São Paulo.

Experimental Techniques for Systems Control Identification have attracted interest in the industry due to its ease adjustment of mathematical models, simplifying the (design) and troubleshooting of line process control. (This line also makes retention performance characteristics of the manufacturing process during the production cycle possible). Thus, it is proposed in this study, using an experimental technique of Identification Systems applied to data collected in noisy industrial ambient, using linear mathematical structure $A R X$ and ARMAX. These mathematical structure parameters are estimated by the algorithm of least squares (LS).

Keywords: Identification, ARMAX, ARX, industrial systems. 


\section{Capítulo 1}

\section{Introdução}

Em tempos onde a competitividade dita o ritmo do desenvolvimento industrial, a melhoria contínua na qualidade do processo de fabricação e dos produtos é cada vez mais determinante. Além disso, a maximização da produção, acompanhada da redução dos custos operacionais, respeitando leis ambientais e primando pelo uso racional de energia são cada vez mais exigidos no cenário econômico atual.

Investimentos em automação industrial tornam-se um requisito considerável para atender tais exigências de mercado. Estes devem ser aplicados desde níveis de chão de fábrica, onde o controle é distribuído em equipamentos de campo mais modernos ditos "inteligentes"; até o nível de gerenciamento com análise e otimização dos processos, em centros de controle, capazes de monitorar e atuar todo processo produtivo.

Todavia, vale salientar que a substituição de equipamentos, apenas, não produz, obrigatoriamente, a melhoria na qualidade do produto final, nem tão pouco a otimização do custo de produção. Isto porque é indispensável considerar a continuidade do processo, ou seja, é necessário contemplar uma correta sintonia das malhas de controle. O observado é que grande parte das malhas em operação apresenta problemas de sintonia, ou são sintonizadas de forma deficitária, possuindo, assim, um pior desempenho, o que representa um custo ainda maior para a indústria. (ARRUDA et al., 2008)

Os controladores industriais para processos são, em sua grande maioria, do tipo proporcional-integrativo-derivativo (PID). Esta popularidade se deve principalmente à simplicidade no ajuste de seus parâmetros para se obter um bom desempenho e pelo 
fato de que seu algoritmo está disponível em muitos equipamentos industriais. A ação destes controladores se dá pela combinação das características particulares dos seus parâmetros, ajustados de forma precisa.

A técnica de sintonia dos controladores consiste em encontrar o conjunto de parâmetros do controlador respeitando às especificações de desempenho requeridas em cada processo. Para isso, é muito importante que se conheça o modelo matemático que descreva adequadamente o comportamento do processo em interesse.

A obtenção de modelos que reproduzem exatamente o comportamento de um sistema é algo em geral inviável. Na prática, os modelos se aproximam satisfatoriamente do comportamento do sistema para uma determinada aplicação específica dada uma faixa de operação limitada. Deste modo, não existe um modelo para um determinado sistema, mas diversos modelos para o mesmo. Nem sempre o modelo que mais se aproxima do comportamento de um sistema é o mais correto, mas apenas o mais adequado, ou eficaz, para uma determinada aplicação. Todavia, é importante ressaltar que a obtenção do modelo matemático deve estabelecer um compromisso entre a simplicidade do modelo e a precisão de sua resposta.

Os modelos podem ser descritos na forma de função de transferência, espaço de estado ou em resposta em frequência sobre toda a faixa de operação. De forma geral, as informações que os compõe são obtidas a partir dos conhecimentos científicos, ou oriundos dos dados obtidos diretamente da planta através de testes empíricos, ou mesmo, como se pratica habitualmente, através do uso combinado dessas duas técnicas, isto é, aplica-se um pouco de conhecimento científico sobre os dados coletados do sistema.

Vale salientar que as duas últimas técnicas descritas caracterizam-se por serem mais utilizadas nos processos industriais, pois se valem da obtenção de sinais de processo sem modificar o funcionamento habitual da planta nos ambientes fabris. Além disso, a extrema complexidade das leis físico-químicas dos fenômenos envolvidos ou mesmo a falta de conhecimento total do sistema são razões que dificultam a utilização da modelagem por métodos científicos, validados através de experimentos diretamente conduzidos para excitar o processo e medir sua resposta.

De forma pragmática, os processos reais são representados por modelos ideais sem a presença de distúrbios ou ruídos inerentes ao processo. Tais perturbações podem ser originadas a partir de instrumentos ou métodos utilizados nas medições ou atuações, ou 
seja, as irregularidades podem ser intrínsecas aos equipamentos de aquisição ou atuação dos sinais, ou podem ocorrer por processos de desgastes e falhas naturais aos sistemas acarretados pelo uso ao longo do tempo; ou mesmo por perturbações inesperadas ao funcionamento típico do sistema. Independentemente da fonte, os distúrbios interferem de forma qualitativa e quantitativa na qualidade dos modelos matemáticos estimados e precisam ser considerados nos processos, com o objetivo de estimar modelos mais exatos e próximos dos reais; bem como tornar o processo de sintonia mais adequado ao sistema de produção em interesse.

\subsection{Motivação}

Em virtude da automação industrial ser cada vez mais presente nos ambientes fabris, a motivação desse estudo consiste em aumentar a eficiência dos processos com procedimentos adequados de sintonia das malhas de controle, a partir de uma modelagem eficaz, mesmo em situações não ideais em que se tem a presença de ruídos. Esta ação busca a estabilidade e o desempenho satisfatório dos sistemas e colaborará com a maximização da economia de matéria prima, melhoria do produto final, qualidade aos consumidores e redução dos custos de produção; possibilitando, assim, uma maior competitividade as empresas.

\subsection{Objetivo}

O objetivo deste projeto é o desenvolvimento e validação de técnicas experimentais de identificação aplicadas aos sistemas dinâmicos industriais considerando a presença dos ruídos provenientes de diferentes fontes, a fim de que modelos matemáticos mais adequados possam ser indicados em procedimentos de sintonia e controle mais eficientes de sistemas.

Para o cumprimento deste objetivo são propostas algumas atividades, como:

1. Coleta dos sinais a serem identificados, oriundos de um processo industrial.

2. Preparação dos sinais que serão utilizados na identificação. Isto através da análise do conjunto de dados de entrada e da redução do efeito do ruído nos sinais de entrada e saída, pelo do eventual uso de filtros. 
3. Escolha da estrutura que melhor representará o sistema em interesse, etapa baseada em aproximar o modelo ao sistema em interesse.

4. Validação da arquitetura proposta através de estudos em dados de plantas reais.

\subsection{Organização da Dissertação}

O texto desta dissertação encontra-se organizado em cinco capítulos, incluindo este de introdução. No capítulo seguinte, contextualiza o leitor a cerca do assunto abordado, através um estudo da arte da arquitetura do sistema de automação.

O capítulo 3 apresenta o desenvolvimento teórico sobre modelagem e identificação de sistemas com descrição de algoritmos difundidos na literatura.

No capítulo 4 é mostrado, em detalhes, os resultados do estudo proposto, onde são descritos os ensaios simulados e a identificação de uma planta industrial de usina de cana-de-açúcar.

Por fim, o capítulo 5 é apresentada a conclusão desta dissertação. 


\section{Capítulo 2}

\section{Contextualização}

A evolução tecnológica dos sistemas industriais proporcionou mudanças notórias nos equipamentos e softwares de supervisão e controle dos processos. Neste cenário, a integração entre ambos e a disponibilidade dos dados passaram a serem fundamentais para oferecer maior confiabilidade, flexibilidade e interoperabilidade aos processos industriais, influindo nos custos, nos modos de gestão e manutenção.

Segundo ZEILMANN (2002), a moderna arquitetura distribuída da automação industrial caracteriza-se em promover uma maior integração entre os diferentes níveis de uma fábrica, abrangendo desde o nível de chão de fábrica, passando pelo nível supervisão e chegando até o nível de gerenciamento, como representado na Figura 2.1.

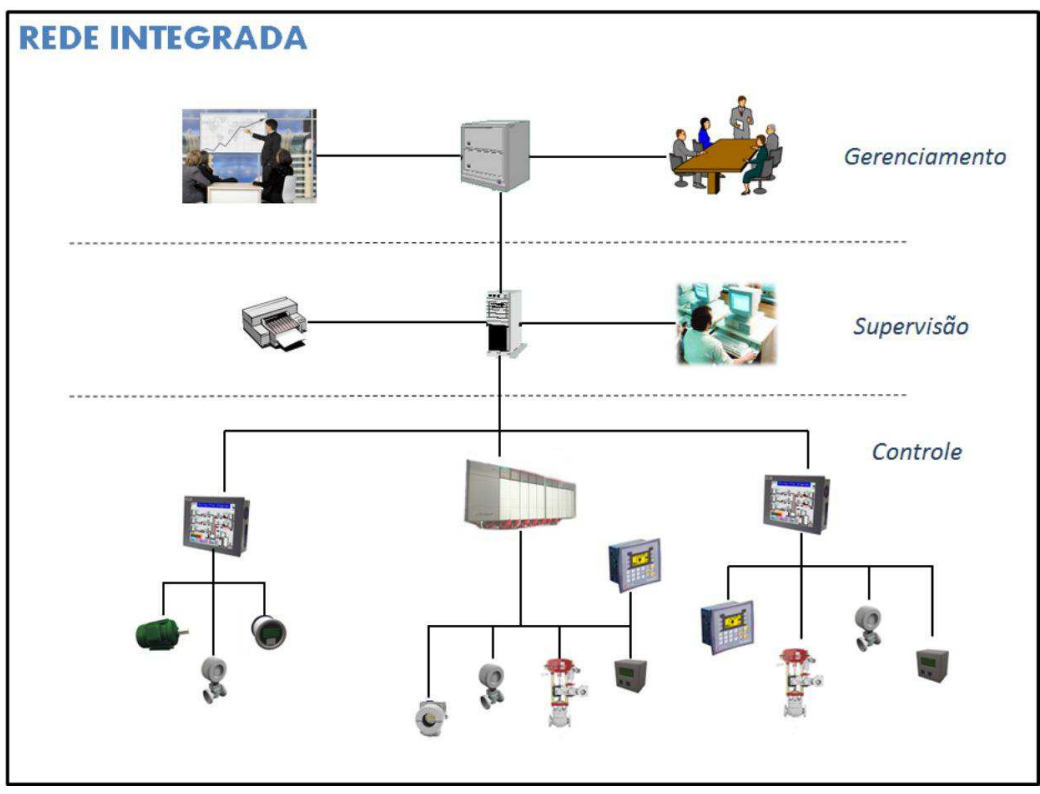

Figura 2.1: Arquitetura de Sistema de Automação Industrial 
No nível mais baixo da arquitetura de automação industrial, denominado chão de fábrica, estão os controladores e os dispositivos de campo inteligentes capazes de executar processamento local e comunicar-se entre si, usualmente, através da comunicação em barramento, denominado barramento de campo (fieldbus).

O nível de supervisão monitora e controla os processos executados em uma planta industrial através de variáveis advindas do campo. Este utiliza, na grande maioria e em diversos meios, os sistemas de Supervisão e Aquisição de Dados, ou Supervisory Control and Data Acquisition (SCADA), que permitem a supervisão do processo em tempo real e engloba as etapas de diagnóstico e sintonia das malhas de controle envolvidas nos processos; possibilitando o aumento na produtividade e na qualidade da automação industrial.

O nível mais alto, denominado de nível de gerência, é responsável pela manipulação e manutenção da base desses dados com as informações sobre a coordenação, o planejamento da produção e os demais negócios de uma empresa.

Em muitos casos, tais níveis ou áreas da empresa encontram-se geograficamente distribuídas, a fim de reduzir os custos e promover a melhoria de atendimento ao cliente. Dessa forma, esse posicionamento estratégico fez surgir a necessidade da integração dados em tempo real, podendo atualmente ser feito através de sistemas baseados na Internet. (JÚNIOR, 2009) (ZEILMANN, 2002).

Logo, alicerçado nas novas tendências tecnológicas em automação industrial antes expostas, serão apresentados neste capítulo conceitos relacionados aos dois níveis mais baixos da hierarquia da automação industrial que servirão de base para compreensão desse estudo.

O nível de gerência não constitui foco desse estudo e pode ser melhor detalhado em NOGUEIRA (2009), SOUZA et al. (2005) VIANA e SILVEIRA (2005).

\subsection{Nível de Chão de Fábrica}

O nível de chão de fábrica é formado por dispositivos que interagem diretamente ao processo, como sensores, controladores e atuadores. Estes dispositivos, seguindo a nova tendência permitida pela evolução da comunicação digital, são denominados dispositivos de campo inteligentes. Isto, pois são capazes de executar o processamento 
local e comunicar-se entre si, possibilitando a troca de dados não só de entradas e saídas, aumentando a confiabilidade e visibilidade de parâmetros no ambiente industrial.

Usualmente, essa comunicação entre controladores de processo, sensores e atuadores, nos níveis inferiores da hierarquia de automação industrial, se dá através da topologia em barramento, denominado barramento de campo (ou redes fieldbuses).

As redes fieldbuses podem ser definidas como redes digitais, bidirecionais, multiponto e serial, de padrão aberto, baseadas no modelo Open Systems Interconnection (OSI)/International Organization for Standardization (ISO), cujos níveis implementados são apenas o 1, 2 e 7 e a de usuário, para atender aos requisitos de tempo de resposta.

Segundo BRANDÃO (2005), os barramentos de campo são peças importantes dentro do ambiente industrial devido a vantagens como: distribuição do controle, facilidade de expansão, interoperabilidade, intercambiabilidade, segurança, determinismo e possibilidade de acesso remoto.

Vale ressaltar que em ambientes industriais a comunicação em tempo real, conseguida a partir da comunicação fieldbus, é um grande diferencial para manter a competitividade entre as empresas; pois as informações coletadas do processo influenciam no histórico de dados de produção, bem como nas decisões futuras. Assim, os benefícios tecnológicos e funcionais obtidos com a utilização de barramento de campo fazem dessa solução importante componente no estado da arte em instrumentação e controle de plantas industriais.

Existem diversos tipos de protocolo de barramento de campo utilizados nas diversas áreas industriais - indústrias petroquímicas, farmacêuticas, de álcool, açúcar, móveis, geração de energia, dentre muitas outras - como Fieldbus Foundation (FF), Profibus-PA e HART. Segundo JÚNIOR (2009), os protocolos de maior destaque e bases instaladas atualmente nesse tipo de processo são o PROFIBUS e FF. Nos tópicos seguintes serão apresentadas as principais características e funcionalidades destes protocolos para melhor compreensão da realização desse estudo. Informações adicionais podem ser mais bem detalhadas em BRANDÃO (2005), NOGUEIRA (2009), ou mesmo nas próprias especificações desses protocolos. 


\subsubsection{PROFIBUS}

Baseado em padrões internacionais reconhecidos, como o European Fieldbus Standard EN 50170 e EN50254 e pelo padrão IEC 61158-2, este protocolo caracteriza-se em possibilitar redução de custos, flexibilidade, confiança, atendimento as mais diversas aplicações e interoperabilidade com outros protocolos ou padrões. (ALBUQUERQUE e ALEXANDRIA, 2009).

O PROFIBUS é um protocolo do tipo multi-mestre/escravo. Estes são chamados de estações ativas e podem ser classificados em: mestre Classe 1, responsável pelas operações cíclicas e pelo controle das malhas do sistema, são representados pelos Controlador Lógico Programável (CLP); ou em mestre Classe 2, responsável pelos acessos acíclicos dos parâmetros e funções dos equipamentos, tem por função: configuração, manutenção e diagnóstico da rede de campo. (SMAR, 2011) (JÚNIOR, 2009). Já os dispositivos escravos (dispositivos de entrada/saída, válvulas, sensores e transmissores de medidas) não têm direito de acesso direto ao barramento e podem somente reconhecer informações recebidas ou emitir mensagem ao mestre quando solicitados. São denominados de estações passivas.

No nível de chão de fábrica, o PROFIBUS é subdividido em PROFIBUS-DP e PROFIBUS-PA, como a figura 2.2 .

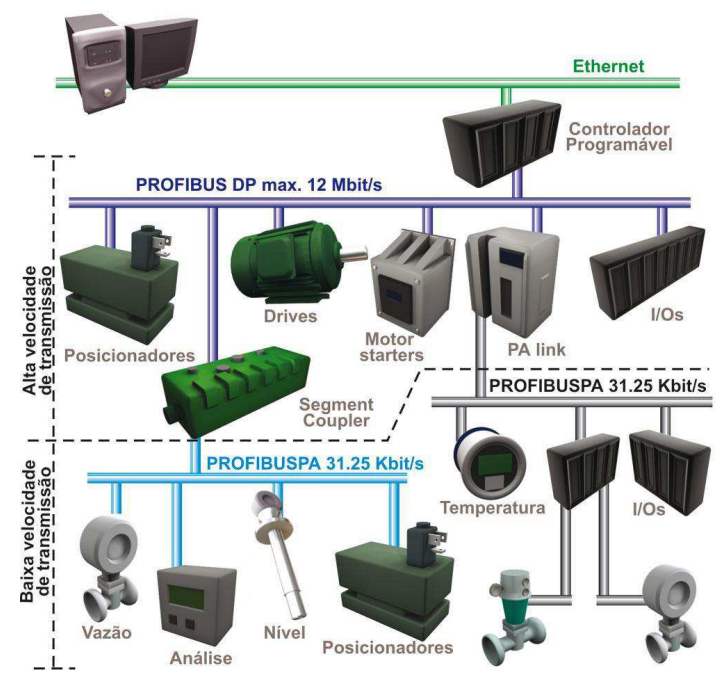

Figura 2.2: Subdivisão da rede PROFIBUS em nível de chão de fábrica.

Outra versão desse protocolo é o PROFINET utilizado nos níveis hierárquicos superiores e por isso não será detalho nessa parte do estudo. Esta descrição pode ser 
melhor detalhado em (ALBUQUERQUE e ALEXANDRIA, 2009), (SMAR, 2011) e (JÚNIOR e CARDOSO, 2010).

O PROFIBUS PA é aplicado à automação de processo e seus equipamentos são estruturados internamente em unidades lógicas padronizadas chamadas de módulos ou blocos funcionais. Segundo SMAR (2002), o bloco de função é um algoritmo em tempo real que transforma os sinais de entrada em sinais de saída. A figura 2.3 mostra o fluxo de informação do processo e a aplicação dos blocos funcionais.

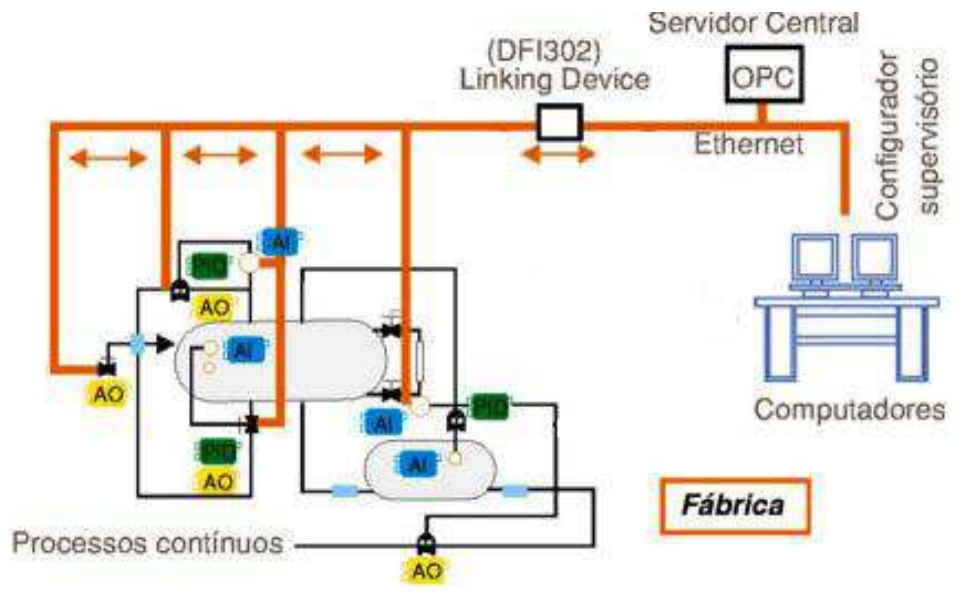

Figura 2.3: Fluxo de informação do processo com uso de Blocos Funcionais.

Deve-se salientar que a interoperabilidade e a intercambialidade dos dispositivos de campo dos diferentes fabricantes são obtidos também pelo uso de blocos funcionais.

Alguns dos blocos funcionais são:

- Bloco de Entrada Analógica- AI -(Analog Input Block): fornece o valor medido pelo sensor, com estado e escala." (JÚNIOR e CARDOSO, 2010)

- Bloco de Saída Analógica- AO -(Analog Output Block): fornece o valor da saída analógica especicada pelo sistema de controle (JÚNIOR e CARDOSO, 2010).

Segundo JÚNIOR (2009), a padronização do protocolo inclui dentre outros blocos, os blocos de entrada e saídas. Os blocos de controle e cálculo, que estão dentro dos mestres, do tipo 1, no protocolo PROFIBUS DP, não possuem padronização, ou seja, as variáveis são tratadas de formas diferentes para cada fabricante. Dessa forma, os controladores não padronizados terão seus conjuntos de parâmetros e algoritmos variando a cada malha. Assim, um software de sintonia de malha precisará de especificação 
de drives para cada fabricante, o que resulta em um sistema ineficiente, com custo alto e não integrável.

A figura 2.4 representa uma malha de controle formada pelos blocos funcionais e o controlador em um ambiente de rede de comunicação PROFIBUS.

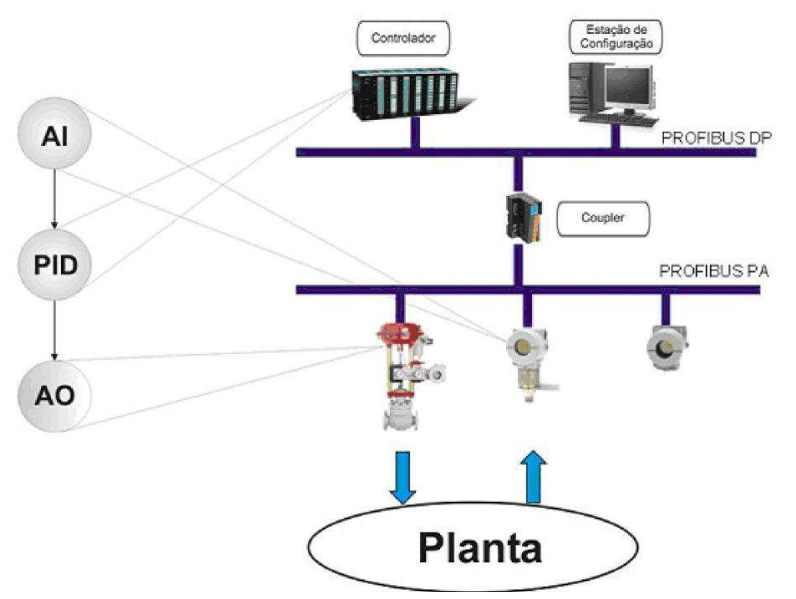

Figura 2.4: Subdivisão da rede PROFIBUS em nível de chão de fábrica.

\subsubsection{FIELDBUS FOUNDATION (FF)}

É um protocolo de comunicação industrial especificamente desenvolvido para aplicações robustas e para realização de controle distribuído dos processos. Uma das funções dos equipamentos de campo, neste tipo de rede, é executar a aplicação de controle e supervisão. Esta é a grande diferença entre Foundation Fieldbus e outras tecnologias, que dependem de um controlador central para executar os algoritmos. Além disso, esse tipo protocolo caracteriza-se por ser digital, bidirecional e permitir comunicação simultânea entre vários equipamentos conectados à rede.

A base da arquitetura Fieldbus Foudation é a programação dos blocos funcionais ( assim como o Profibus, porém com mais recursos), os quais executam as tarefas necessárias às aplicações existentes tais como: aquisição de dados, controle PID, cálculos e atuação. Todo bloco funcional contém um conjunto de parâmetros de controle e algoritmo associado, além de uma base de dados (entrada/saída) e um nome definido pelo usuário ( $\operatorname{tag}$ que deve ser único para a aplicação do usuário). Um equipamento FF pode conter um número definido de blocos funcionais. A interligação dos blocos funcionais é que define a estratégia de controle e a programação do processo a ser controlado. 


\section{(ALBUQUERQUE e ALEXANDRIA, 2009) (ZEILMANN, 2002).}

Vale salientar que nestes blocos funcionais as interfaces e os comportamentos são definidos na norma regulamentadora do FF, que define uma linguagem universal para descrição de aplicativos de controle de processo e automação. Nesta especificação é definido um conjunto básico de parâmetros usado por qualquer bloco, além da biblioteca padrão de blocos. Adicionalmente, estão previstas opções para que os fabricantes adicionem funcionalidades aos blocos já existentes ou mesmo desenvolvam novos blocos, caso necessário. (JÚNIOR, 2009).

O FF é um protocolo interoperável suportado por pela quase totalidade dos grandes fabricantes mundiais de instrumentação. Segundo CUNHA (2009), dentre outros benefícios, o uso do protocolo FF possibilitou à indústria:

- Menores Gastos com Equipamentos Supervisórios: os dispositivos oferecem auto diagnósticos;

- Fácil configuração do sistema: iteração entre o operador e o protocolo é feita através de blocos funcionais;

- Redução de hardware: os sensores e atuadores comunicam direto com a rede sem necessidade de subsistema Entrada/Saída, figura 2.5.

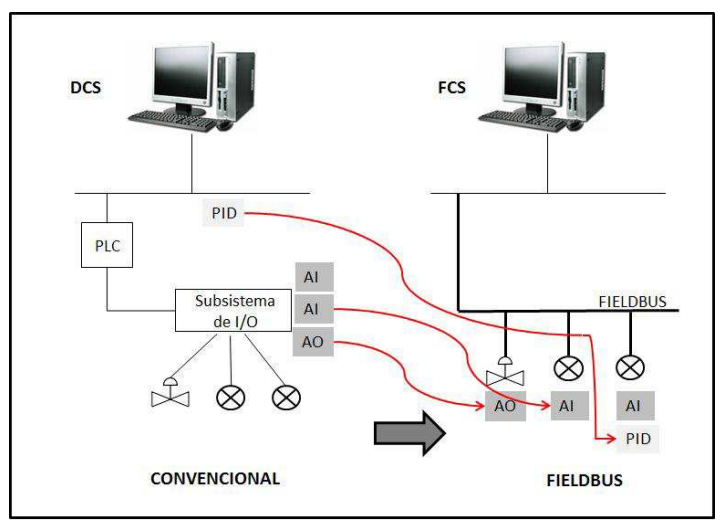

Figura 2.5: Diagrama Geral de um Bloco Funcional.

- Menor custo na implementação de novas malhas de controle: na implantação de novas malhas de controle, o protocolo necessita apenas da adição de novos dispositivos;

- Facilidade de supervisão: Os dados dispostos no protocolo FF são dispostos em 
um servidor de dados. Atualmente, o padrão OPC (Object Linking and Embedding for Process Control) é adotado como o padrão de comunicação entre softwares supervisórios e protocolo FF.

\subsection{Nível de Supervisão}

Os sistemas de automação industrial modernos atingiram um nível de complexidade que a intuição e experiência humana não são mais suficientes ou eficientes para construir rapidamente modelos bem definidos dos mesmos. Um ambiente representativo torna-se necessário pra que se alcance tal objetivo.

Dessa forma, softwares conhecidos como supervisórios ou SCADA permitem a supervisão, operação e a visualização,através de telas gráficas elaboradas, de qualquer processo industrial ou comercial, independente do tamanho da planta.

São utilizados extensivamente nas indústrias podendo ir de centenas a milhares de pontos de entradas ou saídas das diversas partes do controle de processo. (ZEILMANN, 2002) (JÚNIOR, 2009) (SILVA, 2005) (JURIZATO e PEREIRA, 2003).

Segundo SILVA (2005), os primeiros sistemas SCADA permitiam informar periodicamente o estado corrente do processo industrial, monitorando sinais representativos de medidas e estados de dispositivos, através de um painel de lâmpadas e indicadores, sem que houvesse qualquer interface com operador.

Atualmente, os sistemas de automação industrial utilizam tecnologias da comunicação e informática que tornam mais eficaz a supervisão e controle dos processos industriais. Esses sistemas efetuam a coleta de dados em ambientes complexos e apresenta-os de modo "amigável" para o operador com recursos gráficos elaborados (como gráficos, animações, relatórios, etc.) e conteúdo multimídia. Assim, os sistemas exibem de forma clara a evolução do estado dos dispositivos e do processo controlado, permitindo informar as anomalias e sugerir medidas a serem tomadas automaticamente.

Os sistemas SCADA baseiam-se em tags, nomes que representam e associam as variáveis de processo ao sistema de supervisão e controle, como unidade básica de dados. A partir daí, as estratégias de controle, relatórios, históricos, dentre outras tarefas são possíveis; o que gera grande flexibilidade de configuração para o usuário. 
Além disso, esses sistemas podem verificar condições de alarme, identificadas quando o valor da tag ultrapassa uma condição ou faixa pré-estabelecida, programando, a gravação de registros em banco de dados, ativação de som, envio de mensagem, email, etc.

A arquitetura geral de um sistema SCADA dá-se através da comunicação com equipamentos de campo (sensores/atuadores), cujas informações são enviadas a uma estação remota (CLP, por exemplo), que dentre outras funções lêem as entradas, realiza cálculos ou controles e atualiza a saídas. Em seguida, as informações são enviadas as estações de monitoração central (unidades responsáveis por recolher informações geradas pelas estações remotas e agir em conformidade com evento destacados, podendo ser centralizados em único computador ou distribuídos por uma rede de computadores), via rede de comunicação, de modo a permitir o compartilhamento das informações coletadas. Essa arquitetura do sistema SCADA é demonstrada na figura 2.6.

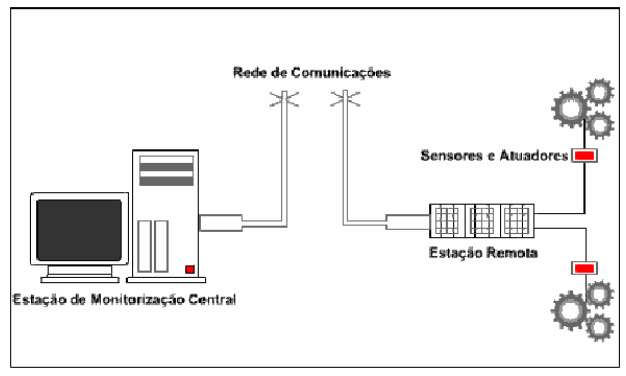

Figura 2.6: Arquitetura do Sistema Supervisão e Controle.

Segundo SILVA (2005), as tecnologias computacionais utilizadas para o desenvolvimento dos sistemas SCADA têm evoluído bastante nos últimos anos, possibilitando um aumento gradativo da confiabilidade, flexibilidade e conectividades.

Vale salientar que, atualmente, os diversos softwares de supervisão adotaram alguns padrões de comunicação de interface Windows, sendo o padrão OPC o mais difundido em aplicações industriais; e o padrão Dynamic Data Exchange (DDE), que possibilita ao supervisórios importar e exportar dados para outros aplicativos como Microsoft office ou Matalb aumentando, assim, o poder de análise matemática do sistema. (ZEILMANN, 2002).

JANKE (2000) afirma que o OPC tornou-se um padrão em ambientes industriais, por ser considerado mais robusto e eficiente do que outros meios de comunicação entre aplicativos, por exemplo, padrão de DDE. Além disso, segundo CUNHA (2009), outro 
ponto importante, é que o OPC possibilita uma grande economia no tempo gastos com o desenvolvimento de novos aplicativos e na manutenção dos existentes, em virtude de sua característica maior: a interoperabilidade.

\subsection{1 $O P C$}

Desde o final da década de 90, os sistemas supervisão e controle de sistemas utilizam as facilidades promovidas pelo sistema OPC (Object Linking and Embedding for Process Control), que possibilitou aos distintos fabricantes desenvolverem apenas um driver para comunicação entre os dispositivos. Diferentemente do modo antigo, o qual cada fabricante tinha de desenvolver drives proprietários para suportar seus dispositivos nas aplicações. (PANTONI, 2006).

Dessa forma, a interface OPC torna possível a interoperabilidade entre os equipamentos de diferentes fabricantes, promovendo uma maior integração dos dados de toda a empresa, sejam provenientes do chão de fábrica ou dos setores corporativos.

Tradicionalmente, era necessário um desenvolvimento de driver customizado para trocar dados entre diferentes dispositivos, como por exemplo: um software de supervisão tinha seus próprios drivers para se comunicar com cada um dos outros dispositivos existentes no mercado, esses drivers não poderiam ser utilizados em outro software de supervisão. A tecnologia OPC elimina estes requisitos pela padronização de uma interface comum de alto desempenho que permite que este trabalho seja feito apenas uma vez, ou seja, os desenvolvedores de sistemas implementam o driver para comunicação com o sistema OPC e esse "traduz" para os diferentes dispositivos, como ilustrado na figura2.7. (OPCFOUDATION, 2009).

OPC é um padrão de comunicação aberto, que tem como principal objetivo permitir a interoperabilidade vertical entre sistemas dentro de uma organização. Este sistema é baseado nas tecnologias Microsoft OLE COM (Component Objetc Model) e DCOM (Distributed Component Object Model) e caracteriza-se por ser um conjunto comum de interfaces, métodos e propriedades de comunicação.

O funcionamento do OPC é alicerçado na tradicional arquitetura cliente-servidor, conforme a figura 2.8 .

O funcionamento dessa arquitetura ocorre de forma simplificada, um ou mais ser- 


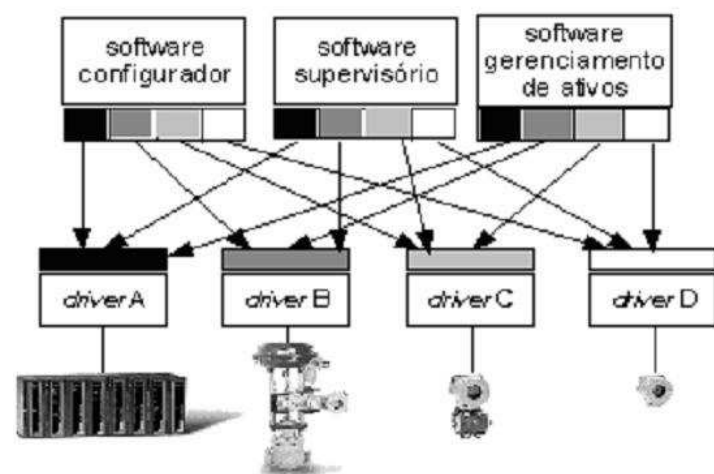

(a)

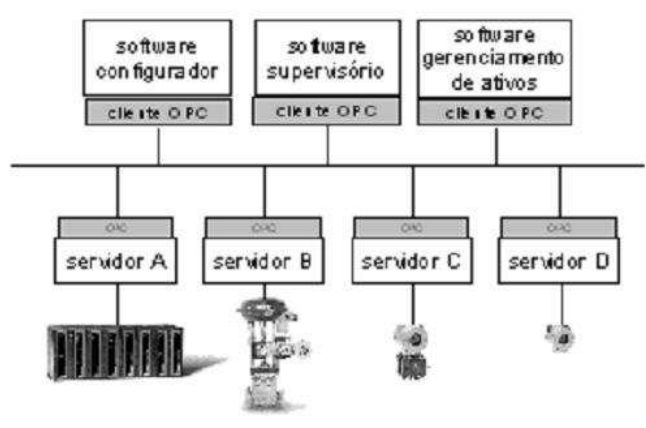

(b)

Figura 2.7: Comunicação entre os dispositivos de campo e supervisórios (a) através de drivers de dispositivos e (b) usando sistema OPC.

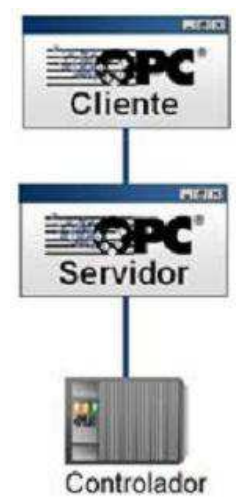

Figura 2.8: Arquitetura Cliente-Servidor.

vidores fornecem dados para uma ou mais aplicações clientes. Vale ressaltar que uma aplicação cliente pode solicitar dados a um ou mais servidores OPC, e o inverso também é verdadeiro, um servidor OPC pode transferir dados a um ou mais clientes. Portanto, o OPC possibilita uma variedade enorme de comunicações, basta que os aplicativos sejam compatíveis com o sistema OPC.

É importante observar que o OPC não elimina o protocolo proprietário dos dispositivos, como do CLP, por exemplo, ou de outro equipamento de campo. O que acontece é que o servidor OPC "traduz" este protocolo proprietário para o padrão OPC. Portanto é necessário o desenvolvimento de um servidor OPC específico para cada um dos diferentes protocolos de comunicação existentes. (OPCFOUDATION, 2009).

As principais especificações desenvolvidas são:

- $\underline{\text { OPC versão } 1.00}$ Fornece e descreve definições, interfaces e serviços comuns a 
todas as especificações.

- OPC DA (Data Access): Principal especificação do OPC fornece a funcionalidade de transferência de dados em tempo real e contínua de CLPs, IHMs (Interface Homem Máquina), sistemas supervisórios e similares.

- OPC HDA (Historical Data Acess): Fornece mecanismos consistentes e uniformes acesso aos dados históricos

- OPC Alarmes e Eventos - AE - (Alarmsש́Events): Fornece notificações de alarmes e eventos sob demanda, como alarme de processo, ações de operador, etc.

- OPC UA (UnifiedArchiteture): Especificação emergente, baseada em tecnologia orientado a WEB (como TCP/IP, HTTP, SOAP e XLM), esta especificação OPC permite a integração das várias outras especificações (como OPC DA, OPC AE, OPC HDA, etc). Bem como, possibilitou a portabilidade, ou seja, os clientes e servidores OPC podem ser implementados em qualquer tecnologia e em qualquer plataforma, eliminando a obrigatoriedade da tecnologia COM da Microsoft.

FONSECA (2002) evidencia as seguintes vantagens conseguidas com a utilização do sistema OPC:

- Padronização das interfaces de comunicação entre os servidores e clientes de dados de tempo real, facilitando a integração e manutenção dos sistemas;

- Eliminação da necessidade de drivers de comunicação específicos;

- Melhoria do desempenho e otimização da comunicação entre dispositivos de automação;

- Interoperabilidade entre sistemas de diversos fabricantes;

- Integração com sistemas de gerência e aplicações Windows (Excel, etc.)

- Redução dos custos e tempo para desenvolvimento de interfaces e drivers de comunicação, com consequente redução do custo de integração de sistemas;

- Facilidade de desenvolvimento e manutenção de sistemas e produtos para comunicação em tempo real; 


\subsubsection{Sintonia das Malhas de Controle}

Recentemente, mesmo com o avançado das técnicas de controle, ainda se observa o uso predominante do controlador Proporcional - Integral - Derivativo (PID) a uma larga faixa de processos industriais. Segundo ASTRÖM e HÄNGGLUD (2001) e ANG et al. (2005) mais de 90\% das malhas industriais existentes ainda são do tipo PI/PID, esta longevidade é devido a sua simplicidade, facilidade de implementação, aplicabilidade, robustez, versatilidade e baixo custo.

Um controlador PID tem a tarefa de gerar um sinal de controle capaz de corrigir a diferença entre o sinal de referência e o sinal de saída do processo que está controlando. A equação (2.1) descreve o comportamento desses controladores. Nesta equação, a ação de controle dá-se pela soma da combinação da característica particular de cada termo: proporcional, integral e derivativo, como pode ser visto no diagrama de blocos da figura 2.9 .

$$
u(t)=K\left(e(t)+\frac{1}{T_{i}} \int_{0}^{t} e(\tau) d(\tau)+T_{d} \cdot \frac{d e(t)}{d(t)}\right)
$$

Onde: $K$ é o ganho proporcional, $T_{i}$ é o tempo integral, $T_{d}$ é o tempo derivativo, $u(t)$ e $e(t)$ são, respectivamente, sinal de controle e sinal de erro no domínio do tempo.

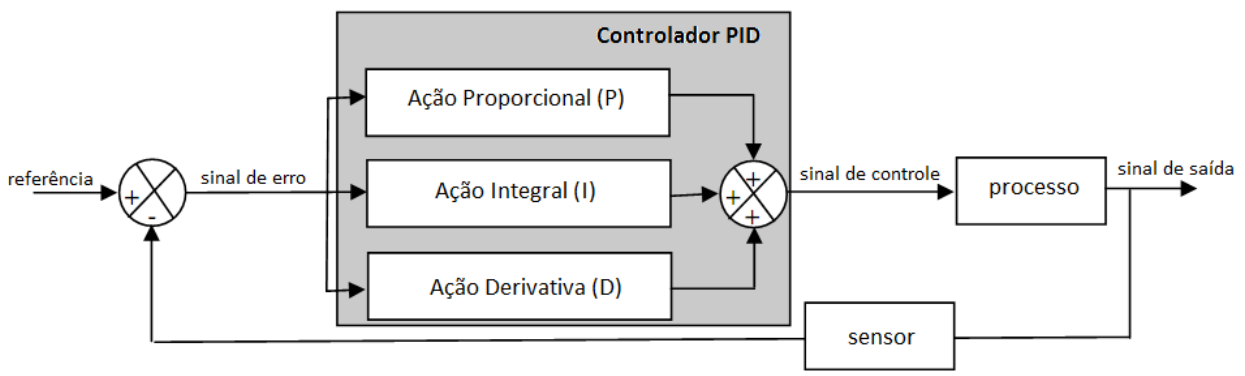

Figura 2.9: Diagrama de Blocos representando controlador PID.

O termo proporcional, expresso na equação (2.1) pela parcela referente a $K e(t)$, gera um sinal de controle proporcional ao valor do erro. Esse termo tem ação direta no valor de sobressinal (quanto maior o ganho, maior o sobressinal) e no valor do erro (este pode ser diminuído com aumento do ganho; caso o erro fique constante o valor do ganho também ficará constante).

O termo integral, dá-se de acordo com a parcela $K \frac{1}{T_{i}} \int_{0}^{t} e(\tau) d(\tau)$ da equação $(2.1)$. 
Este termo irá gerar um sinal de saída do controlador proporcional a integral do erro, ou seja, este termo provocará uma variação na saída do controlador indefinidamente enquanto houver erro. Enquanto que o termo proporcional muda instantaneamente o sinal de controle quando ocorre um erro, é a ação integral que continua mudando este sinal enquanto existir este erro. Dessa forma, o valor do sinal de erro poderá ser nulo em regime permanente. Todavia, é importante observar que o termo integral também irá gerar mais oscilações e instabilidade ao sistema.

Já a ação derivativa, expressa pela parcela $K T_{d} \cdot \frac{d e(t)}{d(t)}$ na equação $(2.1)$, irá gerar um sinal do controlador proporcional à derivada do erro. Como a derivada de uma função está relacionada com a tendência de variação desta função em um determinado tempo, aplicar um controle de sinal proporcional à derivada do erro equivale a aplicar uma ação baseada na tendência de evolução do erro. A ação derivativa é então dita como antecipatória ou preditiva e tende a fazer com que sistema reaja mais rapidamente. Assim, esta ação será utilizada para respostas mais rápidas em regime transitório. Uma vez que em regime permanente, o sinal de erro é constante e a ação derivativa será nula, ou seja, esta ação atua apenas durante a resposta transitória. Vale observar, que esta ação tende a aumentar a estabilidade relativa do sistema.

Ao unir a ação dos três termos, combinam-se as vantagens do controle básico do termo proporcional, a precisão da ação integral e o efeito estabilizador da ação derivativa, ao mesmo tempo em que torna mais rápida a resposta do sistema. Todavia, cria-se o desafio de ajustar o valor, ou intensidade, de cada um dos termos, processo chamado de sintonia do controlador PID.

Sintonizar o controlador PID significa encontrar valores numéricos para os parâmetros Proporcional, Integral e Derivativo tal que garantam a estabilidade e a robustez desejada ao sistema. Resultando assim na redução de perdas de matéria-prima, eficiência da produção, minimização dos impactos ambientais e na melhoria da qualidade do produto final (OGATA, 2003) (NETO e GOMES, 2010).

OVIEDO et al. (2006) relata que uma porcentagem significativa dos controladores instalados opera em modo manual (o operador paremetriza com auxilio de tabelas ou de forma empírica o controlador o controlador PID - sistema de malha aberta ) e mais de $50 \%$ dos PIDs instalados, que operam em modo automático (quando os controladores são parametrizados através de ensaios com softwares de otimização que 
determinam automáticamente os melhores coeficientes - malha fechada) apresentam grandes instabilidade no sistema. Isto é causado, em muitos casos, devido a uma pobre sintonia dos parâmetros do controlador.

A tarefa de sintonia dos controladores PID, na maioria dos casos é realizada de forma empírica pelos operadores e técnicos responsáveis, modo manual. Esta tarefa, basicamente, consiste em variar os ganhos do controlador e avaliar o impacto destas alterações junto a variável de saída do processo. Não obstante, este método é demorado e não é simples de ser realizado, pois depende muito da experiência e conhecimento do operador; chegando-se ao ponto de apenas certos operadores, tidos como mais experientes, conseguirem realizar uma boa sintonia. Ainda assim, é possível que sintonias feitas por operadores diferentes resultem em valores díspares para os mesmos parâmetros do controlador. Dessa forma, por vezes, encontrar o conjunto de ganhos satisfatórios para o início da operação de um dado processo pode resultar em uma tarefa enfadonha e nada sistemática.

Visando otimizar tal processo, técnicas de auto sintonia, modo automático, dos controladores têm sido estudado ao longo dos anos. Muitos métodos foram desenvolvidos e várias melhorias têm sido apresentadas. Segundo YU (2006), a escolha do método correto de sintonia de dependerá das particularidades do processo, como: tipo, ordem dos sistemas, não linearidades, incertezas, etc..

Segundo ASTRÖM e HÄNGGLUD (1995), Ziegler e Nichols foram os pioneiros no desenvolvimento de métodos de sintonia de controladores PID. Eles propuseram dois métodos que, com base em dados experimentais do processo, permitem ao operador determinar um conjunto de parâmetros iniciais para o controlador PID. Um dos métodos é baseado na análise gráfica para sistemas de primeira ordem, com tempo morto e cuja entrada é um degrau unitário. Já o segundo método, aplica-se a sistemas de malha fechada, baseia-se nos valores de ganho e período críticos, obtidos experimentalmente, a partir de uma oscilação sustentável (estabilidade marginal), quando a entrada é, também, um degrau unitário.

Muitas versões modificadas dos métodos Ziegler e Nichols (ZN) são proposta na literatura. Segundo YU (2006), JÚNIOR (2009) e (CARMO, 2006), Chien, Hrones e Reswick modificaram, dez anos depois, o método da curva de reação de Ziegler e Nichols para que a malha de controle fornecesse uma resposta ao degrau com o menor 
tempo de subida. Para isto, foi sugerido dois critérios de desempenho: um método de resposta rápida, sem sobre elevação, e um outro com $20 \%$ de sobre elevação (overshoot). Os parâmetros, desta modificação, foram determinados a partir do sistemas de primeira ordem com tempo morto.

Outro método fundamentado nas idéias de ZN, descritas por YU (2006) e JÚNIOR (2009), foi o sugerido por Cohen e Coon. Estes propuseram que os parâmetros do controlador PID fossem dados pela relação entre o tempo morto e a constante de tempo $(\theta / \tau)$ - fator de incontrolabilidade. Este método caracterizou-se por desenvolver uma sintonia de controlador PID com tempos mortos mais elevados do que estudado por $\mathrm{ZN}$.

Ainda segundo estes autores, uma regra mais conservadora de sintonia é proposta por Tyreus-Luyben, que é baseado em um sistema integrador com tempo morto e apresenta melhor desempenho em sistemas de multivariáveis. Já Takahashi adaptou os métodos de Ziegler e Nichols para controladores PID discretos, levando-se em consideração no ajuste dos parâmetros PID e no tempo de amostragem.

Conforme CARMO (2006), Aström \& Hägglund propuseram, em 1984, o método do relé em malha fechada, como uma solução ao método de oscilação sustentável proposta por ZN, uma vez que algumas plantas industriais não permitem que a estabilidade marginal seja atingida, por questões operacionais, estruturais ou porque reduziria a vida útil dos componentes da planta. Assim, uma alternativa seria substituir o controlador por um relé com histerese. O objetivo deste método é produzir oscilações limitadas e controladas no processo que permita estimar o ganho e o período críticos do processo. Segundo Arruda e Barros (2003), este método tem sido amplamente utilizado como ferramenta de estimação para sintonia on-line de controladores, devido à sua simplicidade.

MANNALA (2004) descreve que Zhuang:Zhuang, em 1992, estendeu o método de Aström-Hägglund para o projeto para controladores PID de duas entradas e duas saídas (Two Input Two Output - Duas Entradas e Duas Saídas (TITO)) através de algumas modificações nas fórmulas originais.

O método de alocação de pólos, usados principalmente em sistemas de baixa ordem, consistem em calcular os ganhos do controlador de forma que o sistema tenha os pólos posicionados em lugar pré-determinado de modo que contemple o melhor desempenho 
da malha.

Outras metodologias aplicadas à sintonia de controlador PID baseiam-se em conjunto de métodos alicerçados em modelos internos como: controle por modelo interno (Internal Model Control (IMC)), além dos métodos de síntese direta (Síntese Direta (SD)) de sintonia Lambda (Lambda-Tuning), que foram desenvolvidos utilizando o modelo IMC. Estes três modelos são baseados na adoção de modelos do processo que conduzem expressões analíticas para a sintonia dos controladores. Vale observar que o método IMC se caracteriza por permitir incertezas no modelo, enquanto que o LambdaTuning é utilizado onde existem grandes atrasos de transporte ou quando o atraso é variante no tempo. (JÚNIOR, 2009)

Há ainda na literatura métodos baseados em técnicas de otimização que utilizam os índices de desempenho como critério, que pode ser definido como uma medida quantitativa do desempenho da malha de um sistema. Os critérios mais utilizados são os critérios de integrais do erro como integral absoluta do erro (Integrated Absolute Error - Integral do valor Absoluto do Erro (IAE)), integral do erro (Integrated Error - Integral do Erro (IE)), integral quadrática do erro (Integrated Square Error - Integral do Erro Quadrático (ISE)), integral do tempo multiplicado pelo erro absoluto (Integrated of the Time Multiplied by Absolute Error - Integral do Erro Absoluto Multiplicado pelo Tempo (ITAE)) e a integral do tempo multiplicado pelo erro quadrático (Integrated of the Time Multiplied by Square Error - Integral do Erro Quadrático Multiplicado pelo Tempo (ITSE)) (CARMO, 2006).

Aström-Hägglund (1995) ressalta que é necessária uma atenção ao determinar os critérios e limites, caso contrário o critério escolhido pode ter um valor ótimo, porém o controle pode continuar instável devido ao critério não ser eficaz para o controle.

ANG et al. (2005) apresenta softwares comerciais de sintonia existentes no mercado de automação industrial, como pode ser observado na tabela 1. Muitos desses softwares são utilizados em plataforma Windows com tecnologia OPC que os tornam integráveis ao sistema fieldbus. Vale salientar que alguns desses softwares de sintonia são proprietários e caracterizam por ser utilizados para sintonizar os controladores dos próprios fabricantes como Profit PID (Honeywell), PID Self-Tuner (Siemens), DeltaV -Tune (Emerson), PID-Tools (Altus), PID-Analyser (ATOS), entre outros.

Além disso, este autor ainda observa que os métodos de sintonia mais utilizados são 
IMC e Lambda Tunig; e que o pIDtune (EngineSoft) utiliza a equação Auto Regressive with External Input - Auto Regressivo com entrada exógena (ARX).

Tabela 2.1: Principais Softwares de Sintonia PID comercial (ANG et al., 2005).

\begin{tabular}{|c|c|c|c|c|}
\hline Nome do Produto & $\begin{array}{l}\text { Baseado } \\
\text { em } \\
\text { Modelo }\end{array}$ & $\begin{array}{c}\text { Suporta } \\
\text { Operações } \\
\text { online }\end{array}$ & $\begin{array}{c}\text { Sistema de } \\
\text { Operação } \\
\text { depende }\end{array}$ & Comentários \\
\hline AdvaControlLoopTuner & - & Sim & $\begin{array}{l}\text { Microsoft } \\
\text { Windows } \\
\text { Advant OCS } \\
\text { system }\end{array}$ & $\begin{array}{l}\text { Seleciona } \\
\text { rápido, normal } \\
\text { ou desempenho } \\
\text { amortecido de } \\
\text { malha fechada. } \\
\text { Utiliza método } \\
\text { de alocação de } \\
\text { pólos. }\end{array}$ \\
\hline IMCTune & Sim & Não & $\begin{array}{l}\text { Microsoft } \\
\text { Windows } \\
\text { MATLAB }\end{array}$ & $\begin{array}{l}\text { Utiliza método } \\
\text { IMC. }\end{array}$ \\
\hline Model ID \& PID & Sim & - & $\begin{array}{l}\text { Microsoft } \\
\text { Windows }\end{array}$ & $\begin{array}{l}\text { Utiliza método } \\
\text { IMC. }\end{array}$ \\
\hline Robust PID Tune & - & Não & $\begin{array}{l}\text { Microsoft } \\
\text { Windows }\end{array}$ & $\begin{array}{l}\text { Seleciona en- } \\
\text { tre o método } \\
\text { IMC, Lambda- } \\
\text { Tuning com } \\
\text { malha aberta ou } \\
\text { fechada. }\end{array}$ \\
\hline INTune & Sim & Sim & $\begin{array}{l}\text { Microsoft } \\
\text { Windows }\end{array}$ & $\begin{array}{l}\text { Utiliza método } \\
\text { IMC avançado. }\end{array}$ \\
\hline
\end{tabular}




\begin{tabular}{|c|c|c|c|c|}
\hline Nome do Produto & $\begin{array}{c}\text { Baseado } \\
\text { em } \\
\text { Modelo }\end{array}$ & $\begin{array}{c}\text { Suporta } \\
\text { Operações } \\
\text { online }\end{array}$ & $\begin{array}{c}\text { Sistema de } \\
\text { Operação } \\
\text { depende }\end{array}$ & Comentários \\
\hline Control Station & Sim & Não & $\begin{array}{l}\text { Microsoft } \\
\text { Windows }\end{array}$ & $\begin{array}{l}\text { Seleciona re- } \\
\text { gulação } \\
\text { seguidor de } \\
\text { desempenho } \\
\text { usando Lamba- } \\
\text { Tuning. }\end{array}$ \\
\hline DeltaV Tune & Sim & Sim & $\begin{array}{l}\text { DeltaV works- } \\
\text { tation e Del- } \\
\text { taV controller }\end{array}$ & $\begin{array}{l}\text { Utiliza o ZN } \\
\text { modificado, } \\
\text { margem de ga- } \\
\text { nho e de fase, } \\
\text { Lambda-Tuning, } \\
\text { IMC e preditor } \\
\text { de Smith. }\end{array}$ \\
\hline Entech Tookit Tuner & Sim & Sim & $\begin{array}{l}\text { Microsoft } \\
\text { Windows }\end{array}$ & $\begin{array}{l}\text { Utiliza método } \\
\text { Lamba-Tuning } \\
\text { avançado. }\end{array}$ \\
\hline pIDtune & Sim & Não & $\begin{array}{l}\text { Microsoft } \\
\text { Windows } \\
\text { MATLAB }\end{array}$ & $\begin{array}{l}\text { Utiliza método } \\
\text { IMC. }\end{array}$ \\
\hline
\end{tabular}




\begin{tabular}{|c|c|c|c|c|}
\hline Nome do Produto & $\begin{array}{l}\text { Baseado } \\
\text { em } \\
\text { Modelo }\end{array}$ & $\begin{array}{c}\text { Suporta } \\
\text { Operações } \\
\text { online }\end{array}$ & $\begin{array}{c}\text { Sistema de } \\
\text { Operação } \\
\text { depende }\end{array}$ & Comentários \\
\hline Expertune & Sim & Sim & $\begin{array}{l}\text { Microsoft } \\
\text { Windows }\end{array}$ & $\begin{array}{l}\text { Seleciona re- } \\
\text { gulação ou } \\
\text { desempenho } \\
\text { utilizando sin- } \\
\text { tonia de } 1 / 4 \\
\text { de amorteci- } \\
\text { mento ou } 10 \% \\
\text { de sobre sinal } \\
\text { (overshoot), ou } \\
\text { Lambda-Tunnig. }\end{array}$ \\
\hline TunePlus & Sim & Sim & $\begin{array}{l}\text { Microsoft } \\
\text { Windows }\end{array}$ & $\begin{array}{l}\text { Utiliza método } \\
\text { Lambda-Tunnig } \\
\text { e IMC. }\end{array}$ \\
\hline Easy PID Tunnig & Sim & Não & $\begin{array}{l}\text { Microsoft } \\
\text { Windows } \\
\text { MATLAB }\end{array}$ & $\begin{array}{l}\text { Utiliza método } \\
\text { de alocação de } \\
\text { pólos. }\end{array}$ \\
\hline TuneUP & Sim & Sim & $\begin{array}{l}\text { Microsoft } \\
\text { Windows } \\
\text { MATLAB } \\
\text { (opcional) }\end{array}$ & $\begin{array}{l}\text { Utiliza método } \\
\text { Lambda-Tunnig } \\
\text { e método de } \\
\text { otimização. }\end{array}$ \\
\hline TuneWizard & Sim & Sim & $\begin{array}{l}\text { Microsoft } \\
\text { Windows }\end{array}$ & $\begin{array}{l}\text { Utiliza método } \\
\text { IMC ou } \\
\text { Lambda-Tunnig. }\end{array}$ \\
\hline \multicolumn{5}{|c|}{ Continua na próxima página } \\
\hline
\end{tabular}




\begin{tabular}{|c|c|c|c|c|}
\hline Nome do Produto & $\begin{array}{l}\text { Baseado } \\
\text { em } \\
\text { Modelo }\end{array}$ & $\begin{array}{c}\text { Suporta } \\
\text { Operações } \\
\text { online }\end{array}$ & $\begin{array}{c}\text { Sistema de } \\
\text { Operação } \\
\text { depende }\end{array}$ & Comentários \\
\hline RSTune & Sim & Sim & $\begin{array}{l}\text { Microsoft } \\
\text { Windows } \\
\text { Allen-Bradley } \\
\text { PLC-5, SLC } \\
500 \text { ou Con- } \\
\text { trolLogix } \\
\text { PLCs }\end{array}$ & $\begin{array}{l}\text { Utiliza Exper- } \\
\text { tune. }\end{array}$ \\
\hline Tune a Fish & Sim & Sim & $\begin{array}{l}\text { Microsoft } \\
\text { Windows e } \\
\text { PROVOX } \\
\text { Controller }\end{array}$ & $\begin{array}{l}\text { Utiliza Exper- } \\
\text { tune. }\end{array}$ \\
\hline PIDEasy & Sim & Sim & $\begin{array}{l}\text { Microsoft } \\
\text { Windows }\end{array}$ & $\begin{array}{l}\text { Utiliza método } \\
\text { de otimização } \\
\text { proprietários. }\end{array}$ \\
\hline GRAPHIDOR & Sim & Não & $\begin{array}{l}\text { Microsoft } \\
\text { Windows }\end{array}$ & $\begin{array}{l}\text { Gera gráfico 3D } \\
\text { usando P, I utili- } \\
\text { zando método de } \\
\text { minimização do } \\
\text { erro. }\end{array}$ \\
\hline Profit PID & Sim & Sim & $\begin{array}{l}\text { Honeywell } \\
\text { TPS/TDC }\end{array}$ & $\begin{array}{l}\text { Utiliza método } \\
\text { de otimização } \\
\text { min-max pro- } \\
\text { prietários. }\end{array}$ \\
\hline PIDS & Não & Não & $\begin{array}{l}\text { Microsoft } \\
\text { Windows }\end{array}$ & $\begin{array}{l}\text { Seleciona o de- } \\
\text { sempenho base- } \\
\text { ado em ITAE, } \\
\text { ITASE, ISE ou } \\
\text { IAE. }\end{array}$ \\
\hline
\end{tabular}




\begin{tabular}{|c|c|c|l|l|}
\hline Nome do Produto & $\begin{array}{c}\text { Baseado } \\
\text { em } \\
\text { Modelo }\end{array}$ & $\begin{array}{c}\text { Suporta } \\
\text { Operações } \\
\text { online }\end{array}$ & $\begin{array}{c}\text { Sistema de } \\
\text { Operação } \\
\text { depende }\end{array}$ & Comentários \\
\hline \hline CtrLab & Não & Não & $\begin{array}{l}\text { Microsoft } \\
\text { Windows } \\
\text { MATLAB }\end{array}$ & $\begin{array}{l}\text { Seleciona } \\
\text { desempenho } \\
\text { baseado em ISE, } \\
\text { ISTE, IST2E, } \\
\text { ou margem de } \\
\text { ganho e fase. }\end{array}$ \\
\hline
\end{tabular}

\subsubsection{Identificação de Sistemas}

Ao analisar a Tabela 2.1, proposta por ANG et al. (2005), nota-se que grande parte dos softwares comerciais são baseados em modelos matemáticos. YU (2006) e COELHO (2009) salientam que a identificação de sistemas desempenha um papel fundamental na auto sintonia dos controladores PID; e que a escolha do método correto dependeria do conhecimento das particularidades (tipo, ordem, incertezas) do sistema. COELHO (2009) afirma que a configuração dos parâmetros do controlador, para um controle ótimo da planta, depende do comportamento da planta. Logo, pode-se inferir que o sucesso para uma boa sintonia das malhas de controle está relacionado diretamente a uma adequada identificação do sistema.

O Modelo matemático dos sistemas é definido como um conjunto de equações que descrevem seu comportamento dinâmico ou estático. A obtenção de um modelo matemático deve estabelecer um compromisso entre a simplicidade do modelo e a precisão dos resultados da análise (OGATA, 2003). Em outras palavras, modelos matemáticos buscam apenas as características que são suficientes para descrever o sistema com precisão compatível aos objetivos de quem o modela. IWASE et al. (2002), ressalta que o modelo matemático é utilizado para descrever a dinâmica de um sistema, importante para o desenvolvimento de sistemas de controle.

Os modelos matemáticos, segundo SANTOS (2000), são obtidos através de dois modos: o primeiro modo, o analítico, conhecido também como modelagem teórica, é constituído por um modelo matemático formado por uma ou mais equações diferenciais 
e (ou) equações algébricas. O segundo modo, o experimental, baseia-se em um modelo matemático obtido através de experimentos com, apenas, informações de entrada e saída de um determinado processo dinâmico real, e tal modelo é representado por meio de equações das diferenças. O segundo modo é normalmente conhecido por Identificação de sistemas ou modelagem caixa-preta.

As diferenças entre os dois modos fundamenta-se, basicamente, na quantidade de conhecimento sobre o processo real utilizado na obtenção dos modelos. Na modelagem pela analítica ou pela física do processo, o modelo é desenvolvido a partir de toda informação disponível sobre o processo. Por outro lado, métodos experimentais normalmente não pressupõem qualquer conhecimento prévio do sistema, justificando o nome "identificação caixa-preta" (SJOBERG et al., 1995).

Outro método muito difundido é a obtenção de modelos matemáticos com inclusão de informações que se tenha sobre o sistema durante a sua identificação. Procedimentos com esta característica são denominados "identificação caixa-cinza" e são especialmente interessantes porque não exigem do usuário um profundo conhecimento "a priori" do processo, mas permitem a utilização de conhecimento prévio (AGUIRRE et al., 1998).

A escolha de qual método utilizar na modelagem de sistemas é uma questão sem uma resposta definitiva. Segundo AGUIRRE et al. (1998), o volume e tipo de informação "a priori" disponível sobre o sistema poderá vir a ser um elemento determinante na escolha da representação. Todavia, é importante ressaltar que a maioria dos casos industriais os conhecimentos físicos do processo são poucos, ou nenhum; ou mesmo podem ser de difícil construção, sendo extremamente complexos. Assim, para casos práticos, recomenda-se a identificação de sistemas, pois este método consegue elaborar modelos matemáticos de processos dinâmicos a partir de dados experimentais observados da planta de forma rápida e prática, mesmo aplicados aos sistemas complexos. 


\section{Capítulo 3}

\section{Modelagem Empírica ou}

\section{Identificação de Sistemas}

A modelagem empírica, ou identificação, de um sistema dinâmico consiste em determinar o melhor modelo matemático através da análise dos dados de sinais de entrada e saída coletados expirementalmente do sistema desejado. Tal modelo pode ser paramétrico (equação matemática) ou não paramétrico (representação gráfica ou modelo por redes neurais).

Faz-se notório uma utilização mais frequente da representação paramétrica na tentativa de capturar a dinâmica dominante do sistema em termos de um número pequeno de coeficientes. Todavia a opção do tipo de modelo é uma questão aberta a escolha do projetista de acordo com a complexidade da aplicação ou possibilidade de interligação com outros conceitos.

A modelagem pode ser realizada de forma "off-line", ou seja, em batelada, ou de forma "on-line", isto é, de forma recursiva. No método "off-line" os dados são previamente coletados, de uma única vez e então é feita a modelagem. Enquanto que na forma recursiva, à medida que os dados são disponibilizados é realizada a modelagem, e a cada coleta de dados, sucessiva, os parâmetros são atualizados, minimizando o erro entre a saída real e a modelada, como representado na figura 3.1. 


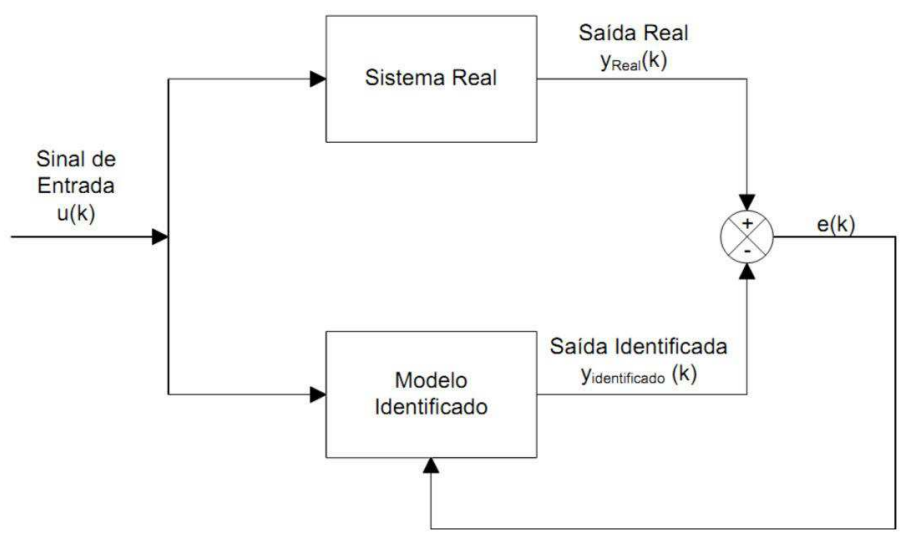

Figura 3.1: Diagrama de Blocos demonstrativo de um processo de modelagem.

De uma forma geral, a modelagem tipo "caixa preta", ou modelagem empírica, inicia-se com a coleta de dados, para isso é necessário uma escolha adequada do sinal de excitação e da taxa de amostragem dos sinais de entrada e saída.

Em seguida, escolhe-se a melhor representação matemática e estrutura que reproduzirão às características do sistema. E então estima-se, através de algoritmos de otimização, os parâmetros desses modelos.

De posse do modelo, é realizado o processo de validação com objetivo de verificar se o modelo escolhido obtém a informação requerida do sistema em estudo. Caso não tenha os resultados esperados, são feitas novas estimações até que o processo seja considerado satisfatório.

Segundo AGUIRRE (2004), a identificação de um sistema é divido em quatro etapas:

- Testes dinâmicos e coletas de Dados

- Escolha da representação matemática

- Determinação da estrutura do modelo

- Estimação de parâmetros

- Validação do Modelo Matemático Proposto

Vale salientar que as etapas citadas servem tanto para sistemas lineares quanto 
para sistemas não-lineares, sendo as principais diferenças a forma como cada fase é implementada.

A figura 3.2 demonstra a representação técnica das etapas do processo de identificação de um sistema. (Ljung ,1999)

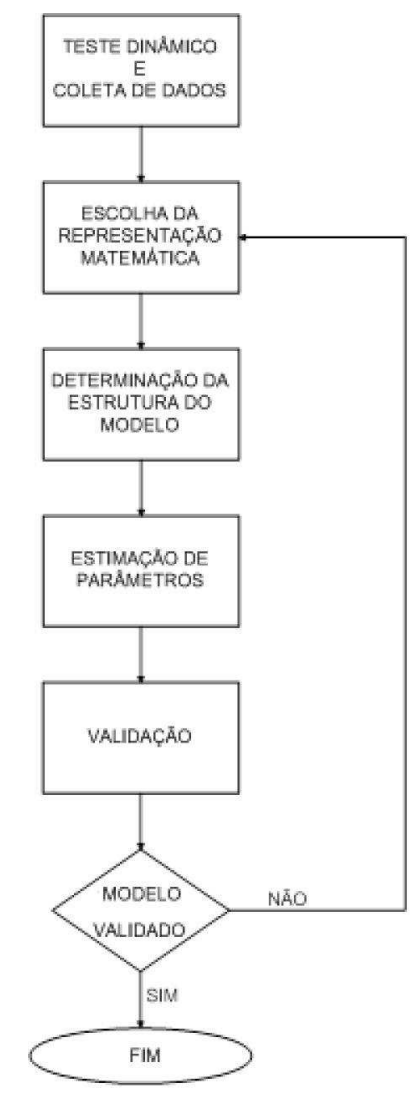

Figura 3.2: Fluxograma de um processo de Identificação.

\subsection{Testes dinâmicos e coletas de dados}

Nesta etapa obtêm-se os sinais necessários para a identificação do sistema. Segundo FERNANDES (2002), as condições experimentais em que o sistema real é submetido influenciam fortemente a qualidade final do modelo.

A dinâmica do processo pode ser determinada a partir da resposta ao sinal de entrada. Muitas vezes, estes sinais, entrada e saída, são obtidos a partir de testes em que o usuário determina as características do sinal de entrada (como frequência do sinal e amplitude) para excitar o sistema e obter o sinal de saída. Contudo, em outras 
situações, o usuário não tem a possibilidade de afetar o experimento e os dados são apenas aferidos no processo, ou seja, os dados são obtidos de forma natural ao processo da planta.

Existem diversos tipos de sinais que podem ser aplicados como entrada da planta como: sinal degrau, impulso, pseudo-aleatório, entre outros. Deve-se atentar nessa fase em aplicar um sinal de entrada que excite o sistema de forma a satisfazer certas propriedades da planta para que a dinâmica desejada para modelagem esteja presente no sinal de saída. Afinal, o modelo poderá representar apenas as características que estejam contidas nos dados. Dessa forma, o sinal a ser aplicado deve possuir um espectro de frequência na região que pretende modelar o sistema. Dentre os sinais existentes os mais indicados são os sinais aleatórios ou pseudo-aleatórios, pois estes possuem potência espectral numa ampla faixa de frequência, aumentando assim a possibilidade de se obter a característica desejada no sinal de saída. Todavia, na prática é mais utilizado o sinal degrau, devido a sua facilidade de obtenção manual. (ASTRÖM e HÄNGGLUD, 1995) (AGUIRRE, 2004)

Outro ponto fundamental que se deve atentar nessa fase é a taxa, ou período, de amostragem que se deve ter para aquisição dos dados. Afim de que um sinal amostrado retenha algumas características fundamentais do sinal original, é necessário que o período de amostragem seja suficientemente baixo. Segundo o teorema de Shannon um sinal que não contenha componentes de frequência acima de $\frac{1}{2 T s}$, sendo $T s$ o período de amostragem, pode ser determinado unicamente a partir de amostras de tal sinal separadas por Ts. Na prática a frequência de amostragem é normalmente cinco a dez vezes maior que a freqüência de interesse contida nos dados. (AGUIRRE, 2004)

Segundo FERNANDES (2002) com o advento da tecnologia dos conversores A/D, a determinação do período de amostragem correto para um determinado processo em estudo passa a ser uma tarefa exclusiva de programação. Em geral, os dados são superamostrados e o problema torna-se eliminar amostras, ou seja, o impasse passa a ser a definição da taxa de decimação de forma a adequar os dados. Uma possível solução para isto é medir o nível de redundância nos dados por meio de funções de correlação mais detalhado em AGUIRRE (2004).

Segundo LJUNG (1999) podem existir outros sinais além dos sinais de controle pertinentes ao sistema que não são controlados pelo usuário e interferem de forma qua- 
litativa e quantitativa nos sistemas: são os ruídos ou distúrbios presentes no processo. Estes podem ser diretamente medidos ou são observados através de sua influência no sinal de saída do sistema. Os distúrbios podem ser originados durante a aquisição dos dados por irregularidades intrínsecas aos equipamentos de medida (são ditos como os ruídos de medição), ou são causados por desgastes e falhas naturais do sistema devido ao uso ao longo do tempo, ou mesmo por perturbações inesperadas.

Vale salientar, que em muitas situações os distúrbios podem ser desprezados, quando a relação sinal/ruído for alta ou quando o ruído for do tipo aleatório e possuir média nula. Entretanto, em outros casos, estes sinais não poderão ser cancelados sendo necessário, portanto, a utilização de técnicas de identificação que trabalhem tais ruídos ou o uso de artíficios que minimize seu efeito, como uso de filtros.

Um filtro comumente usado para eliminação dos distúrbios de medição é o Butterworth. Este caracteriza-se por separarem sinais de baixa frequência, desejados, dos sinais de alta frequência.Além disso, ele possue resposta em frequência pela ordem de acordo com a tabela 3.1 .

Tabela 3.1: Resumo: resposta em Frequência x Ordem do filtro Butterworth .

Resumo dos Filtros Butterworth

\begin{tabular}{cc}
\hline & $H(s)=\frac{\omega_{\mathrm{c}}^{\mathrm{n}}}{\mathrm{Q}(\mathrm{s})}$ \\
\hline Ordem do Filtro $\mathrm{n}$ & $\begin{array}{c}\text { Polinômio Q(s) } \\
1\end{array}$ \\
2 & $s^{2}+\omega_{\mathrm{c}} \omega_{\mathrm{c}} s+\omega_{\mathrm{c}}^{2}$ \\
3 & $s^{3}+2 \omega_{\mathrm{c}} s^{2}+2 \omega_{\mathrm{c}}^{2} s+\omega_{\mathrm{c}}^{3}$ \\
4 & $s^{4}+2,6131 \omega_{\mathrm{c}} s^{3}+3,4142 \omega_{\mathrm{c}}^{2} s^{2}+2,6131 \omega_{\mathrm{c}}^{3} s+\omega_{\mathrm{c}}^{4}$ \\
5 & $s^{5}+3,2361 \omega_{\mathrm{c}} s^{4}+5,2361 \omega_{\mathrm{c}}^{2} s^{3}+5,2361 \omega_{\mathrm{c}}^{3} s^{2}+3,2361 \omega_{\mathrm{c}}^{4} s+\omega_{\mathrm{c}}^{5}$ \\
6 & $s^{6}+3,8637 \omega_{\mathrm{c}} s^{5}+7,4641 \omega_{\mathrm{c}}^{2} s^{4}+9,1416 \omega_{\mathrm{c}}^{3} s^{3}+7,4641 \omega_{\mathrm{c}}^{4} s^{2}+3,8637 \omega_{\mathrm{c}}^{5} s+\omega_{\mathrm{c}}^{6}$
\end{tabular}




\subsection{Escolha da representação matemática a ser utilizada e determinação da estrutura do modelo}

Existem várias formas de representar um sistema real tal como função de transferência, espaço de estado, representações polinomiais, dentre outros. Em identificação, é comum utilizar as representações polinomiais que podem ser do tipo Auto Regressive - Auto Regressivo (AR) (Auto Regressive - Auto Regressivo), ARX (Auto Regressive with External Input - Auto Regressivo com entrada exógena), Auto Regressive Moving Average with Exogeneous Input- Auto Regressivo com média móvel e entrada exógena (ARMAX) (Auto Regressive Moving Average with Exogeneous Input- Auto Regressivo com média móvel e entrada exógena) e Non-Linear Auto Regressive Moving Average with Exogeneous Input - Auto Regressivo com média móvel e entrada exógena não Linear (NARMAX) (Non-Linear Auto Regressive Moving Average with Exogeneous Input - Auto Regressivo com média móvel e entrada exógena não Linear).

A utilização do modelo matemático representativo irá depender da planta em estudo, dos objetivos da modelagem e do conhecimento a priori sobre o sistema desejado. Todavia, depende muito da intuição do engenheiro sobre o processo em questão, alguns modelos são escolhidos após algumas tentativas de modelagem do sistema. Em sistemas de controle baseados em modelos percebe-se uma preferência em utilizar sistemas lineares, haja visto o grande número de técnicas de controle baseadas nestas representações.

\subsubsection{ARX}

Este modelo, ARX (Auto Regressive with External Input - Auto Regressivo com entrada exógena), é classificado como modelo com erro na equação por apresentar uma variável exógena representando o erro do modelo, conforme a equação (3.1) dita como linear nos parâmetros.

$$
\left[1-a_{1} q^{-1}+\cdots-a_{n_{a}} q^{-n_{a}}\right] y(k)=\left[b_{1} q^{-1}+\cdots+b_{n_{b}} q^{-n_{b}}\right] u(k)+e(k)
$$

Onde $u(k)$ e $y(k)$ são os dados de, respectivamente, entrada e saída do sistema em 
análise; $b_{i}$ e $a_{i}$ os coeficientes dos regressores de entrada e saída, $n_{a}$ e $n_{b}$ são referente às ordens dos polinômios, e $q^{-1}$ é o operador de atraso, de forma que $y(k) q^{-1}=y(k-1)$.

A equação (3.1) pode ser reescrita, resultando a esquação 3.2 .

$$
y(k)=\frac{B(q)}{A(q)} u(k)+\frac{1}{A(q)} e(k)
$$

Neste caso, o erro, representativo do ruído, adicionado a saída, $\nu=\frac{e(k)}{A(q)}$, não é branco, ou seja, o ruído é modelado como ruído branco filtrado por um modelo autoregressivo. (AGUIRRE, 2004)

\subsubsection{ARMAX}

O modelo ARMAX (Auto Regressive Moving Average with Exogeneous Input- Auto Regressivo com média móvel e entrada exógena) é descrito pela equação (3.3).

$$
\left[1-a_{1} q^{-1}+\cdots-a_{n_{a}} q^{-n_{a}}\right] y(k)=\left[b_{1} q^{-1}+\cdots+b_{n_{b}} q^{-n_{b}}\right] u(k)+\left[1+c_{1} q^{-1}+\cdots+c_{n_{c}} q^{-n_{c}}\right] e(k)
$$

Ou na forma compacta, este modelo pode ser escrito segundo a equação (3.4).

$$
y(k)=\frac{B(q)}{A(q)} u(k)+\frac{C(q)}{A(q)} e(k)
$$

Assim como o modelo ARX, o modelo ARMAX também é classificado como um modelo de erro na equação. Todavia, este modelo difere-se do anterior por possuir um ponderação estendida no parâmetro do erro $e(k)$, com média não nula ao longo do tempo, isto é, distingui-se por possuir média móvel, bem como por não ser linear nos parâmetros.

\subsection{Estimação de parâmetros}

Nessa fase escolhe-se qual algoritmo utilizar para estimar os parâmetros que representam o comportamento do sistema dinâmico em estudo. 
Dentre os diversos algoritmos, o método dos Mínimos Quadrados (MQ) é o mais conhecido e utilizado entre engenheiros e cientistas, e serve de base para muitas outras técnicas de identificação. (AGUIRRE, 2004) (LJUNG, 1999)

\subsubsection{Mínimos Quadrados}

O método dos mínimos quadrados é uma técnica de otimização que consiste em determinar o melhor ajuste do conjunto de dados, a partir da minimização da soma do quadrado do erro.

Supondo uma variável $y$ relacionada linearmente com conjunto de varáveis $x$ a partir de um conjunto de parâmetros $\phi$, como representa a figura 3.3.

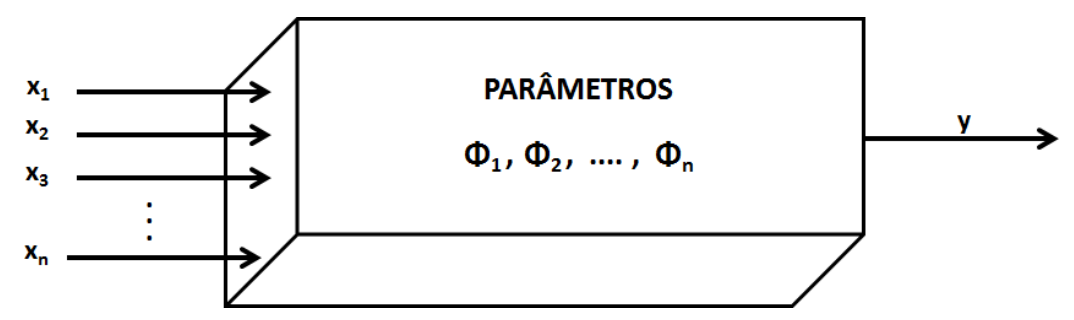

Figura 3.3: Sistema linear com n parâmetros

Assumindo que o conjunto de parâmetros constante $\phi$ seja desconhecido, deseja-se estimar seus valores através do conjunto de "m" pontos observados das variáveis $\mathrm{x}$ e y, nos instantes de tempo de $t_{1}, t_{2}, \cdots t_{n}$. Neste intervalo de tempo denota-se um conjunto de medidas dados por $y(i)$ e $x_{1}(i), x_{2}(i), \cdots, x_{n}(i), i=1,2, \ldots, m$. Assim, pode-se determinar um conjunto de dados com "m" equações lineares, como a equação (3.5).

$$
y(i)=\phi_{1} x_{1}(i)+\phi_{2} x_{2}(i)+\cdots+\phi_{n} x_{n}(i) .
$$

A equação (3.5) é denominada de função de regressores e $\phi$, denominado de coeficiente de regressores.

A equação (3.5) pode ser escrito em formato matricial segundo a equação (3.6).

$$
Y=\Phi X
$$


Onde:

$$
\mathbf{Y}=\left[\begin{array}{c}
y(1) \\
y(2) \\
\vdots \\
y(m)
\end{array}\right] X=\left[\begin{array}{cccc}
x_{1}(1) & x_{2}(1) & \ldots & x_{n}(1) \\
x_{1}(2) & x_{2}(2) & \ldots & x_{n}(2) \\
\vdots & \vdots & \ldots & \vdots \\
x_{1}(m) & x_{2}(m) & \ldots & x_{n}(m)
\end{array}\right] \Phi=\left[\begin{array}{c}
\Phi(1) \\
\Phi(2) \\
\vdots \\
\Phi(m)
\end{array}\right]
$$

Desde que $X$ seja não singular é possível determinar o vetor de prâmetros, como expressa a equação (3.8).

$$
\bar{\Phi}=X^{-1} Y .
$$

Com $X^{-1}$ sendo a inversa da matriz $X$ e $\bar{\Phi}$ sendo a matriz estimada de $\Phi$.

Todavia, quando $m>n$ tem-se então um sistema de de equações sobredeterminado. Como a matriz $X$ não é quadrada ela não pode ser invertida. Este impasse é, então, resolvido através da minimização do erro entre o modelo e os dados experimentais, a partir do ajuste de $\Phi$. Definindo o vetor erro como sendo $\varepsilon=\left(\varepsilon_{1}, \varepsilon_{2}, \cdots, \varepsilon_{m}\right)$ :

$$
\varepsilon=Y-X \bar{\Phi}
$$

Determinando a função custo, como a equação (3.10), que é um índice que quantifica a qualidade do ajuste de $X \bar{\Phi}$.

$$
J_{M Q}=\sum_{i=1}^{m} \varepsilon_{i}^{2}=\varepsilon^{T} \varepsilon .
$$

Substituindo a equação (3.9) na equação (3.10), chega-se a equação (3.11)

$$
J_{M Q}=(Y-X \bar{\Phi})^{T}(Y-X \bar{\Phi}) .=Y^{T} Y-\Phi^{T} X^{T} Y-Y^{T} X \Phi+\Phi^{T} X^{T} Z \Phi
$$

A fim de minimizar a função custo de $J_{M Q}$ com relação a $\Phi$, é necessário resolver $\left(\frac{\partial J_{M Q}}{\partial \bar{\Phi}}=0\right)$. Fazendo isso, tem-se a equação $(3.12)$. 


$$
\frac{\partial J_{M Q}}{\partial \bar{\Phi}}=-2 X^{T} Y+2 X^{T} X \bar{\Phi}=0
$$

Logo:

$$
X^{T} Y=X^{T} X \bar{\Phi}
$$

Onde, $\Phi$ pode ser estimado através da equação (3.14).

$$
\bar{\Phi}=\left(X^{T} X\right)^{-1} X T Y
$$

A equação (3.14) é chamada de estimador por Mínimos Quadrados clássico ou ordinário de $\Phi$. A solução obtida pela equação (3.14) é igual a solução encontrada utilizando a matriz inversa, representada pela equação (3.8).

\subsection{Validação do Modelo Matemático Proposto}

A validação é realizada com objetivo de verificar se os sistemas identificados incorporaram ou não as características desejadas do sistema real. Esta é, também, uma etapa subjetiva, pois o resultado da validação dependerá da aplicação pretendida para o modelo, da quantidade de informação disponível sobre o sistema original e do conhecimento a priori sobre os sistemas (AGUIRRE, 2004) (LJUNG, 1999).

Têm-se duas formas de validar um modelo, pelo Teste Cruzado e/ou pelo Teste de Linearidade. Na Validação Cruzada, utiliza-se duas séries de dados diferentes, com primeiro conjunto de dados realiza-se a identificação e com o segundo conjunto de dados faz-se a validação. Este cuidado de utilizar dois conjuntos de dados é necessário para saber o quão geral é o modelo, ou seja, verifica-se se o modelo é útil para explicar outro conjunto de dados observados no mesmo sistema (LJUNG, 1999) (JÚNIOR, 2009) (AGUIRRE, 2004). Já no Teste de Linearidade os ensaios devem ser repetidos com amplitudes de sinais de entradas distintas, introduzindo um sinal de excitação com amplitude positiva, para a estimação dos parâmetros e, na validação, aplica-se o sinal com amplitude negativa, para verificar os limites do modelo identificado em diferentes condições de operação. 
Existem algumas formas de avaliar a resposta do modelo identificado, como a avaliação visual através de comparação entre gráfico referente à saída do sistema real com a saída estimada.

Outra forma é a avaliação quantitativa através de índices de desempenho como Akaike's Final Prediction Error - Critério do Erro Final de Akaike (FPE), ou Critério do Erro de Predição Final de Akaike, que fornece uma medida de qualidade do modelo. De acordo com esse índice o melhor modelo é o que possue o menor valor, medido conforme a equação (3.15). (LJUNG, 1999).

$$
F P E=V\left(1+\frac{2 d}{N}\right)
$$

Onde:

$d$ é o número de parâmetros estimados;

$N$ é o número de dados medidos e

$V$ é a função perda expressa em (3.16).

$$
V=\operatorname{det}\left(\frac{1}{N} \sum_{1}^{N} \varepsilon\left(t, \theta_{N}\right)\left(\varepsilon\left(t, \theta_{N}\right)\right)^{T}\right)
$$

Se por algum motivo o modelo não for validado, pode-se proceder a um novo experimento de identificação ou a definição de outro conjunto de modelos, tudo isso com o intuito de produzir um novo modelo de qualidade superior ao anterior. 
40CAPÍTULO 3. MODELAGEM EMPÍRICA OU IDENTIFICAÇÃO DE SISTEMAS 


\section{Capítulo 4}

\section{Descrição de Teste e Resultados}

Nesta seção são apresentados os testes e resultados de identificação realizados com dados coletados a partir de sistemas simulados e de plantas industriais reais cujo controle é necessário a eficiência do processo. O objetivo é a validação do método de modelagem empírica utilizando modelos ARX e ARMAX para sistemas industriais com presença de ruído.

\subsection{Testes Simulados}

Inicialmente, foram realizadas simulações com a finalidade de identificar e observar o comportamento dos modelos matemáticos quando aplicados diferentes níveis de ruído branco (sinais que se distribuem aleatoriamente no espectro da frequência, com intensidade constante, tipo de pertubação ideal).

Estes testes foram realizado com auxílio do software Matlab, com seis diferentes sistemas cujas funções de transferência simuladas são expressas na tabela 4.1. Deve salientar que foram escolhidos sistemas com diferentes caracteríticas com relação a $\theta / \tau$, isto é Tempo Morto/Constante de Tempo, variando de 0,1 a 2,3. A relação $(\theta / \tau)$ representa o período de amostragem do sinal e é utilizada como forma de comparação, ou grau de dificuldade, entre os diferentes tipos de sistema de primeira ordem com tempo morto. (ZHUANG, ZHUANG), (LIPTÁK, 1995). 
Tabela 4.1: Sistemas simulados em ambiente Matlab.

\begin{tabular}{|c|c|c|c|c|}
\hline & Sistema & $\theta: \tau$ & $\begin{array}{c}\text { Funçåo de } \\
\text { transferência } \\
\text { malha aberta }\end{array}$ & $\begin{array}{c}\text { Funçầo de transferéncia } \\
\text { malha fechada }\end{array}$ \\
\hline \multirow{2}{*}{1} & $3-20 s$ & \multirow{2}{*}{0.13} & $-30 s+3$ & $-1200 s^{2}+120 s$ \\
\hline & $p=\frac{150 s+1}{15}$ & & $\overline{1500 s^{2}+160 s+1}$ & $60000 s^{3}+3700 s^{2}+242.5 s+6.75$ \\
\hline \multirow{2}{*}{2} & $2-50 s$ & \multirow{2}{*}{0.50} & $-50 s+2$ & $-5000 s^{2}+200 s$ \\
\hline & $p-\frac{100 s+1}{2}$ & & $2500 s^{2}+125 s+1$ & $250000 s^{3}+8000 s^{2}+235 s+1.8$ \\
\hline \multirow{2}{*}{3} & 1.5 & \multirow{2}{*}{1.14} & $-18.75 s+1.5$ & $-937.5 s^{2}+75 s$ \\
\hline & $C_{p}=\frac{2 s+1}{22}$ & & $275 s^{2}+3.4 .5 s+1$ & $13750 s^{3}+1230 s^{2}+79.7 s+0.792$ \\
\hline \multirow{2}{*}{4} & 4.5 & \multirow{2}{*}{1.53} & $-168.8 s+4.5$ & $-2.53 \mathrm{E} 4 \mathrm{~s}^{2}+675 \mathrm{~s}$ \\
\hline & $p-49 s+1$ & & $1838 s^{2}+86.5 s+1$ & $2.75 E 5 \mathrm{~s}^{3}+9668 \mathrm{~s}^{2}+216.1 \mathrm{~s}+0.588$ \\
\hline \multirow{2}{*}{5} & $9-e^{-1425 s}$ & \multirow{2}{*}{1.90} & $.64 .13 s+9$ & $-1828 s^{2}+256.5 s$ \\
\hline & $p-7.5 s+1$ & & $s 3.44 s^{2}+14.63 s+1$ & $1523 s^{3}+320.6 s^{2}+38.63 s+0.474$ \\
\hline \multirow{2}{*}{6} & $G=25$ & \multirow{2}{*}{2.33} & $.437 .5 s \div 25$ & $-30625 \mathrm{~s}^{2}+1750 \mathrm{~s}$ \\
\hline & $G_{p}=\overline{15 s+1}^{e s s}$ & & $\overline{262.5 s^{2}+32.5 s+1}$ & $18375 s^{2}+1803 s^{2}+90.25 s-0.3857$ \\
\hline
\end{tabular}

A coluna "Função de Transferência Malha Aberta", na tabela 4.1, representa o sistema com tempo morto estimado segundo aproximação de Paddé, equação 4.1. (OGATA, 2003)

$$
e^{(\theta s)} \approx \frac{1-0,5 \theta s}{1+0,5 \theta s}
$$

Tais equações foram obtidas do trabalho de JÚNIOR (2009), que estudou a identificação Remota de Plantas Industriais Utilizando tecnologia $O P C$ e $C Y B E R O P C$. Neste, JÚNIOR (2009) alcançou resultados satisfatórios de identificação e de sintonia remota de malha de controle, utilizando controladores PID em ambiente industrial para sinais sem ruído. A metodologia utilizada foi a dos Mínimos Quadrados com modelo ARX e Mínimo Quadrados Recursivos.

\subsubsection{Testes Simulados em Malha Aberta}

Os primeiros passos foram simular os sistemas descritos na tabela 4.1 utilizando os Mínimos Quadrados com equação do tipo ARMAX, que inclue a média não nula do 
sinal erro em sua estrutura. Os resultados desta simulação em malha aberta, podem ser vistos nas figuras 4.1 a 4.18 . Vale ressaltar que a densidade de potência do ruído branco em cada sistema foi aumentada de $10 \%$ a cada passo; ou seja, para cada sistema o valor do ruído branco variou de 0,005, 0,05 e 0,5.

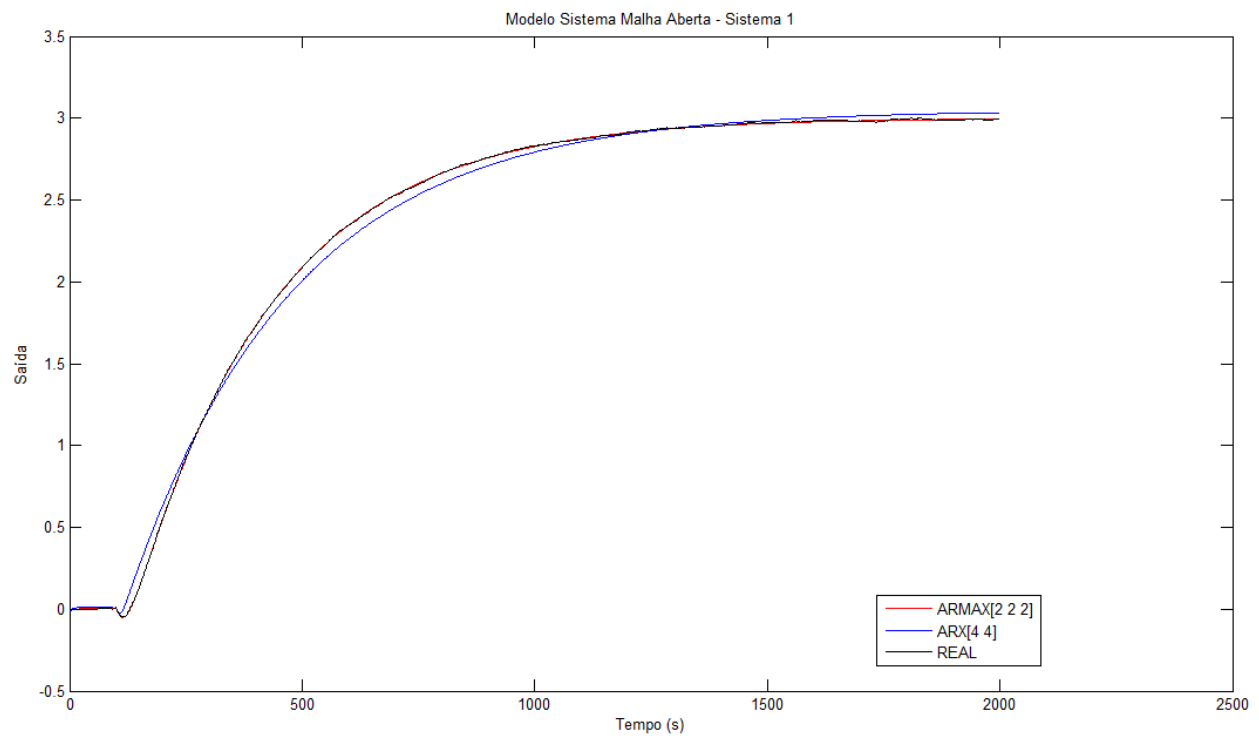

Figura 4.1: Resultado simulação do sistema 1, Malha Aberta, com densidade de potência do ruído branco igual a 0,005.

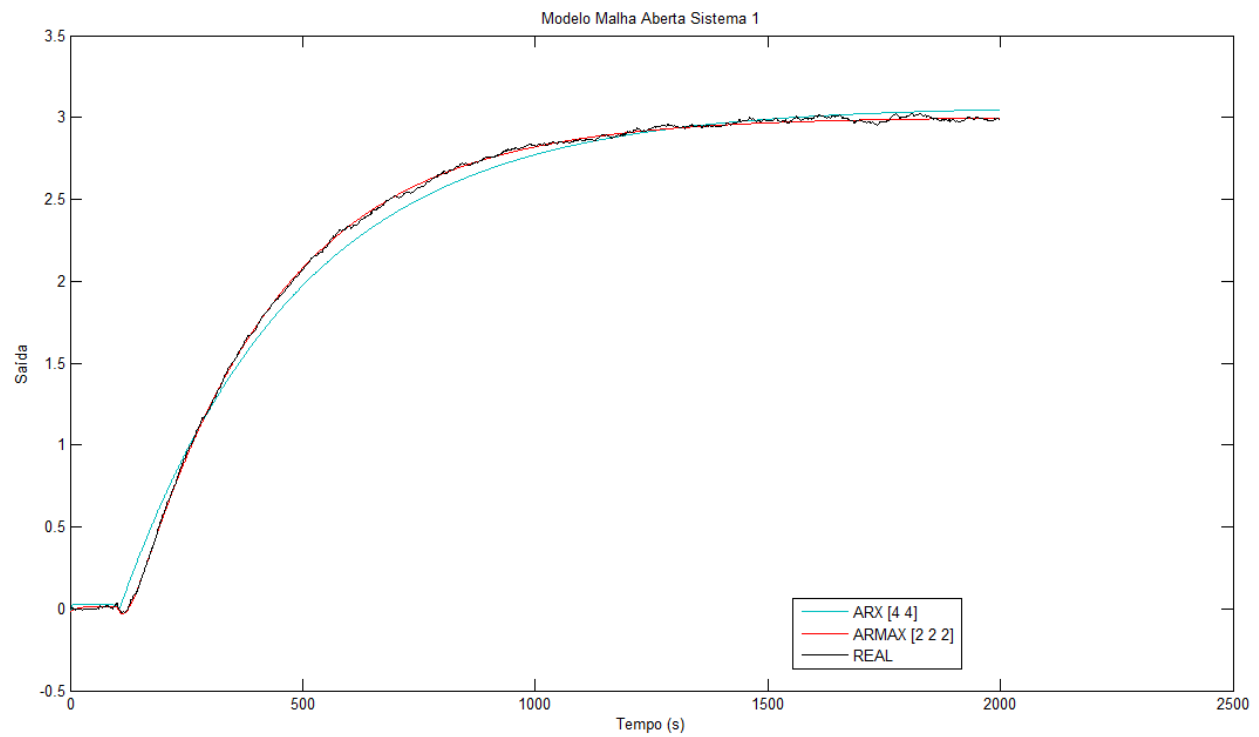

Figura 4.2: Resultado simulação do sistema 1, Malha Aberta, com densidade de potência do ruído branco igual a 0,05 . 


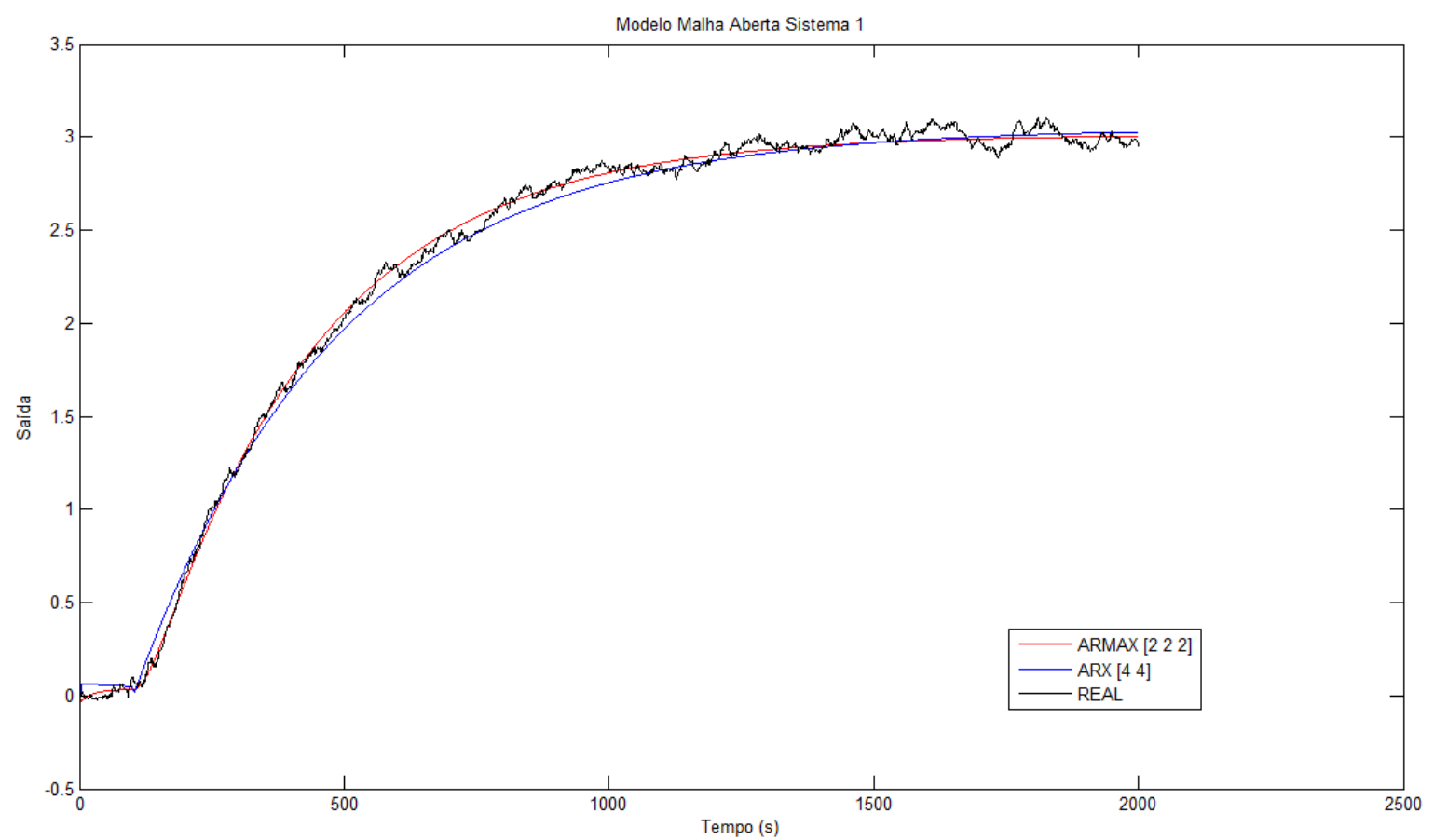

Figura 4.3: Resultado simulação do sistema 1, Malha Aberta, com densidade de potência do ruído branco igual a 0,5 .

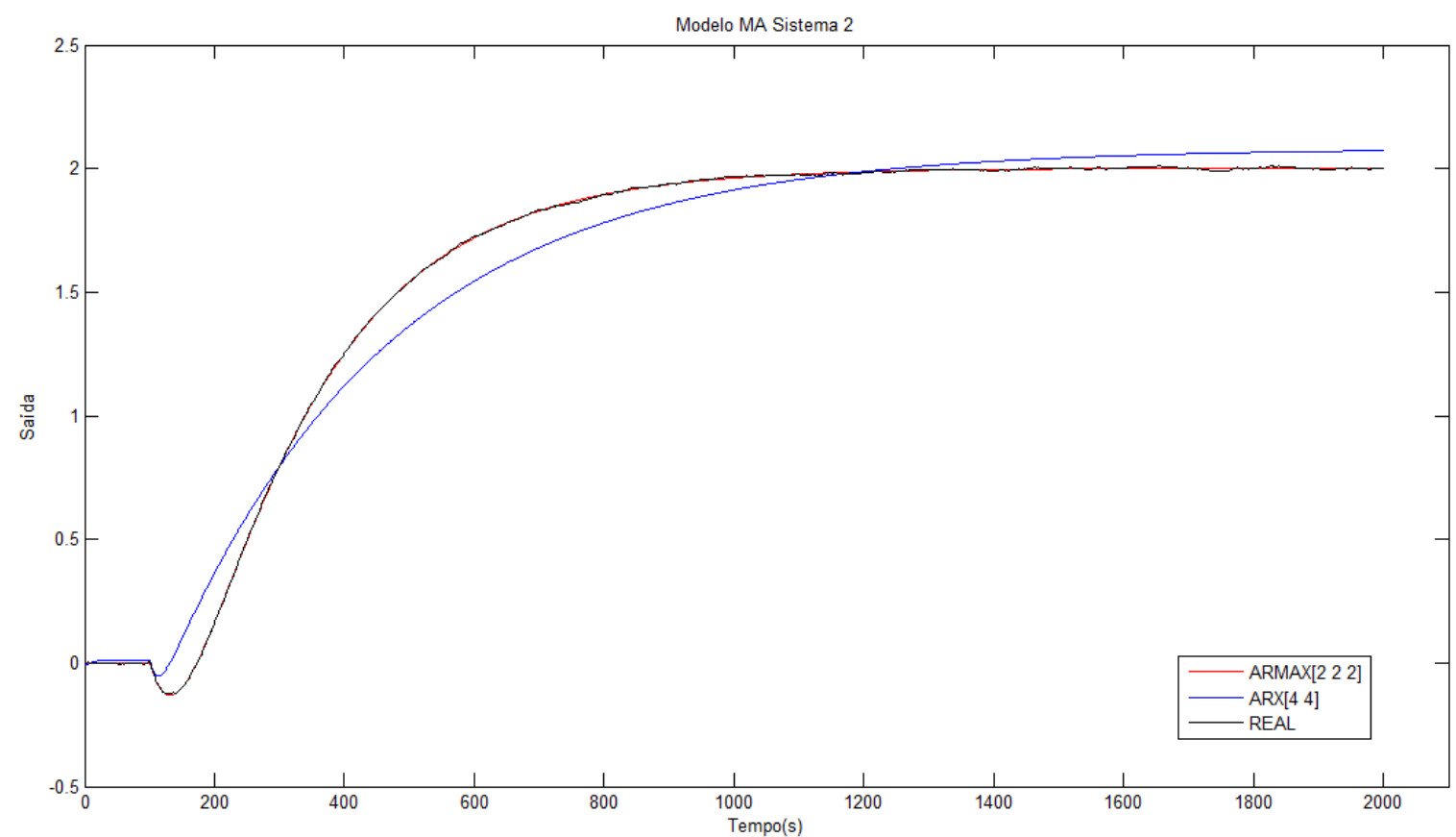

Figura 4.4: Resultado simulação do sistema 2, Malha Aberta, com densidade de potência do ruído branco igual a 0,005 . 


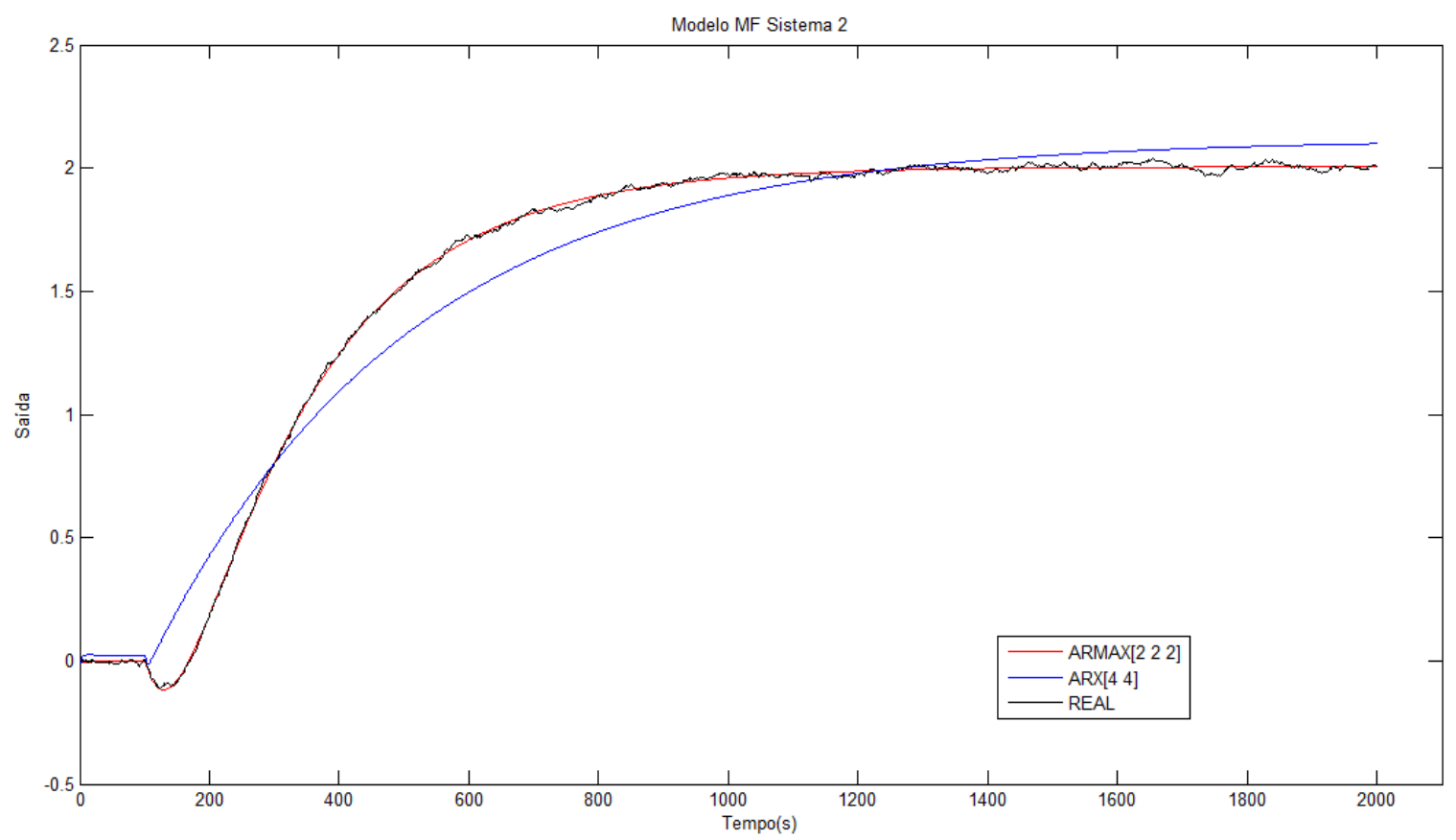

Figura 4.5: Resultado simulação do sistema 2, Malha Aberta, com densidade de potência do ruído branco igual a 0,05 .

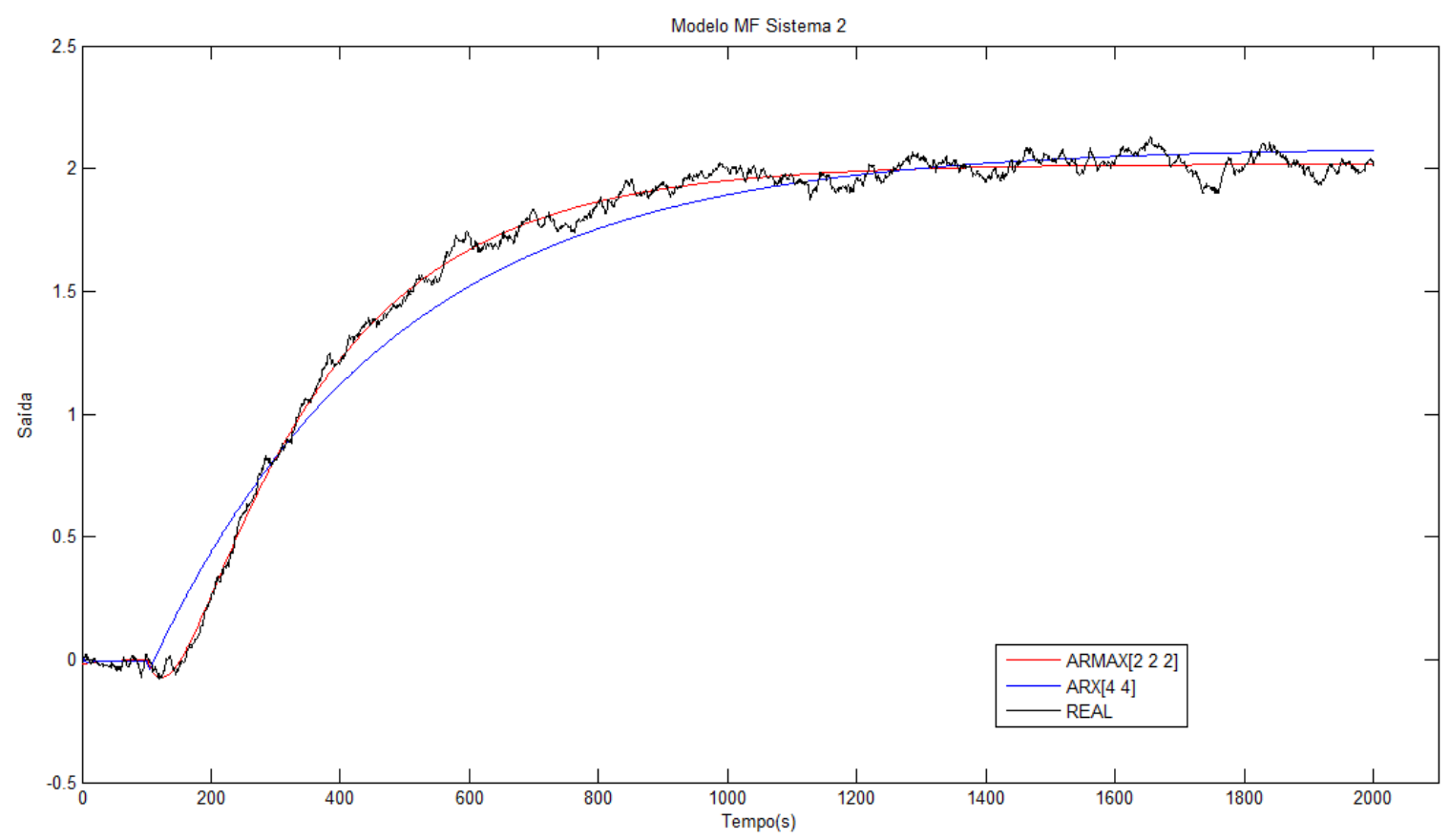

Figura 4.6: Resultado simulação do sistema 2, Malha Aberta, com densidade de potência do ruído branco igual a 0,5 . 


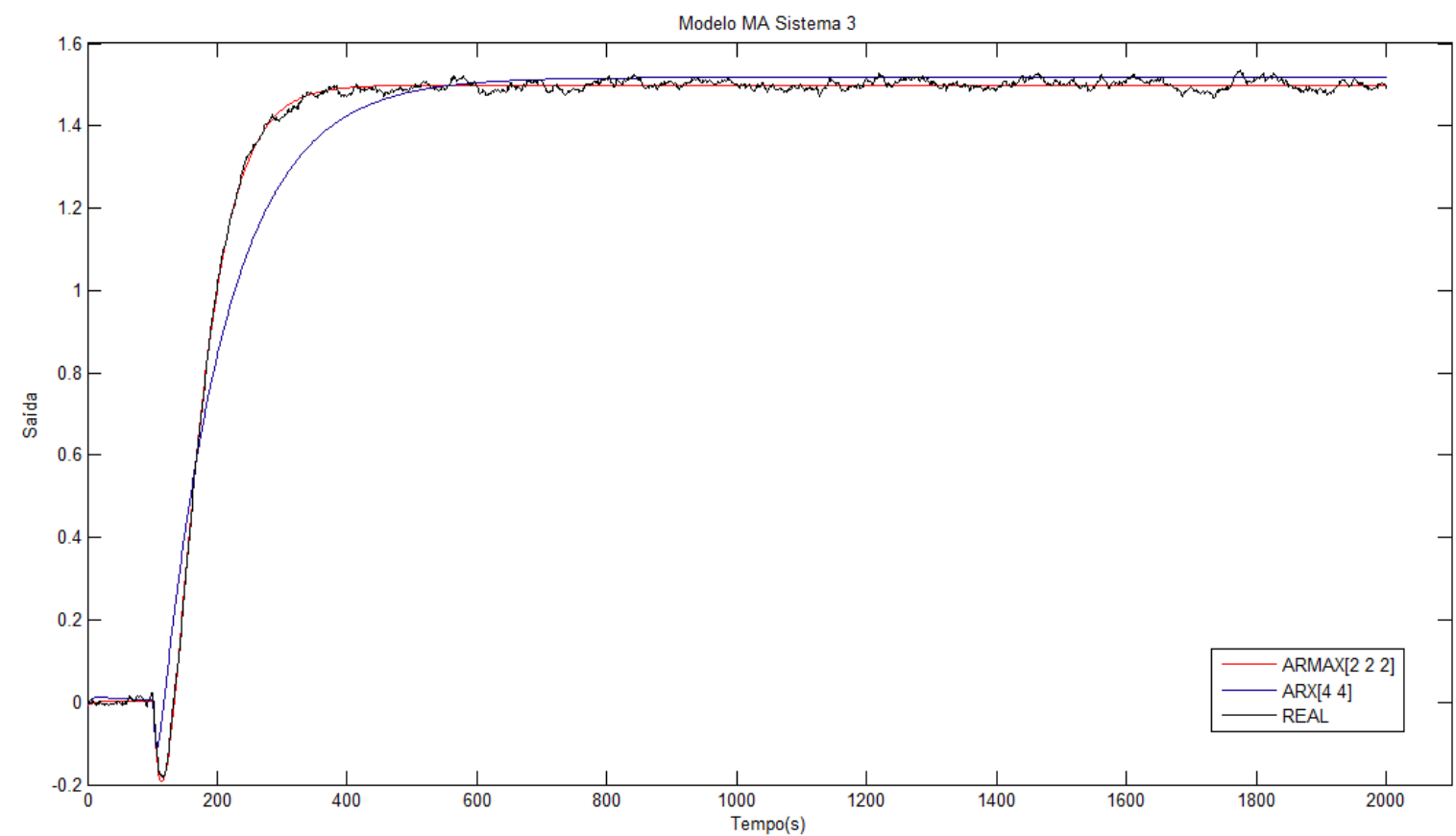

Figura 4.7: Resultado simulação do sistema 3, Malha Aberta, com densidade de potência do ruído branco igual a 0,005 .

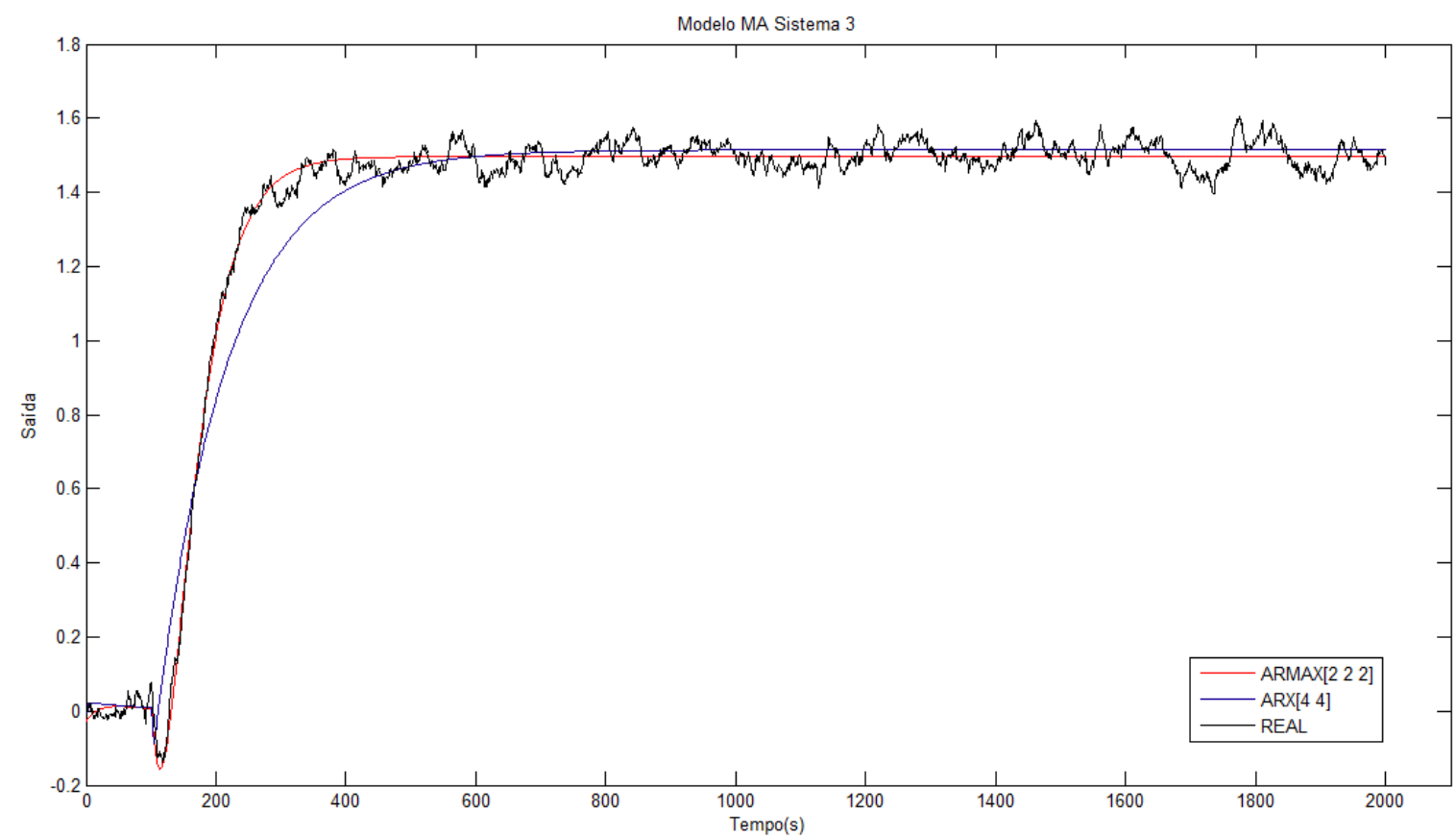

Figura 4.8: Resultado simulação do sistema 3, Malha Aberta, com densidade de potência do ruído branco igual a 0,05 . 


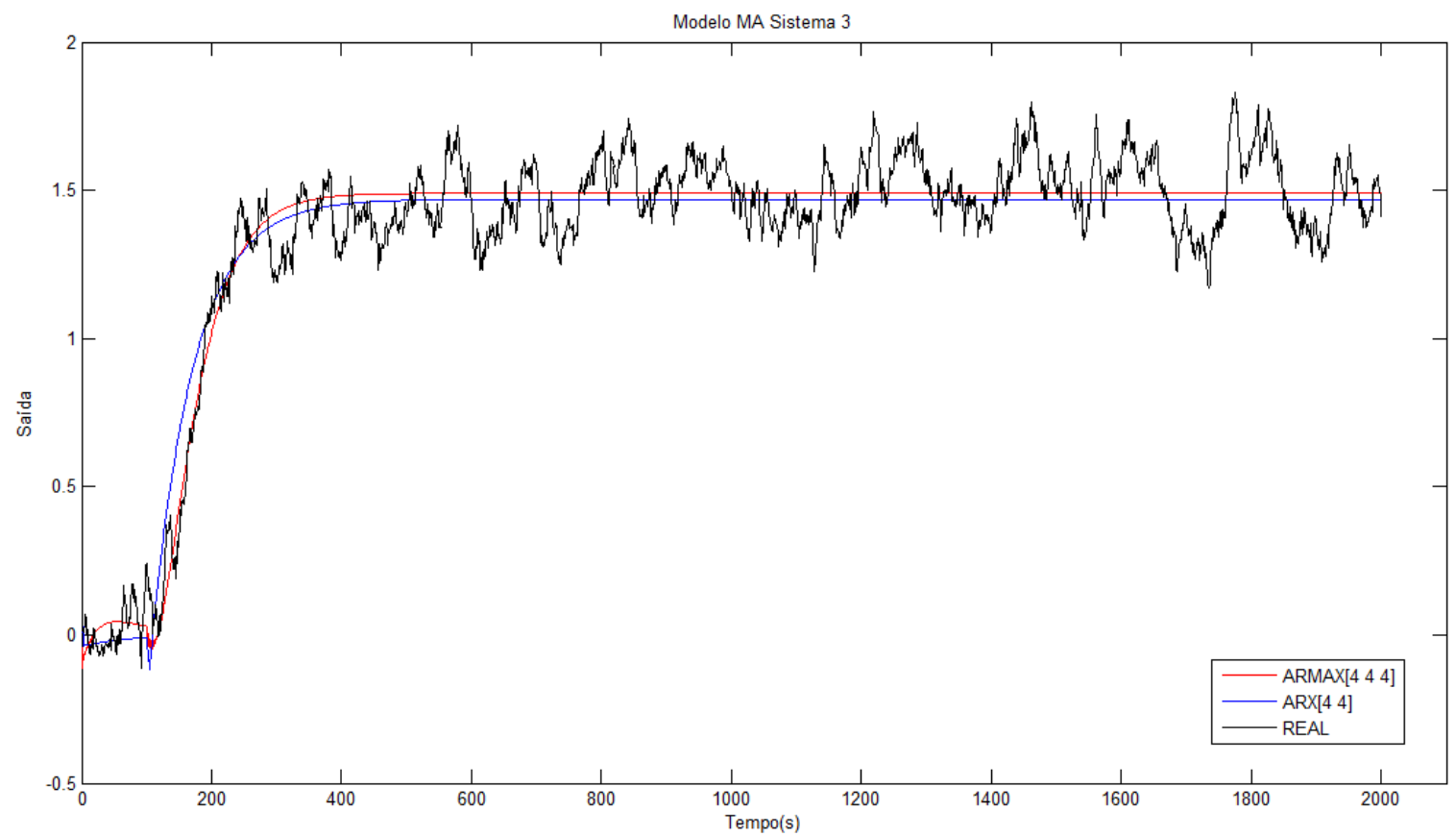

Figura 4.9: Resultado simulação do sistema 3, Malha Aberta, com densidade de potência do ruído branco igual a 0,5 .

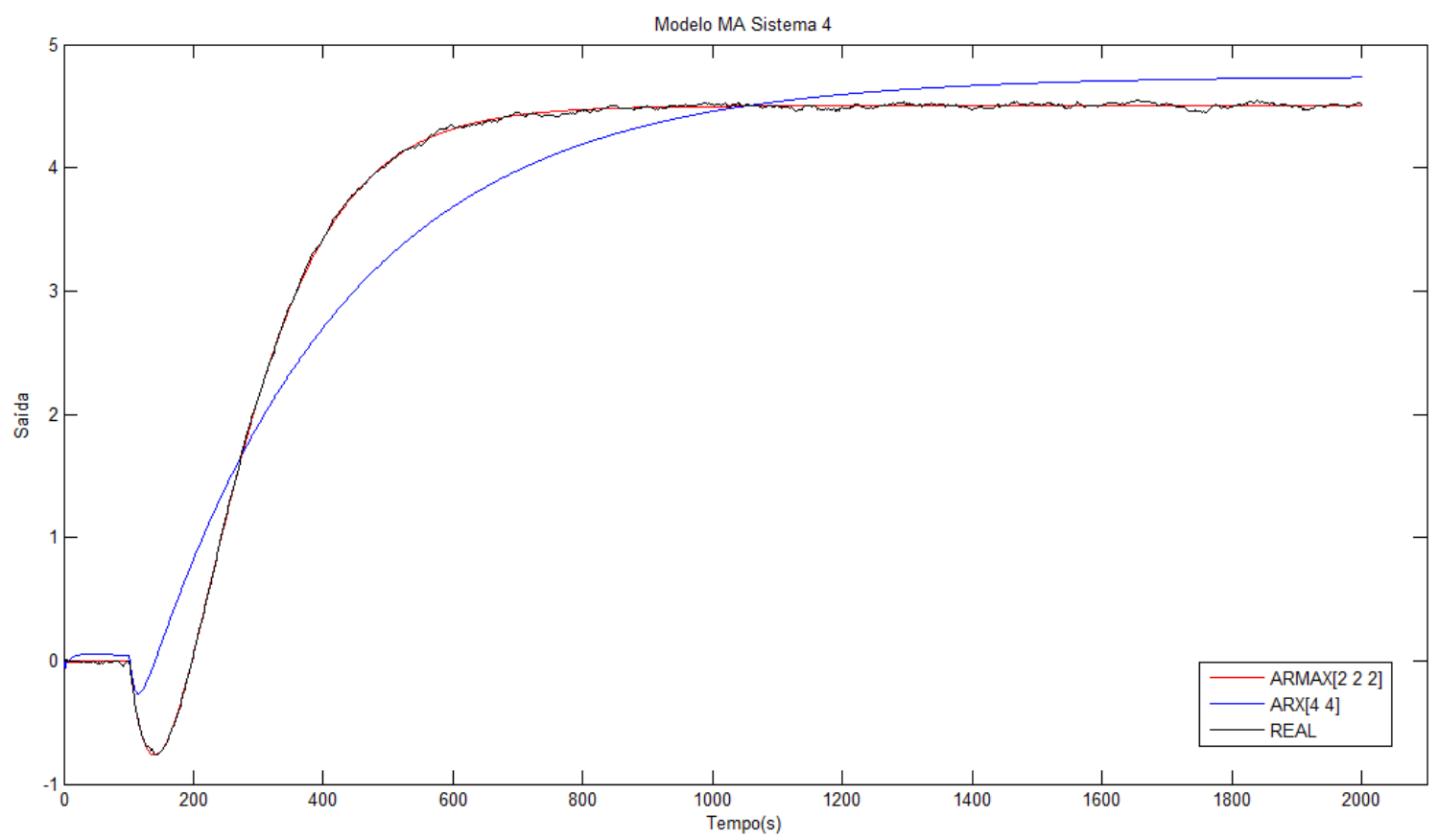

Figura 4.10: Resultado simulação do sistema 4, Malha Aberta, com densidade de potência do ruído branco igual a 0,005 . 


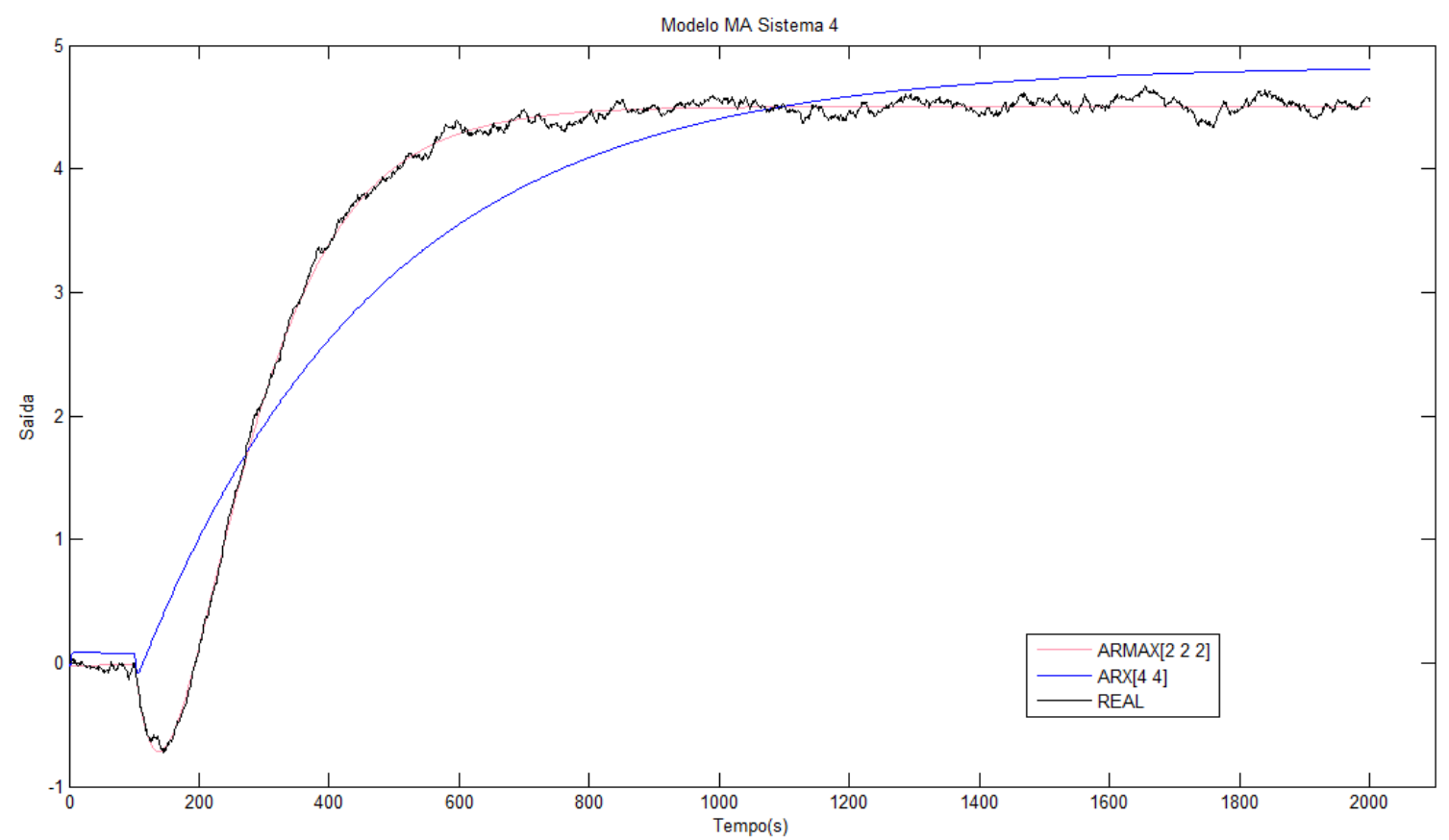

Figura 4.11: Resultado simulação do sistema 4, Malha Aberta, com densidade de potência do ruído branco igual a 0,05 .

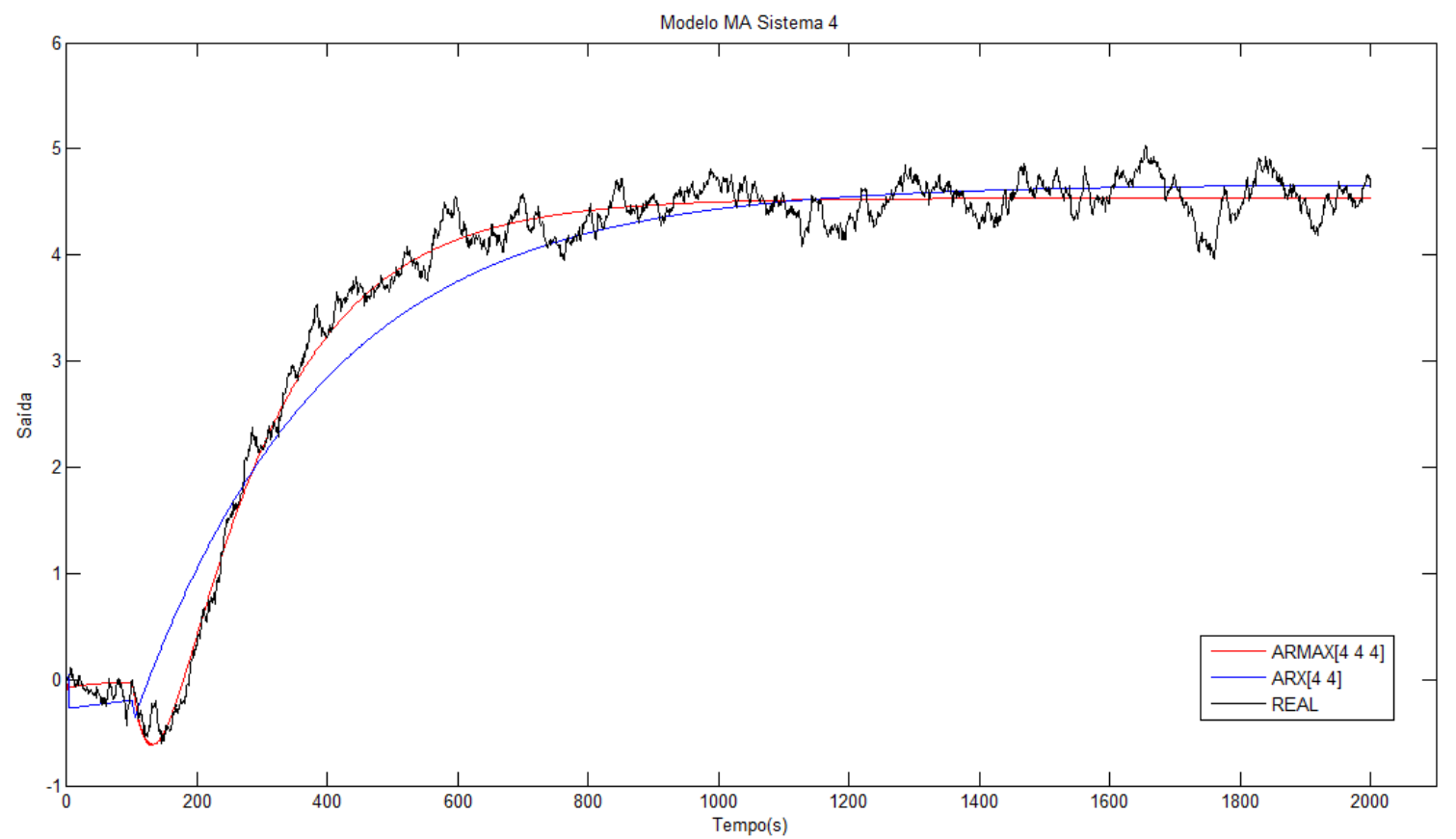

Figura 4.12: Resultado simulação do sistema 4, Malha Aberta, com densidade de potência do ruído branco igual a 0,5 . 


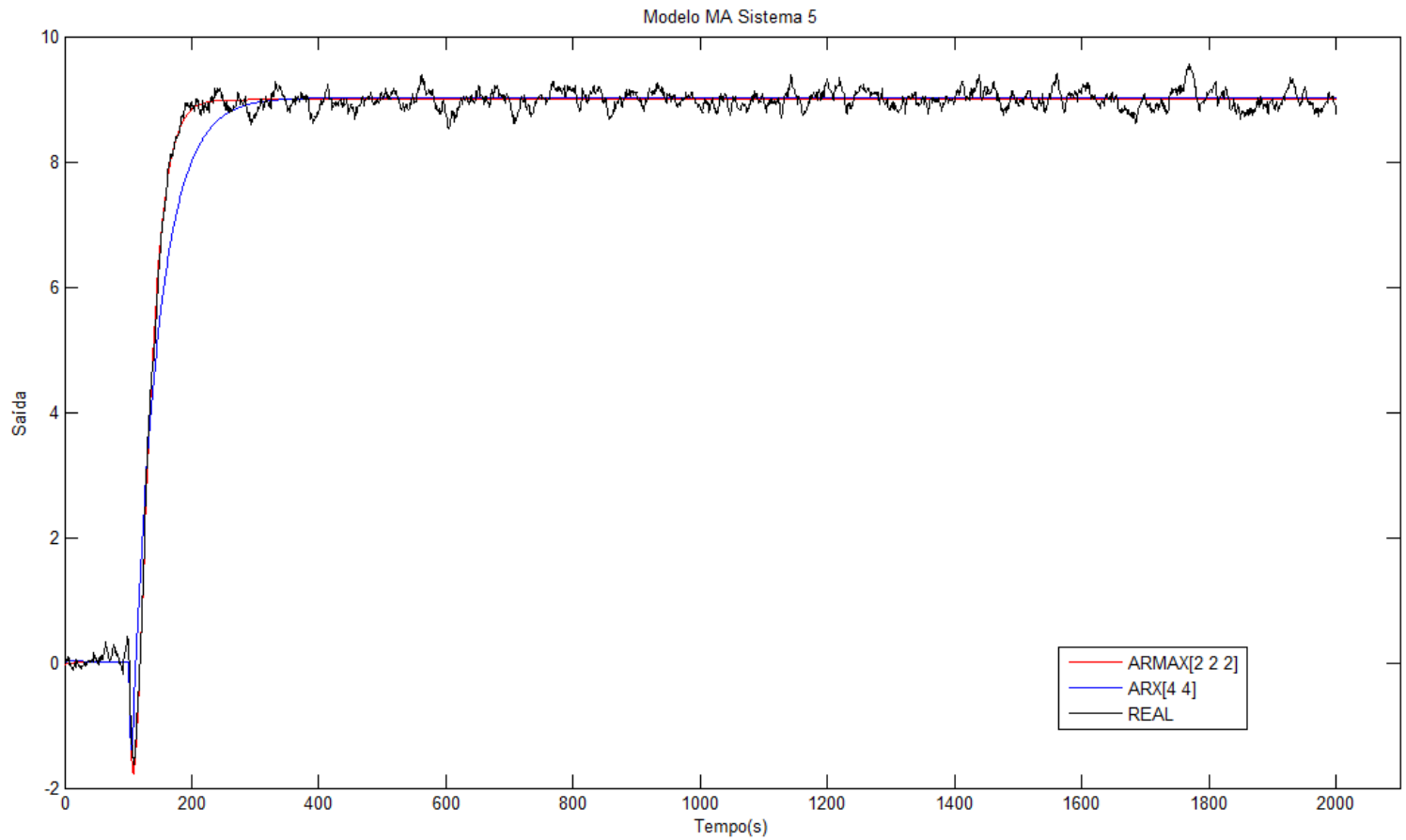

Figura 4.13: Resultado simulação do sistema 5, Malha Aberta, com densidade de potência do ruído branco igual a 0,005 .

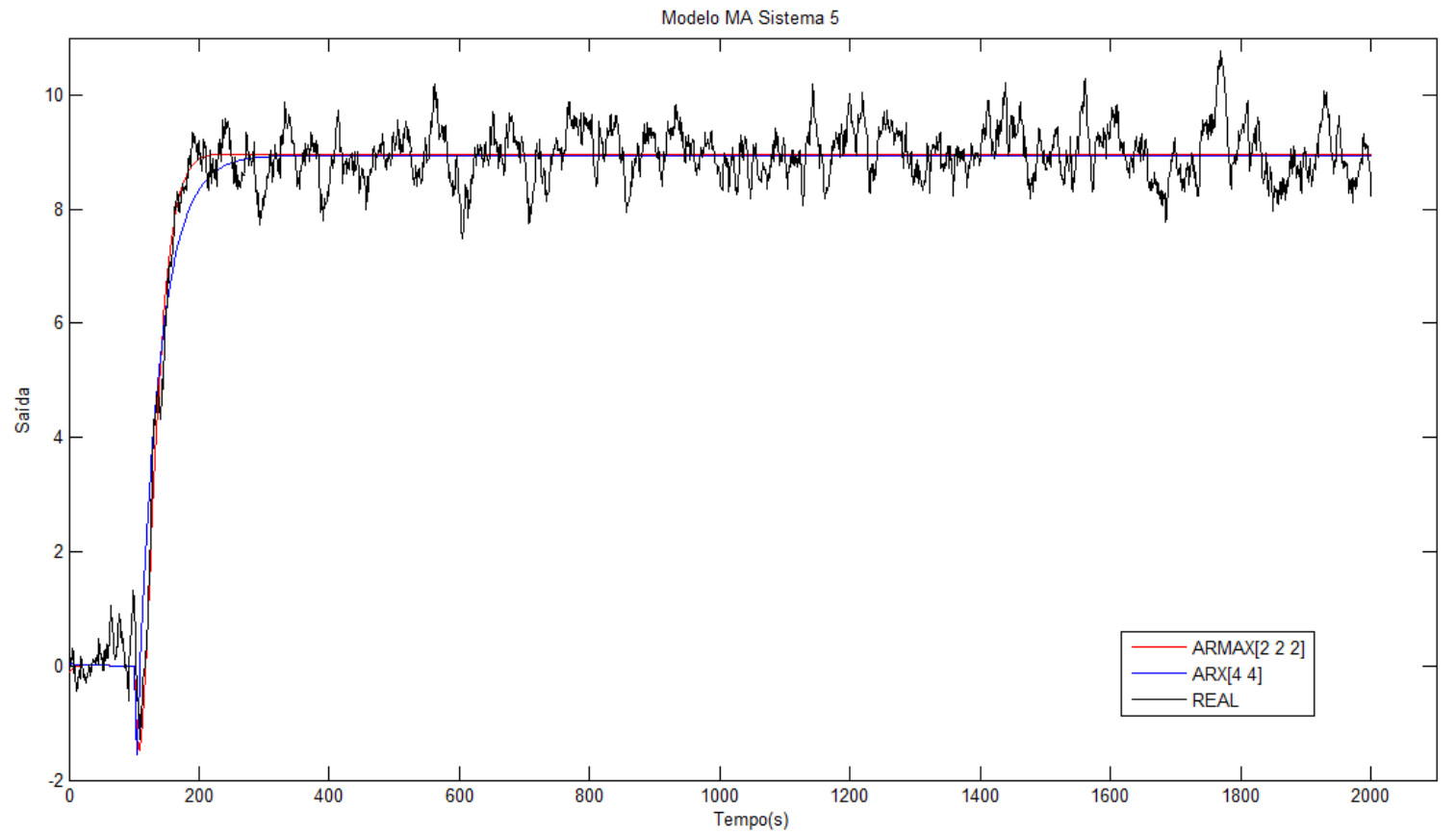

Figura 4.14: Resultado simulação do sistema 5, Malha Aberta, com densidade de potência do ruído branco igual a 0,05 . 


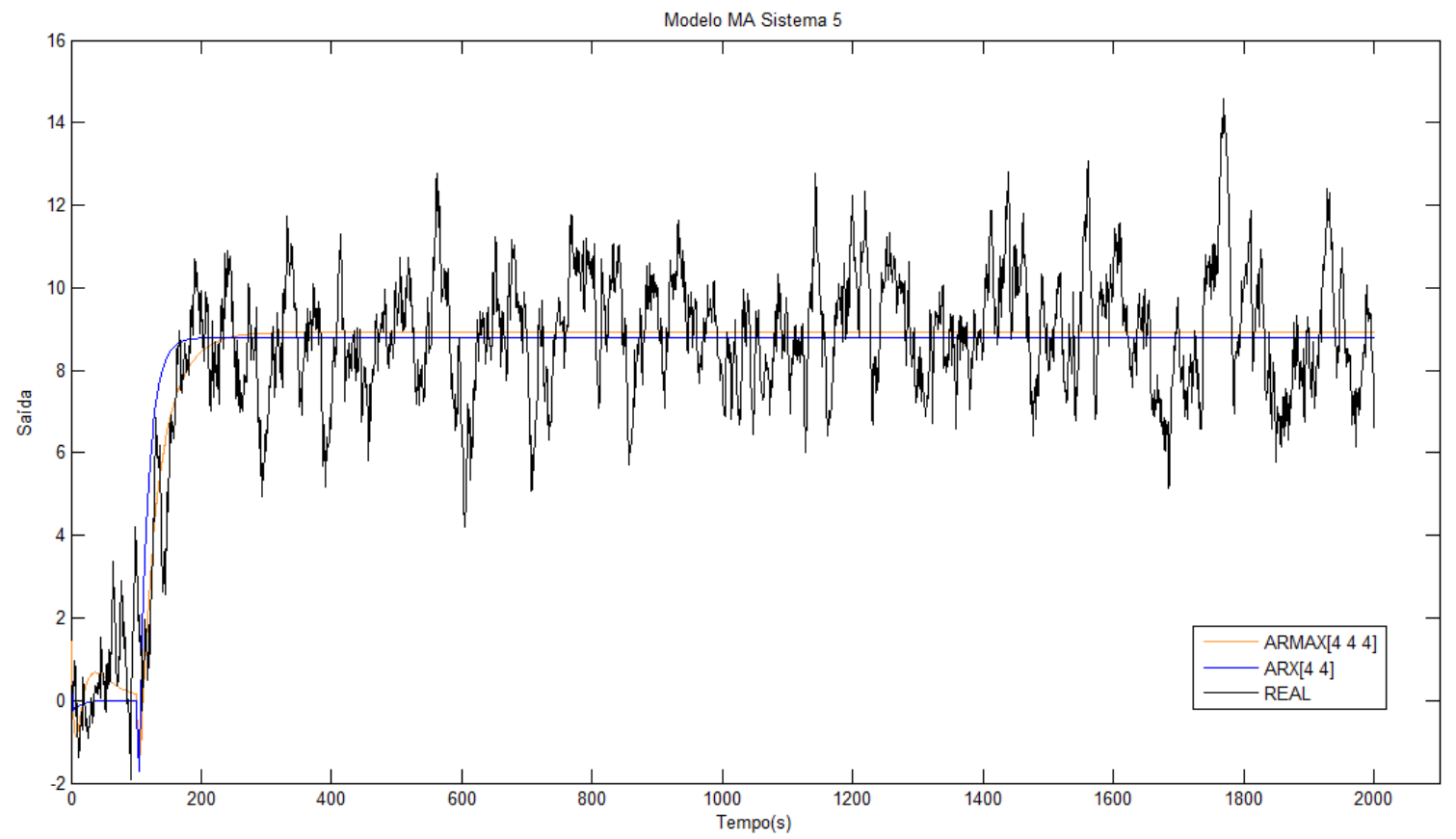

Figura 4.15: Resultado simulação do sistema 5, Malha Aberta, com densidade de potência do ruído branco igual a 0,5 .

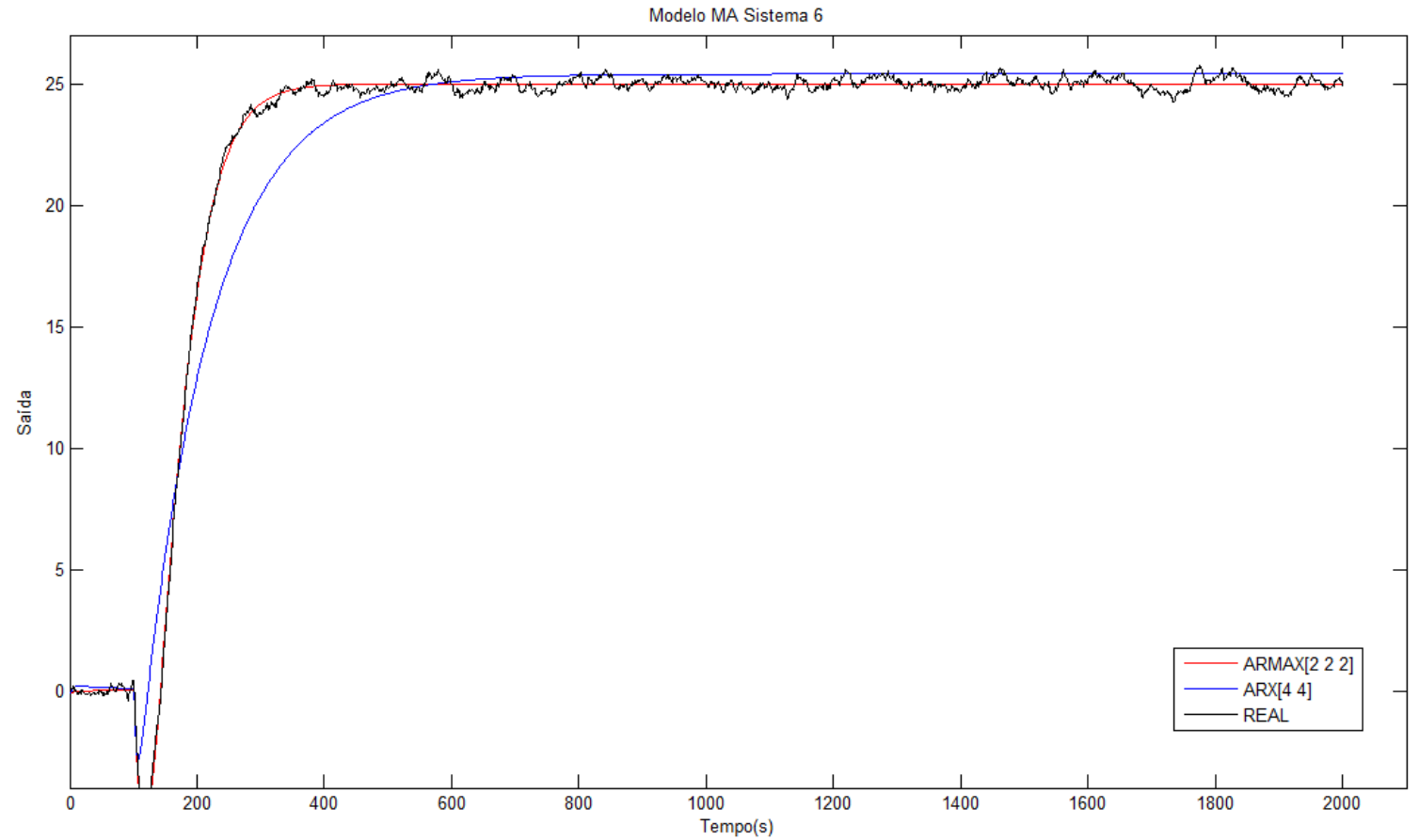

Figura 4.16: Resultado simulação do sistema 6, Malha Aberta, com densidade de potência do ruído branco igual a 0,005 . 


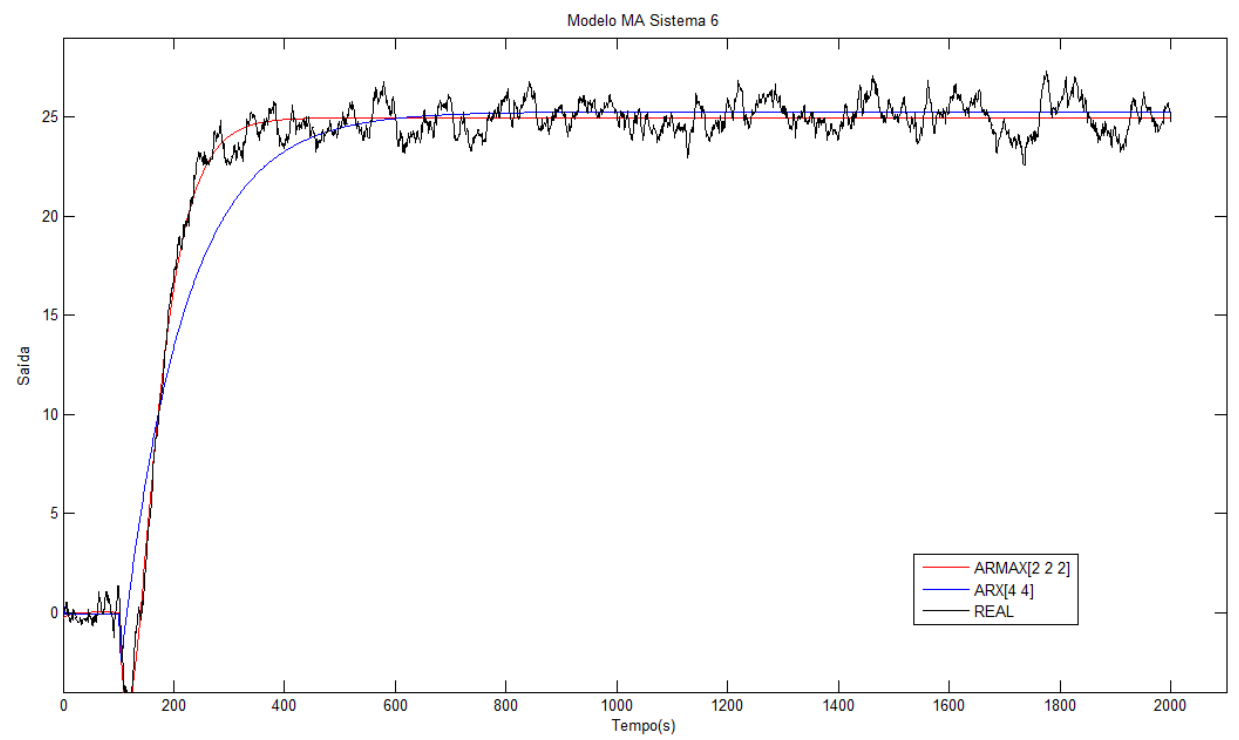

Figura 4.17: Resultado simulação do sistema 6, Malha Aberta, com densidade de potência do ruído branco igual a 0,05 .

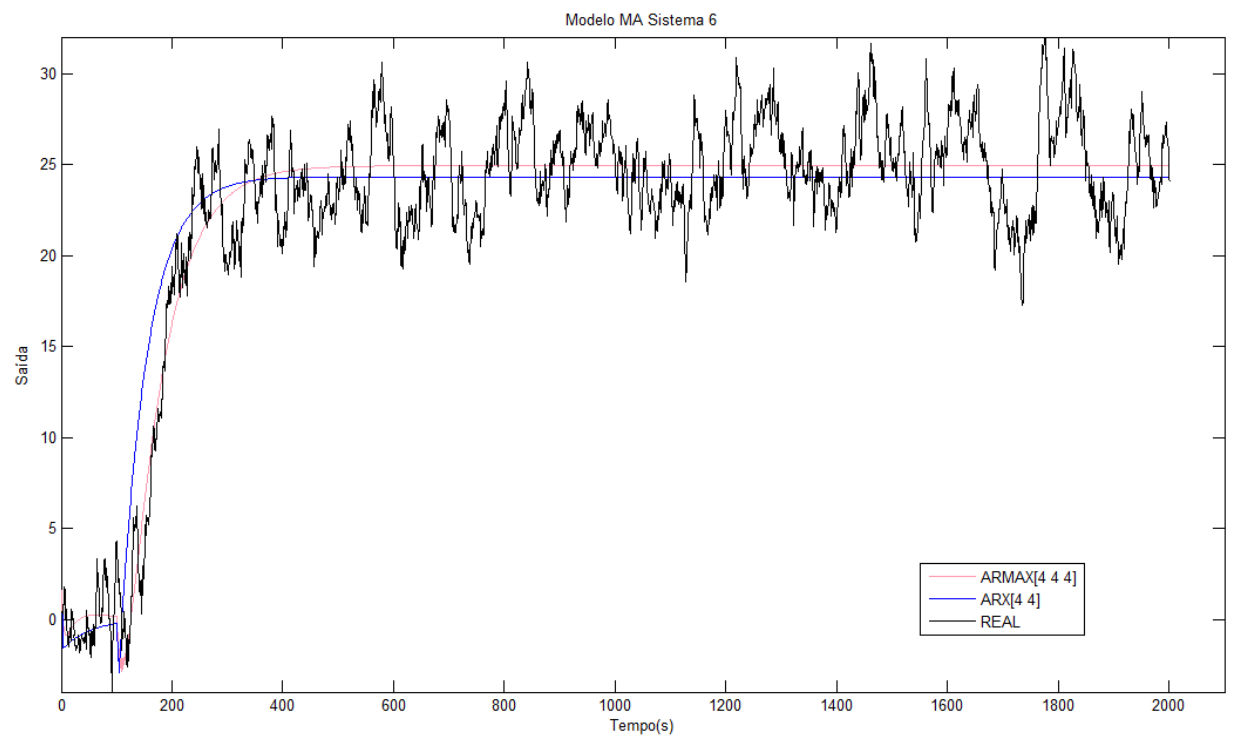

Figura 4.18: Resultado simulação do sistema 6, Malha Aberta, com densidade de potência do ruído branco igual a 0,5 .

Observando as figuras 4.1 a 4.18 verifica-se que o modelo ARMAX apresentou uma melhor aproximação da curva do modelo "real", quando comparado com modelo ARX, por incorporar em sua representação a média móvel do erro do sistema. Isto é ratificado pelo índice FPE, cujos menores valores demonstram as melhores identificações, expressos na tabela 4.2 . 
Tabela 4.2: Índice FPE, para os modelos ARX e ARMAX, dos sistemas simulados em

Malha Aberta.

\begin{tabular}{|c|l|l|l|l|l|l|l|}
\hline $\begin{array}{c}\text { Densidade de } \\
\text { potência de Ruido }\end{array}$ & Modelo & Sistema 1 & Sistema 2 & Sistema 3 & Sistema 4 & Sistema 5 & Sistema 6 \\
\hline \multirow{3}{*}{0,005} & ARX & $1.17962 \mathrm{e}-6$ & $1.22471 \mathrm{e}-6$ & $1.31663 \mathrm{E}-5$ & $2.56288 \mathrm{E}-5$ & 0.00367182 & 0.00777534 \\
\cline { 2 - 8 } & ARMAX & $9.72019 \mathrm{e}-7$ & $9,066 \mathrm{E}-01$ & $1.10768 \mathrm{E}-5$ & $2.02254 \mathrm{E}-5$ & 0.00330181 & 0.00653839 \\
\hline & ARX & $1.04321 \mathrm{e}-5$ & $1.08262 \mathrm{e}-5$ & 0.000116489 & 0.000224279 & 0.0340575 & 0.0689123 \\
\cline { 2 - 7 } 0,05 & ARMAX & $9.72146 \mathrm{e}-6$ & $9.6038 \mathrm{e}-6$ & 0.000110778 & 0.000202269 & 0.0330111 & 0.065902 \\
\hline \multirow{3}{*}{0,5} & ARX & $9.81352 \mathrm{e}-5$ & $9.84668 \mathrm{e}-5$ & 0.00112142 & 0.00206726 & 0.332311 & 0.665229 \\
\cline { 2 - 8 } & ARMAX & $9.71298 \mathrm{e}-5$ & $9.59789 \mathrm{e}-5$ & 0.00110596 & 0.00201604 & 0.328904 & 0.652847 \\
\hline
\end{tabular}

\subsubsection{Testes Simulados em Malha Fechada}

Em seguida, foram realizados os testes de simulação para o sistema em malha fechada com os modelos ARX e ARMAX, como pode ser observado nas figuras 4.20 a 4.37 .

Vale salientar que o diagrama de bloco desses testes podem ser observados na 4.19. O controlador utilizado nesses testes foi o PI(proporcional e integral), equação (4.2), cujos parâmetros, $K_{p}$ e $T_{i}$, foram calculados pela Regra de $\mathrm{ZN}$ - método de análise gráfica ou resposta ao Degrau, melhor descrito no apêndice B.

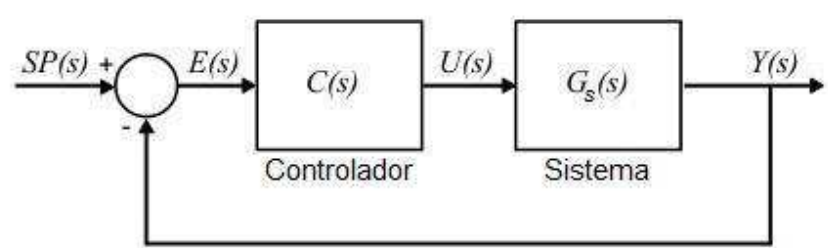

Figura 4.19: Diagrama de Bloco do Sistema Simulado.

$$
C=K_{p}\left(1+\frac{1}{T_{i} s}\right)
$$




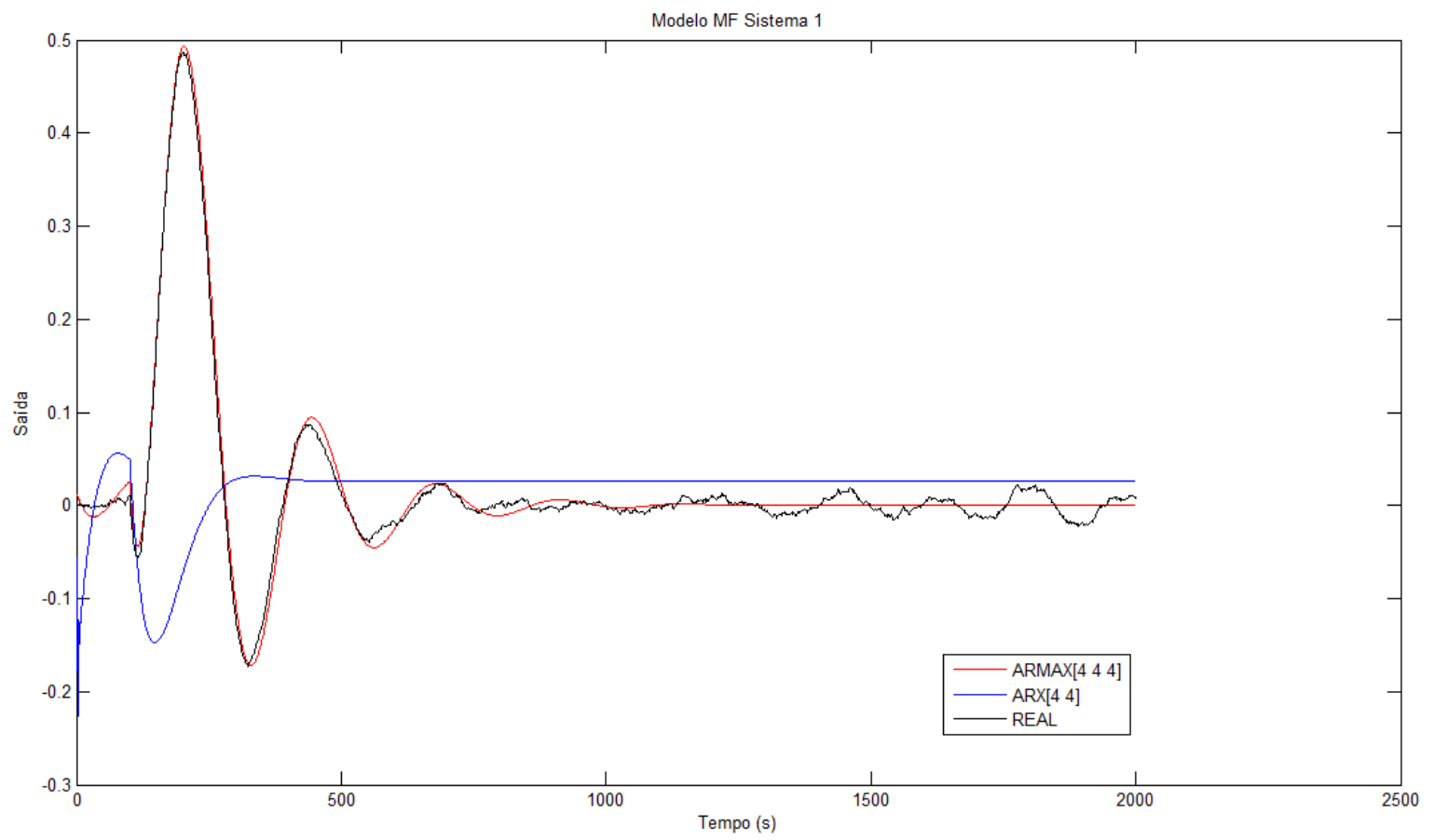

Figura 4.20: Resultado simulação do sistema 1, Malha Fechada, com densidade de potência do ruído branco igual a 0,005.

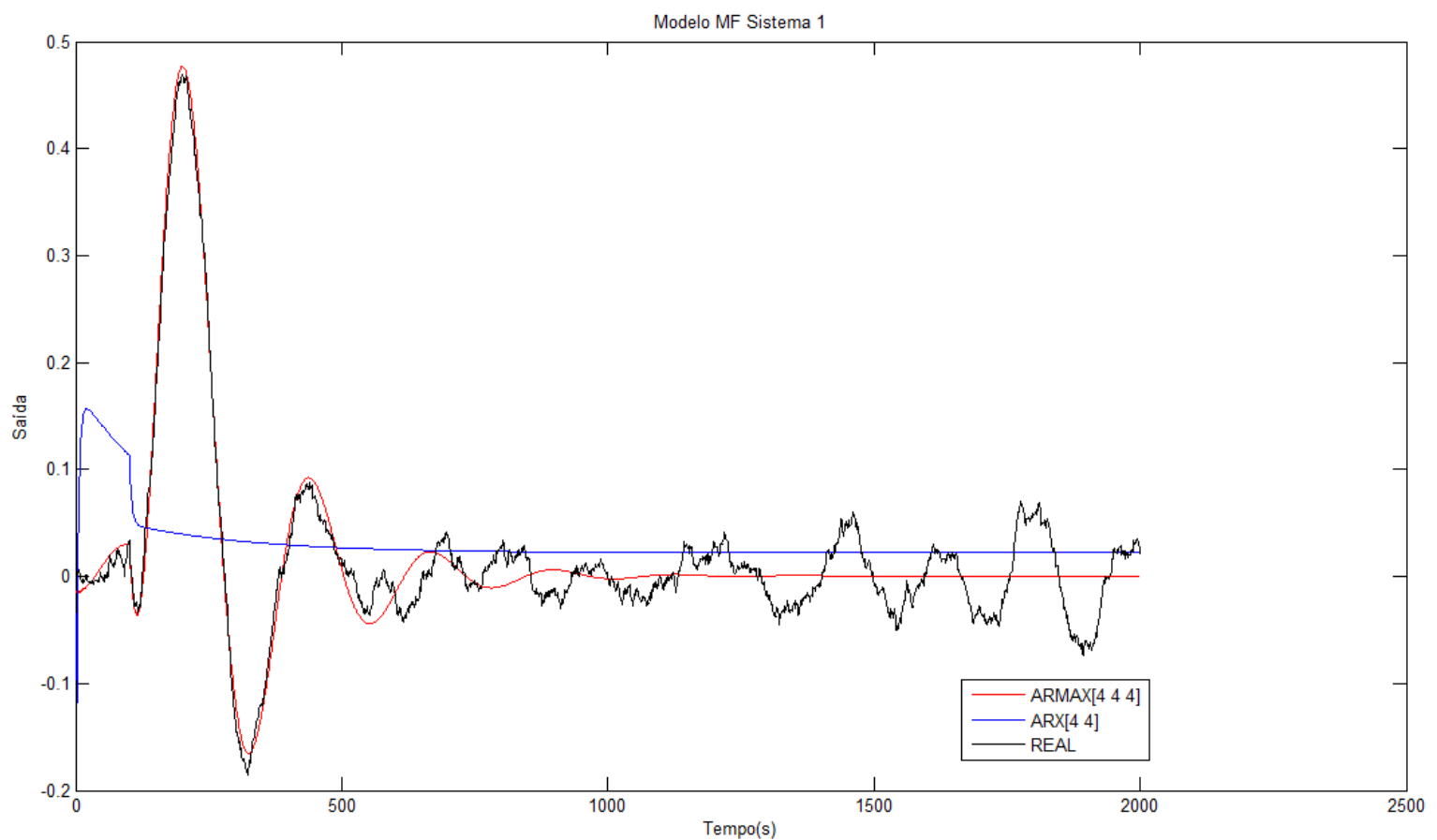

Figura 4.21: Resultado simulação do sistema 1, Malha Fechada, com densidade de potência do ruído branco igual a 0,05 . 


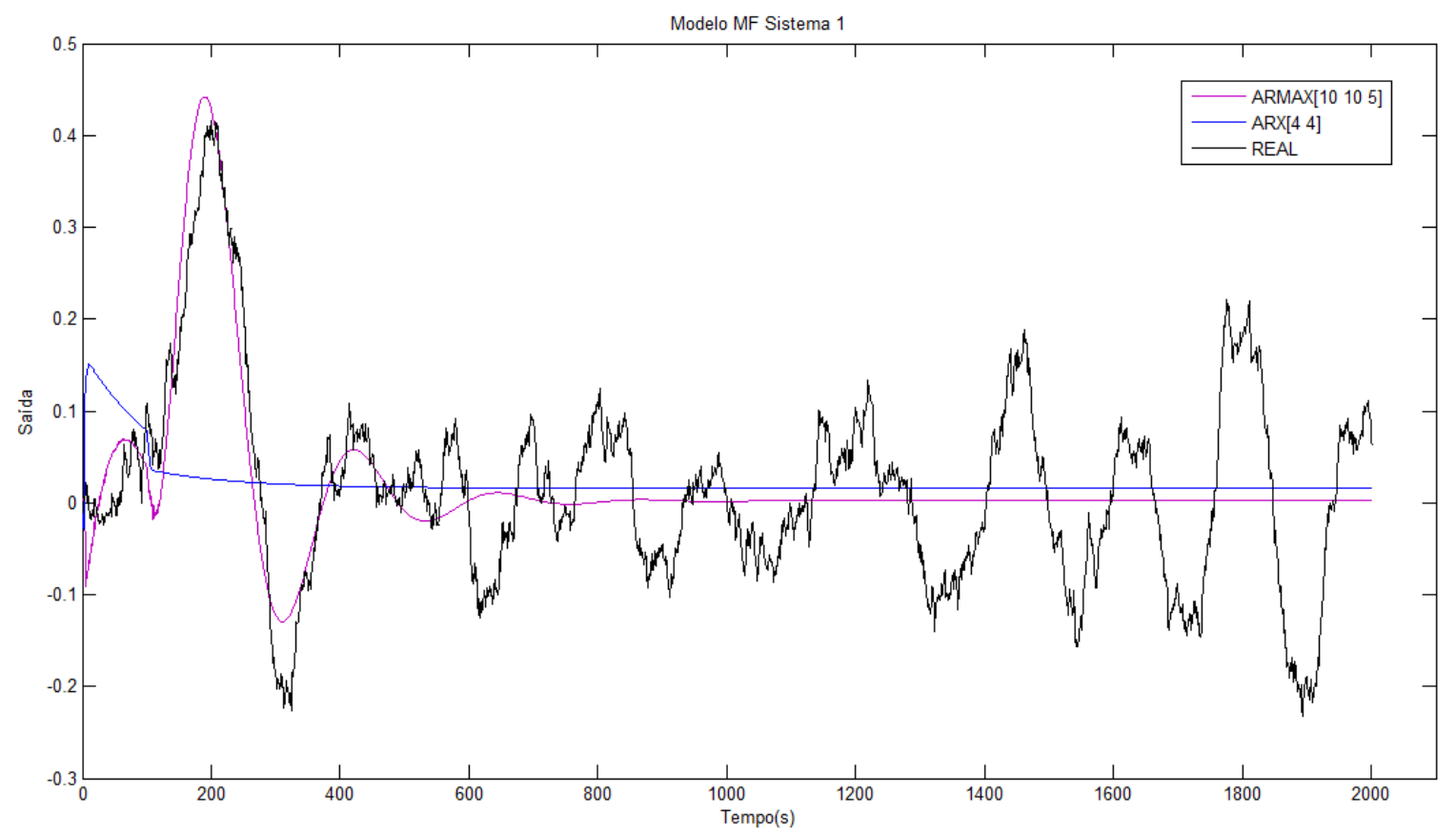

Figura 4.22: Resultado simulação do sistema 1, Malha Fechada, com densidade de potência do ruído branco igual a 0,5 .

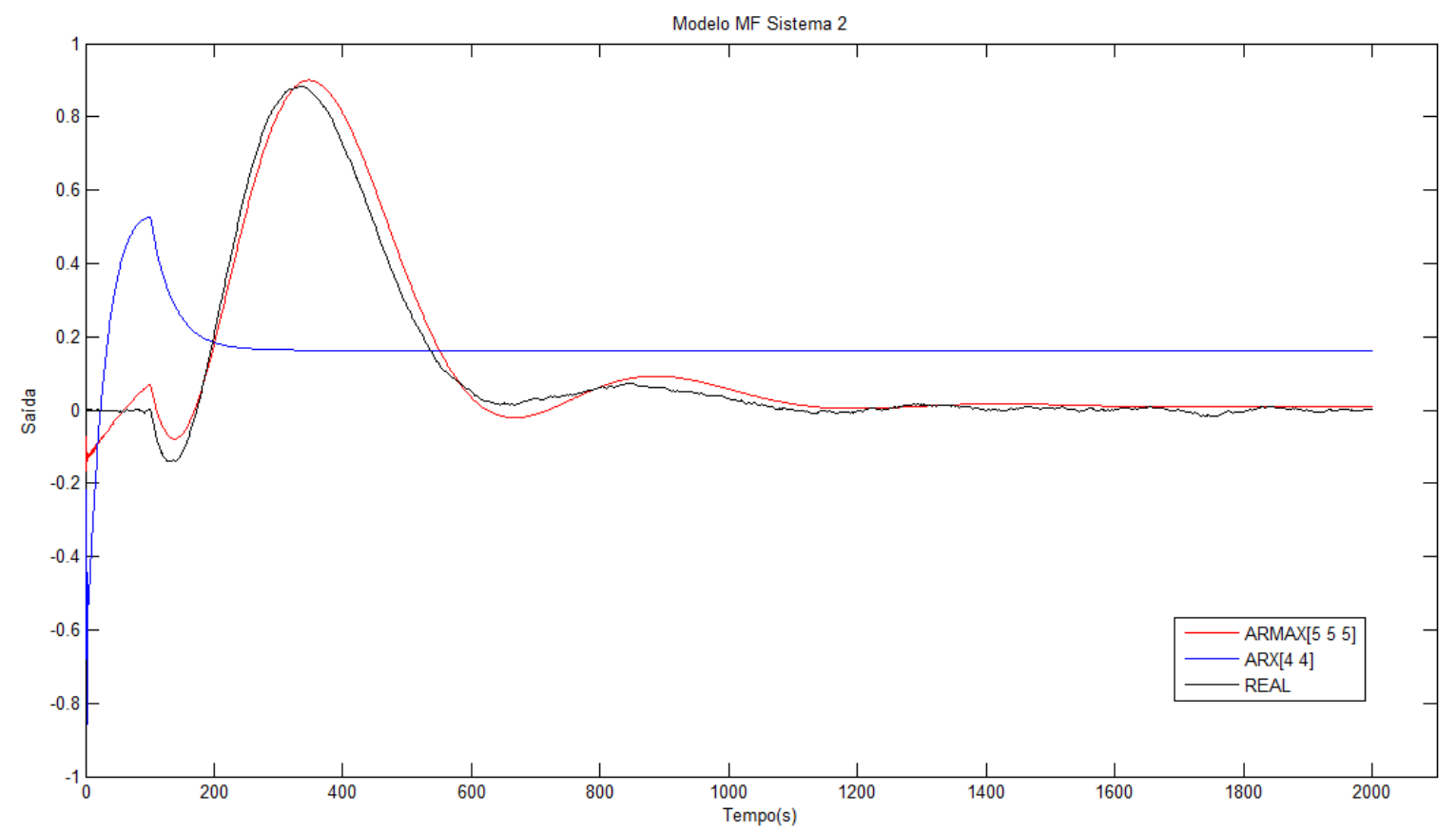

Figura 4.23: Resultado simulação do sistema 2, Malha Fechada, com densidade de potência do ruído branco igual a 0,005 . 


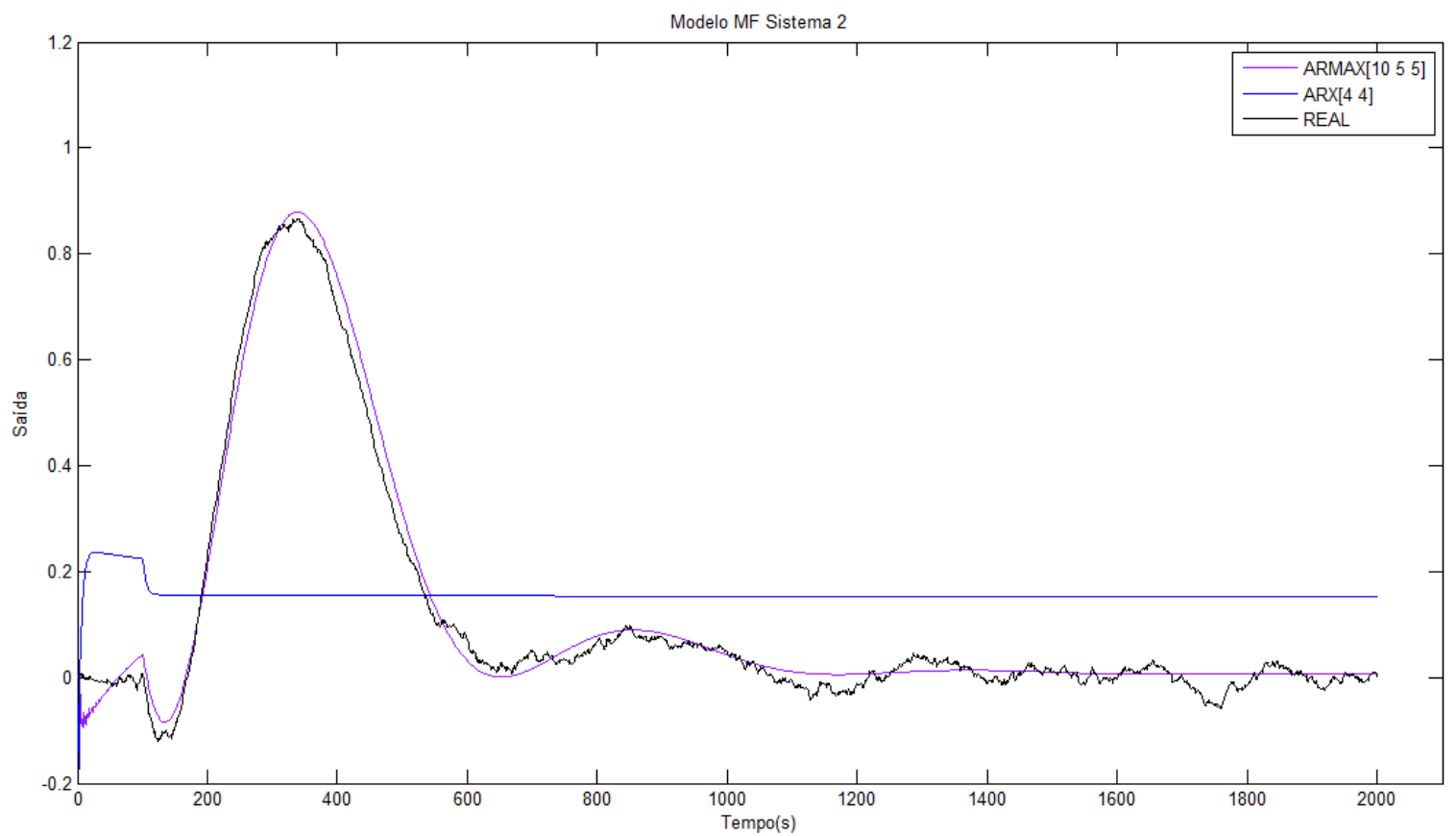

Figura 4.24: Resultado simulação do sistema 2, Malha Fechada, com densidade de potência do ruído branco igual a 0,05 .

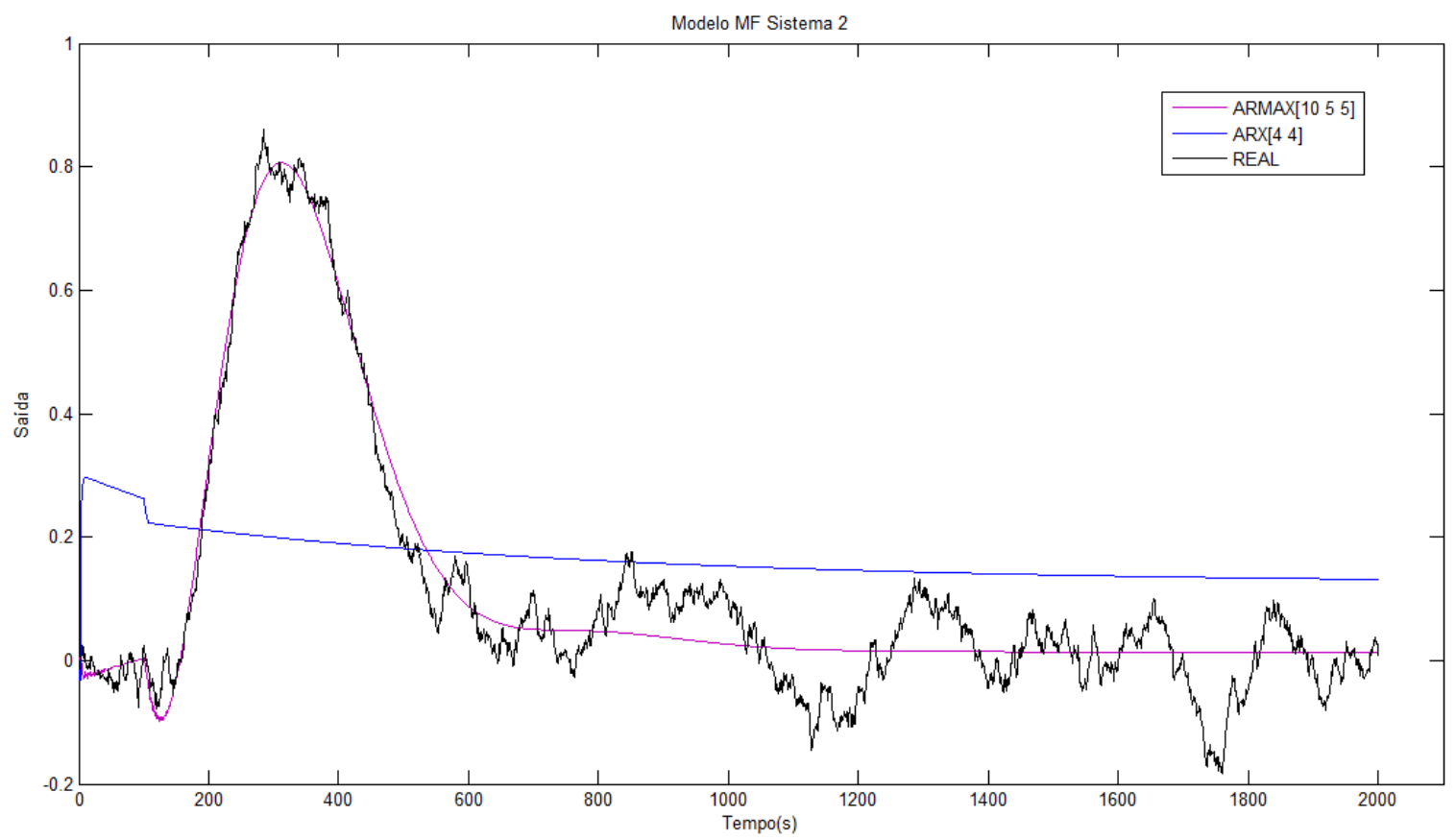

Figura 4.25: Resultado simulação do sistema 2, Malha Fechada, com densidade de potência do ruído branco igual a 0,5 . 


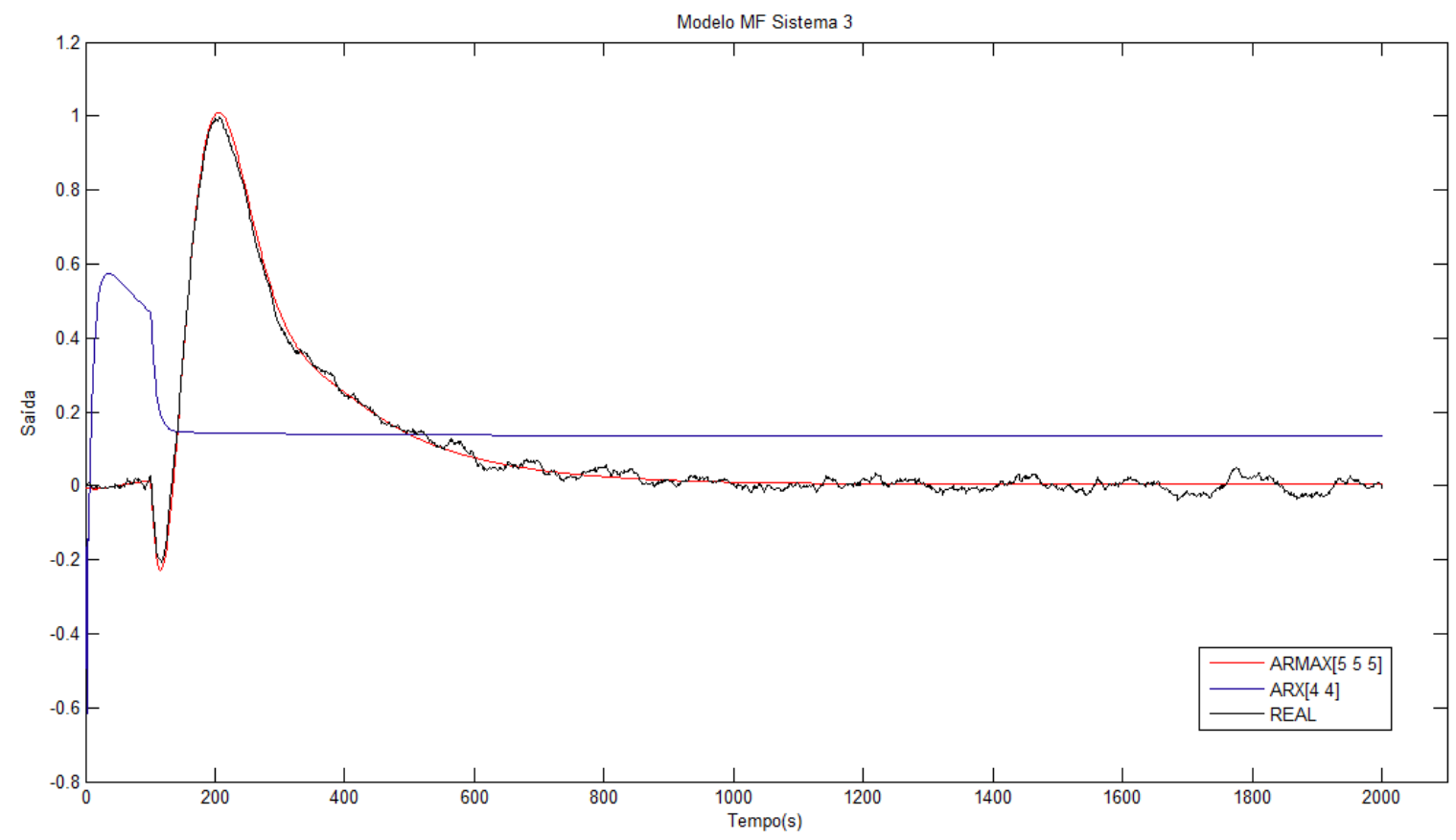

Figura 4.26: Resultado simulação do sistema 3, Malha Fechada, com densidade de potência do ruído branco igual a 0,005.

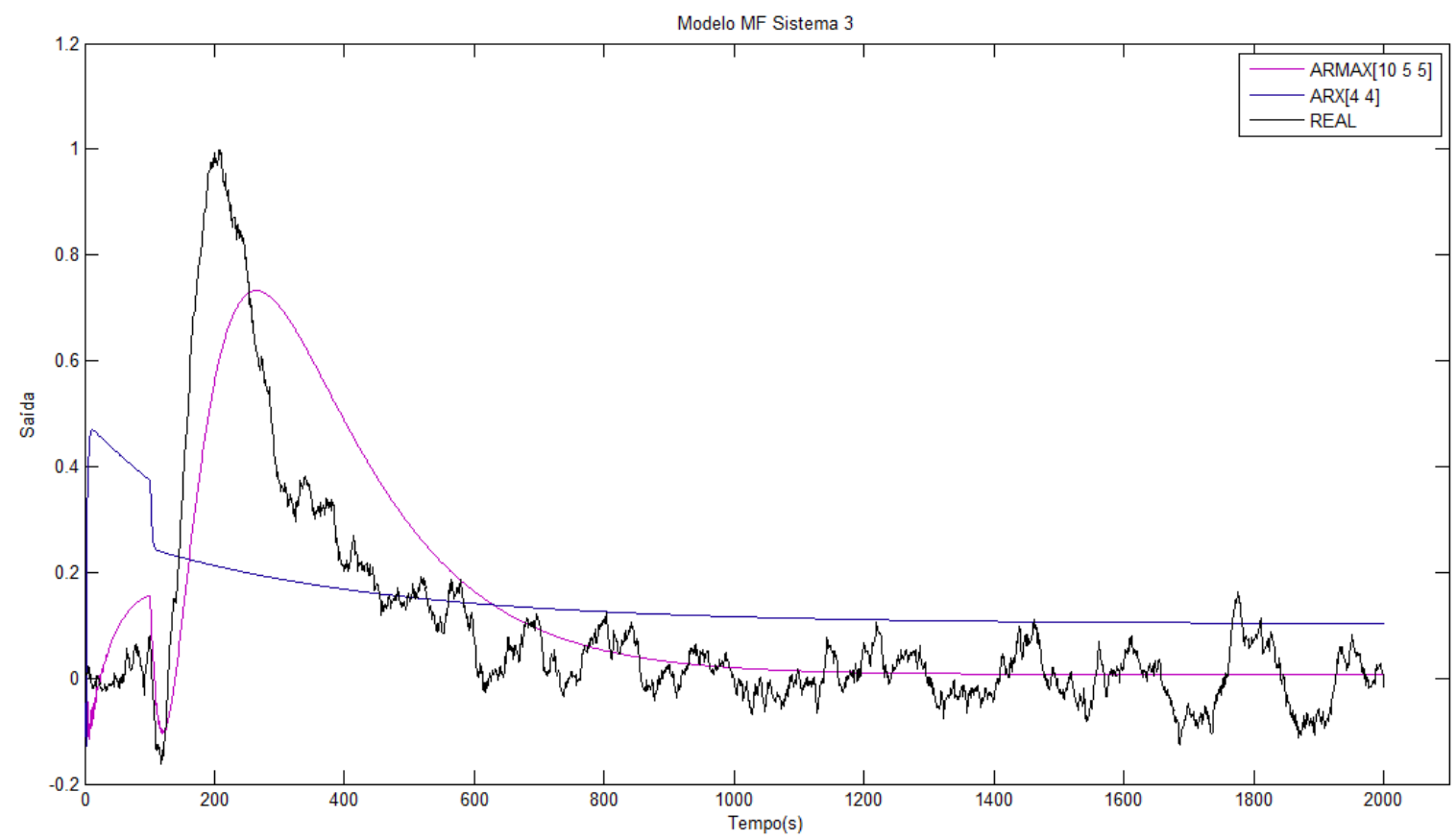

Figura 4.27: Resultado simulação do sistema 3, Malha Fechada, com densidade de potência do ruído branco igual a 0,05 . 


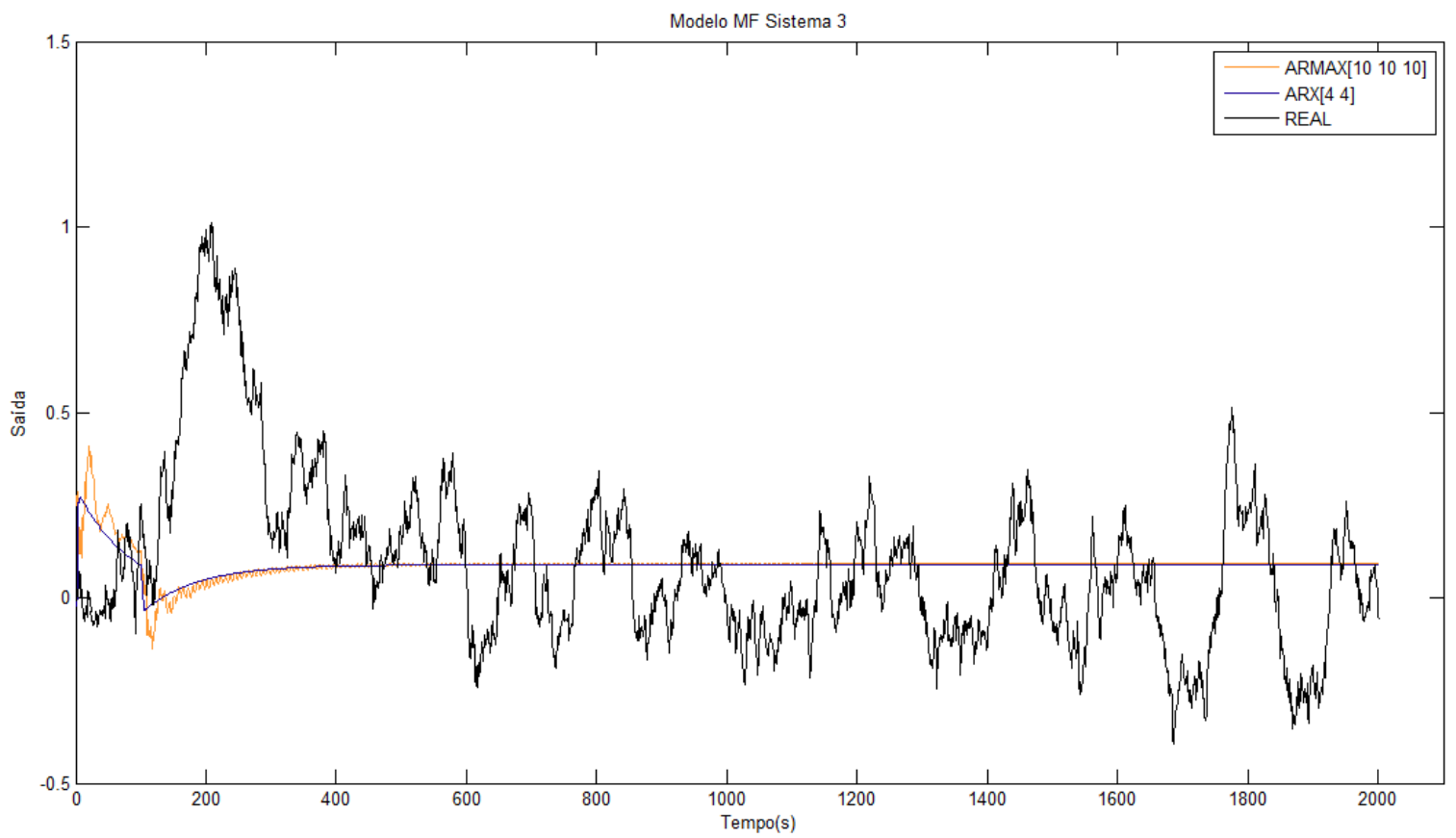

Figura 4.28: Resultado simulação do sistema 3, Malha Fechada, com densidade de potência do ruído branco igual a 0,5 .

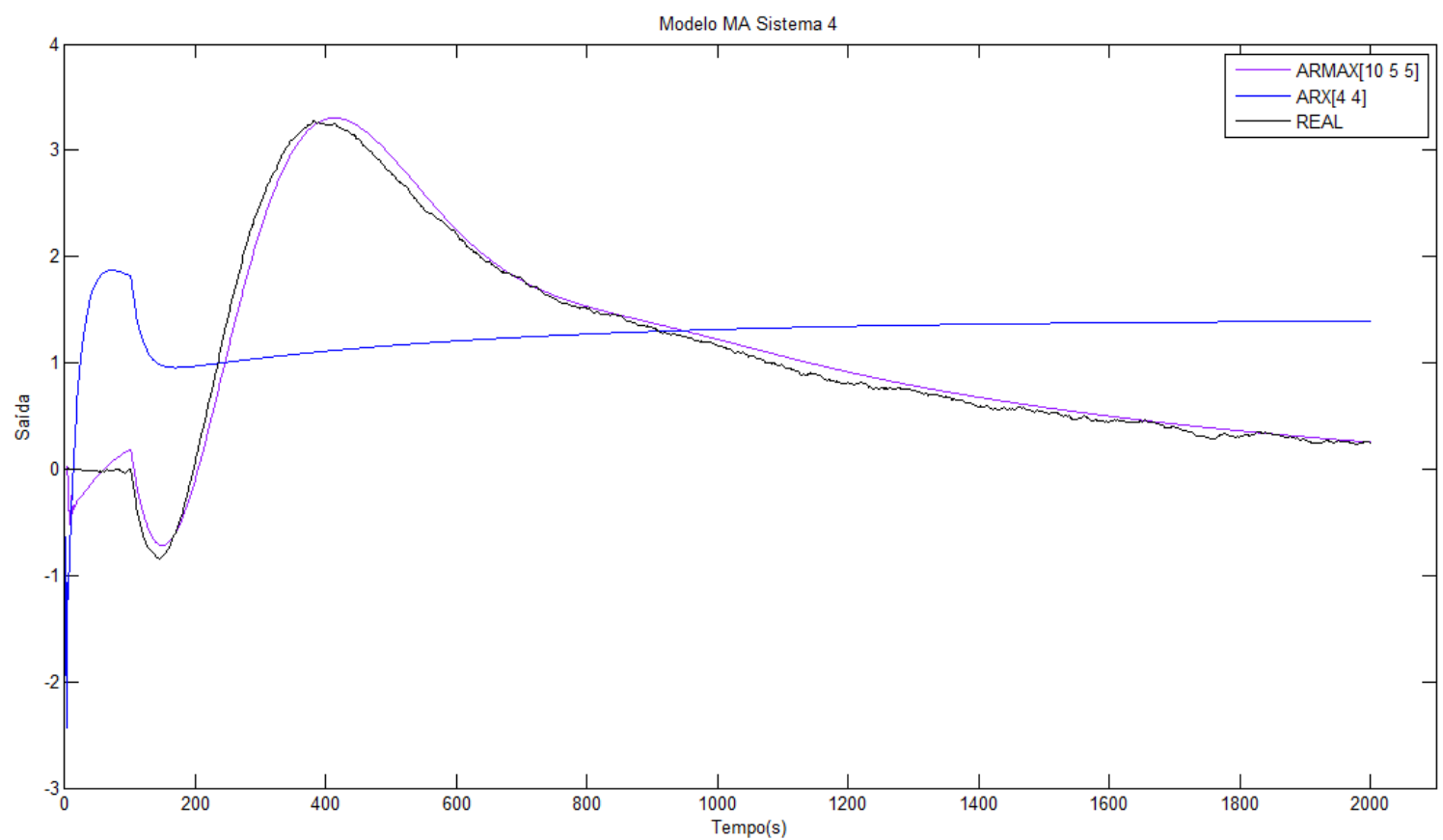

Figura 4.29: Resultado simulação do sistema 4, Malha Fechada, com densidade de potência do ruído branco igual a 0,005. 


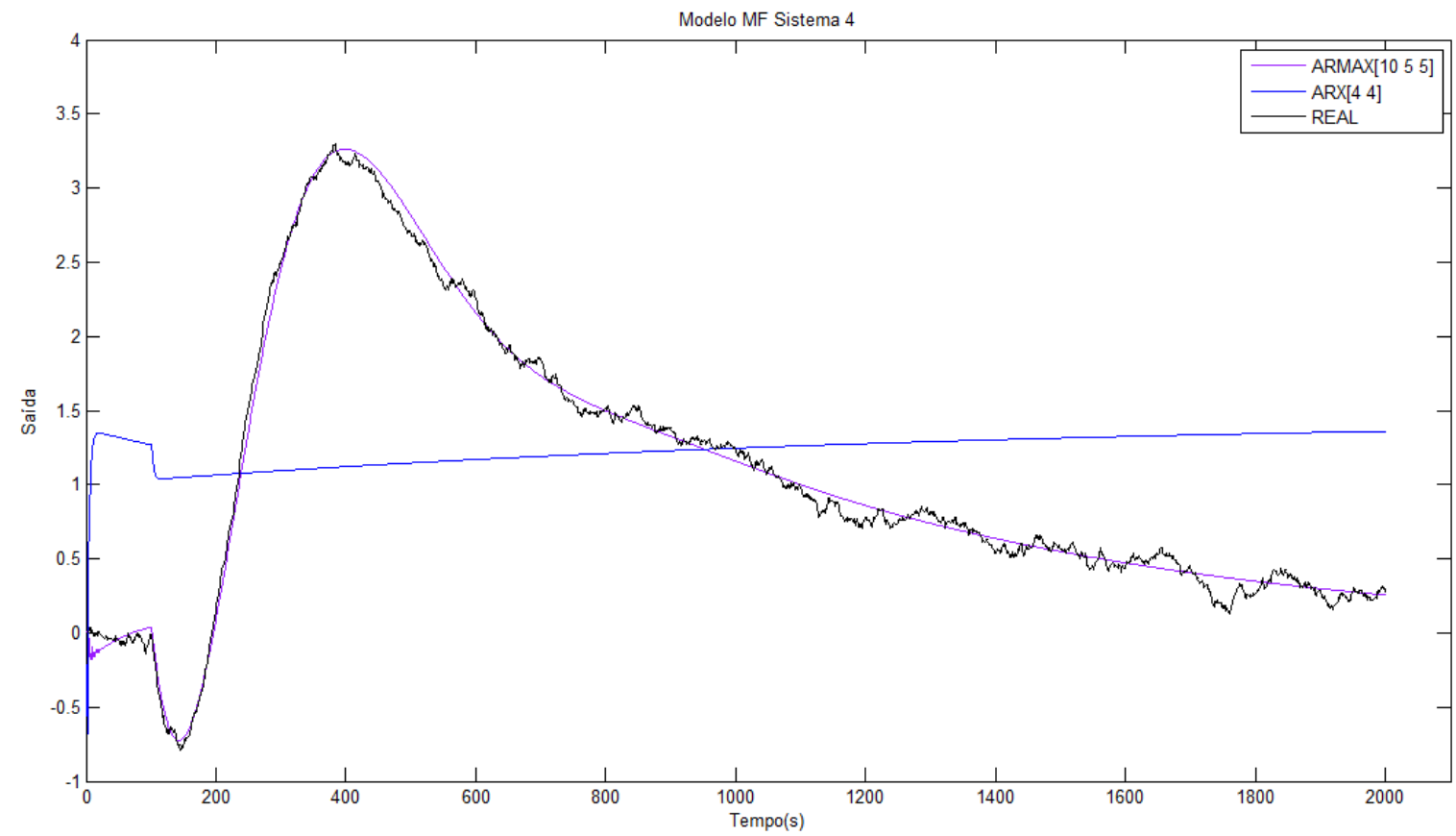

Figura 4.30: Resultado simulação do sistema 4, Malha Fechada, com densidade de potência do ruído branco igual a 0,05.

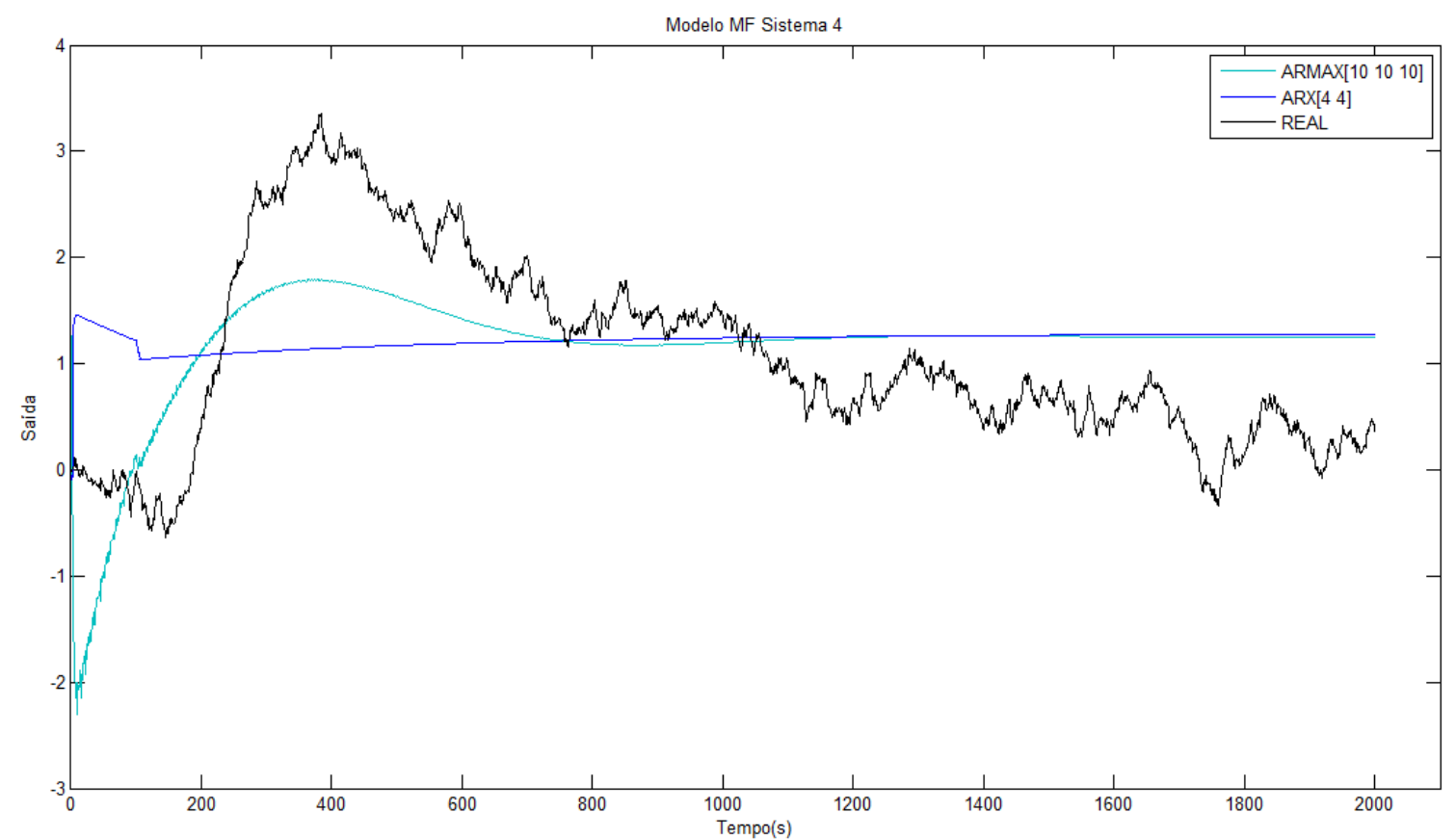

Figura 4.31: Resultado simulação do sistema 4, Malha Fechada, com densidade de potência do ruído branco igual a 0,5 . 


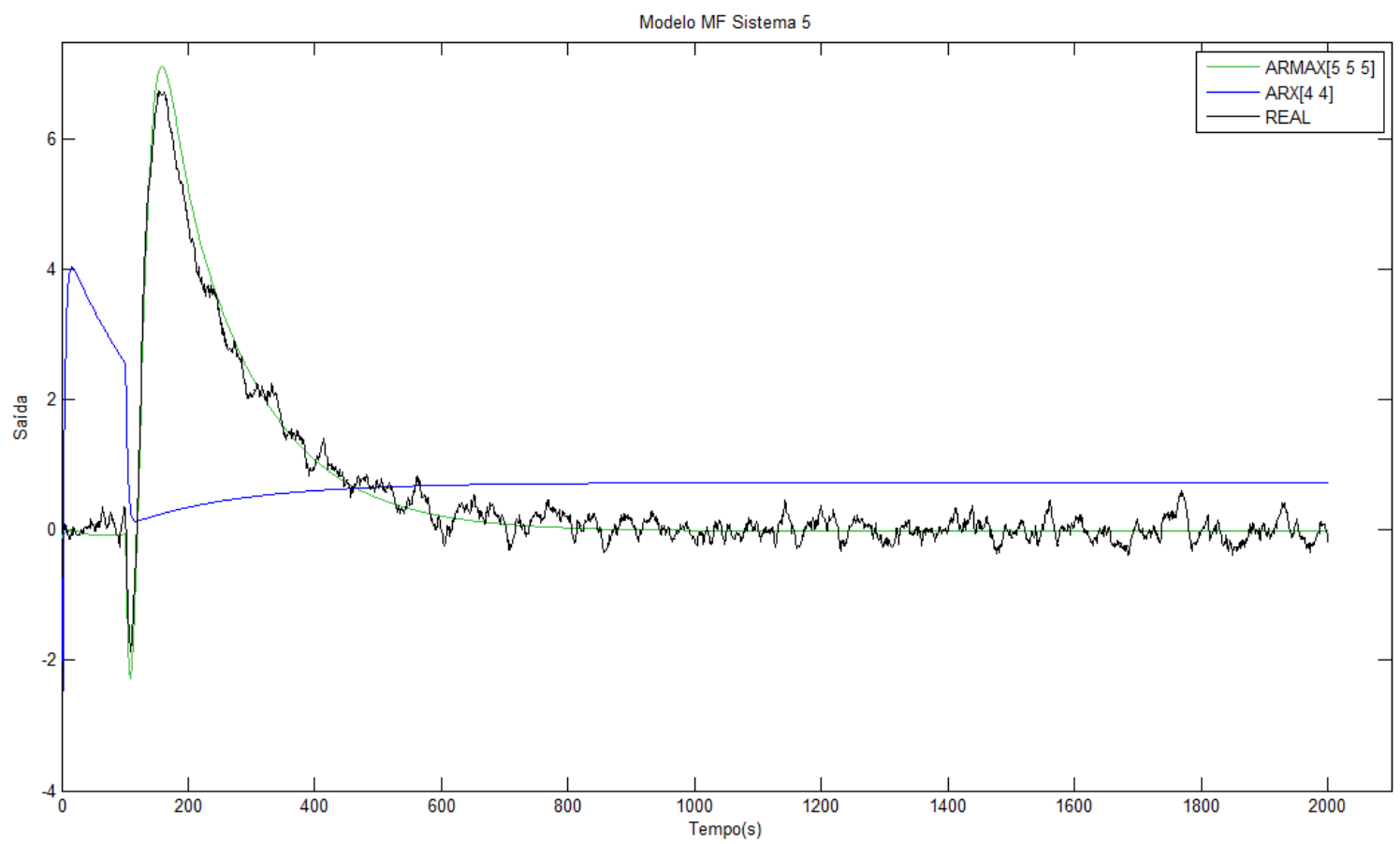

Figura 4.32: Resultado simulação do sistema 5, Malha Fechada, com densidade de potência do ruído branco igual a 0,005 .

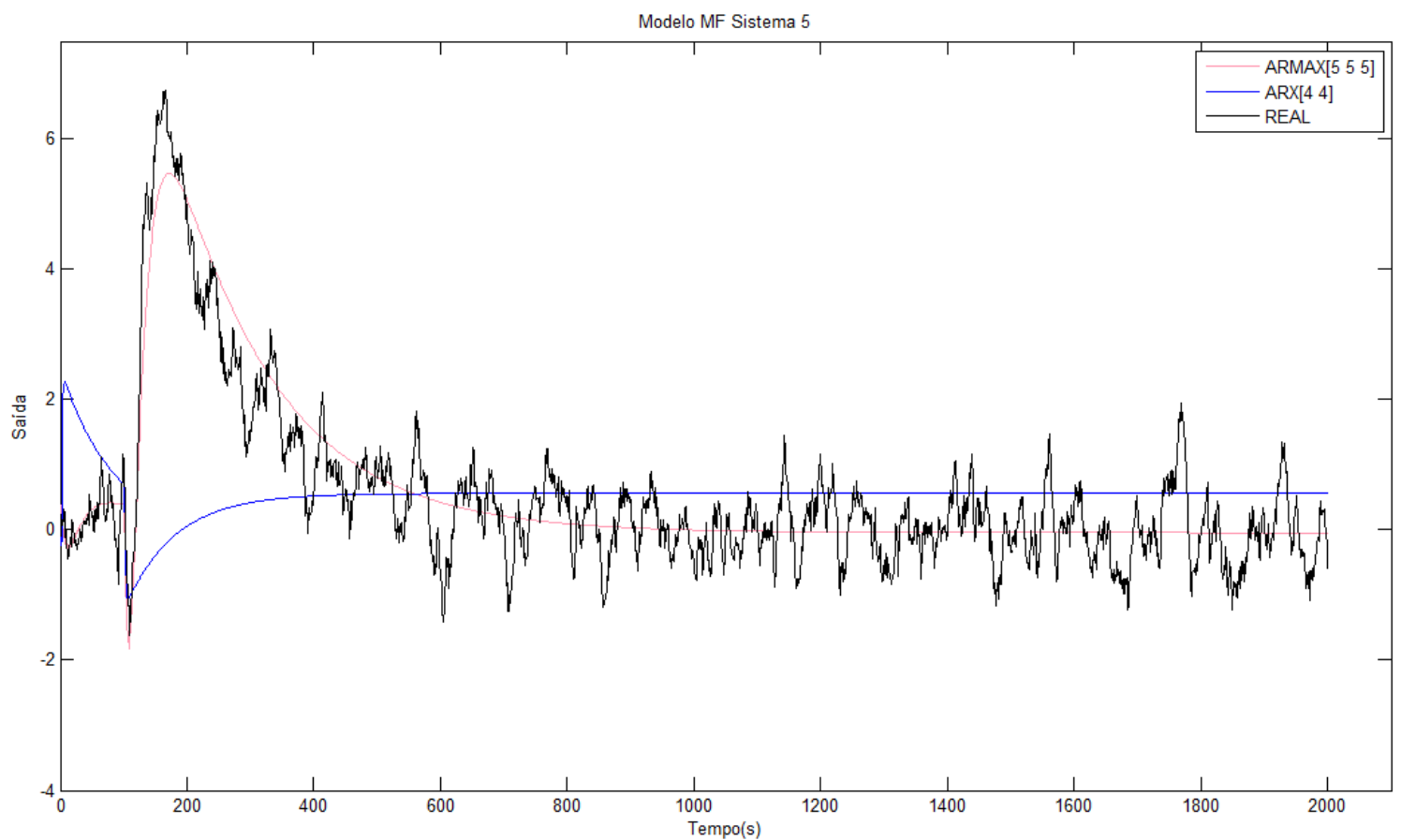

Figura 4.33: Resultado simulação do sistema 5, Malha Fechada, com densidade de potência do ruído branco igual a 0,05 . 


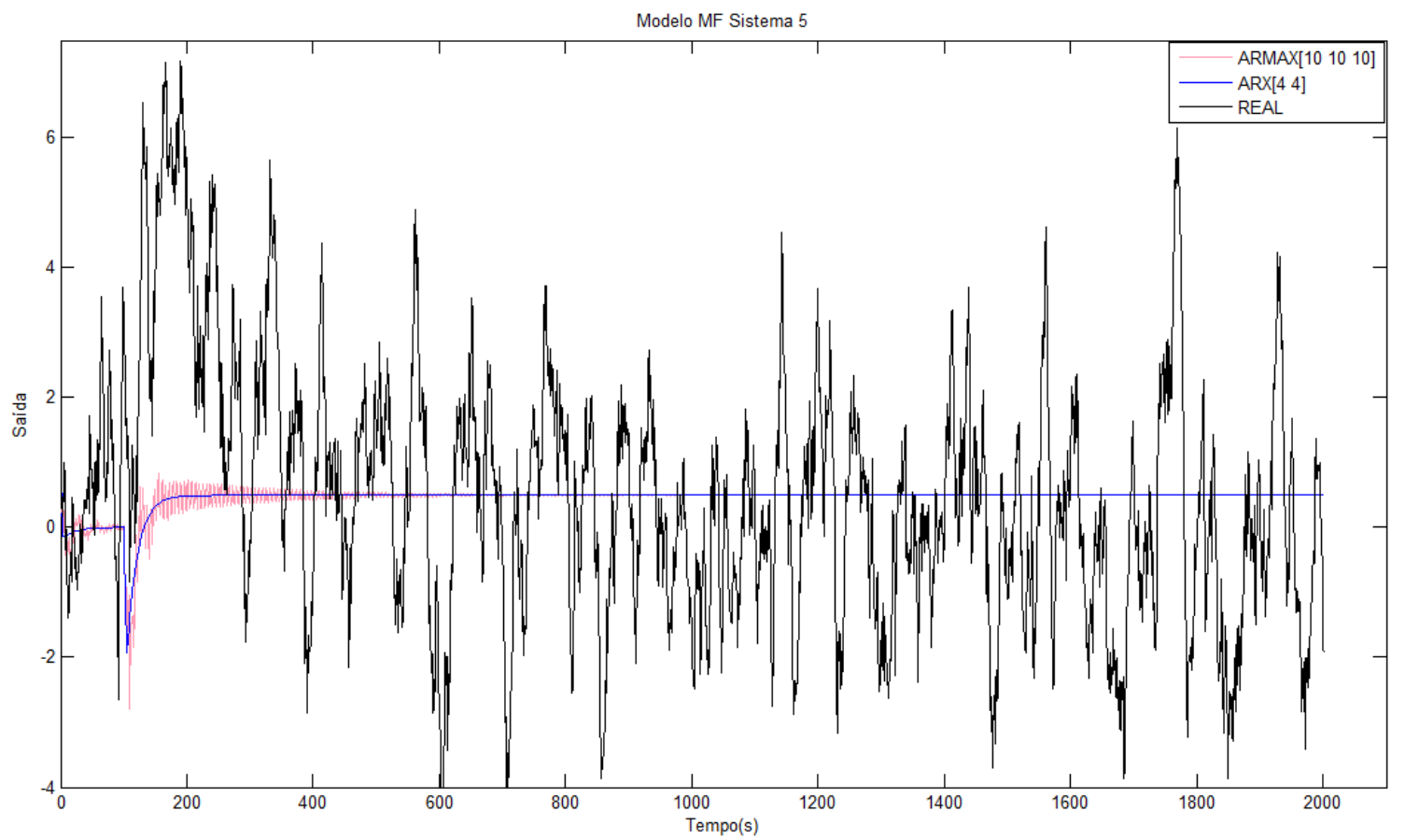

Figura 4.34: Resultado simulação do sistema 5, Malha Fechada, com densidade de potência do ruído branco igual a 0,5 .

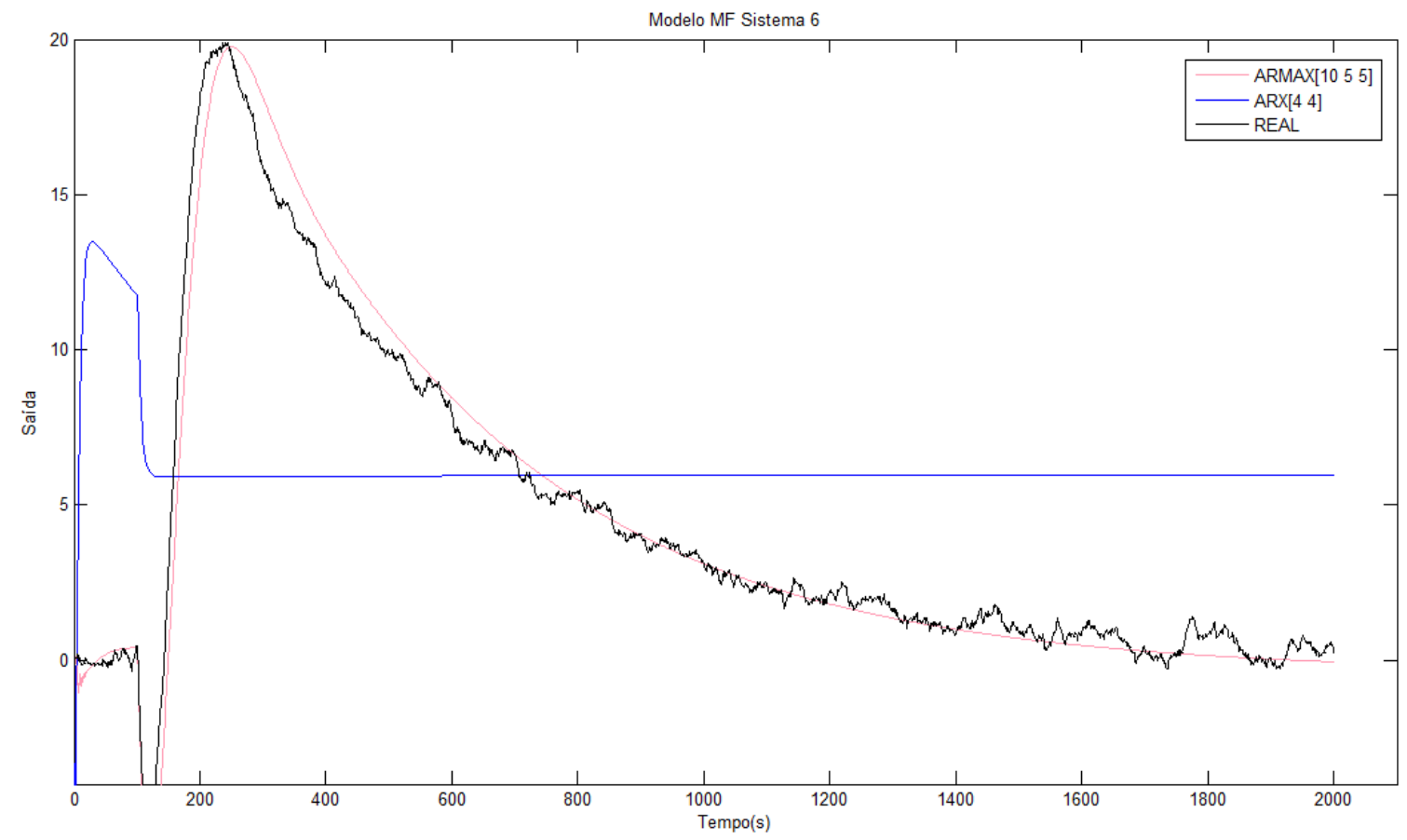

Figura 4.35: Resultado simulação do sistema 6, Malha Fechada, com densidade de potência do ruído branco igual a 0,005 . 


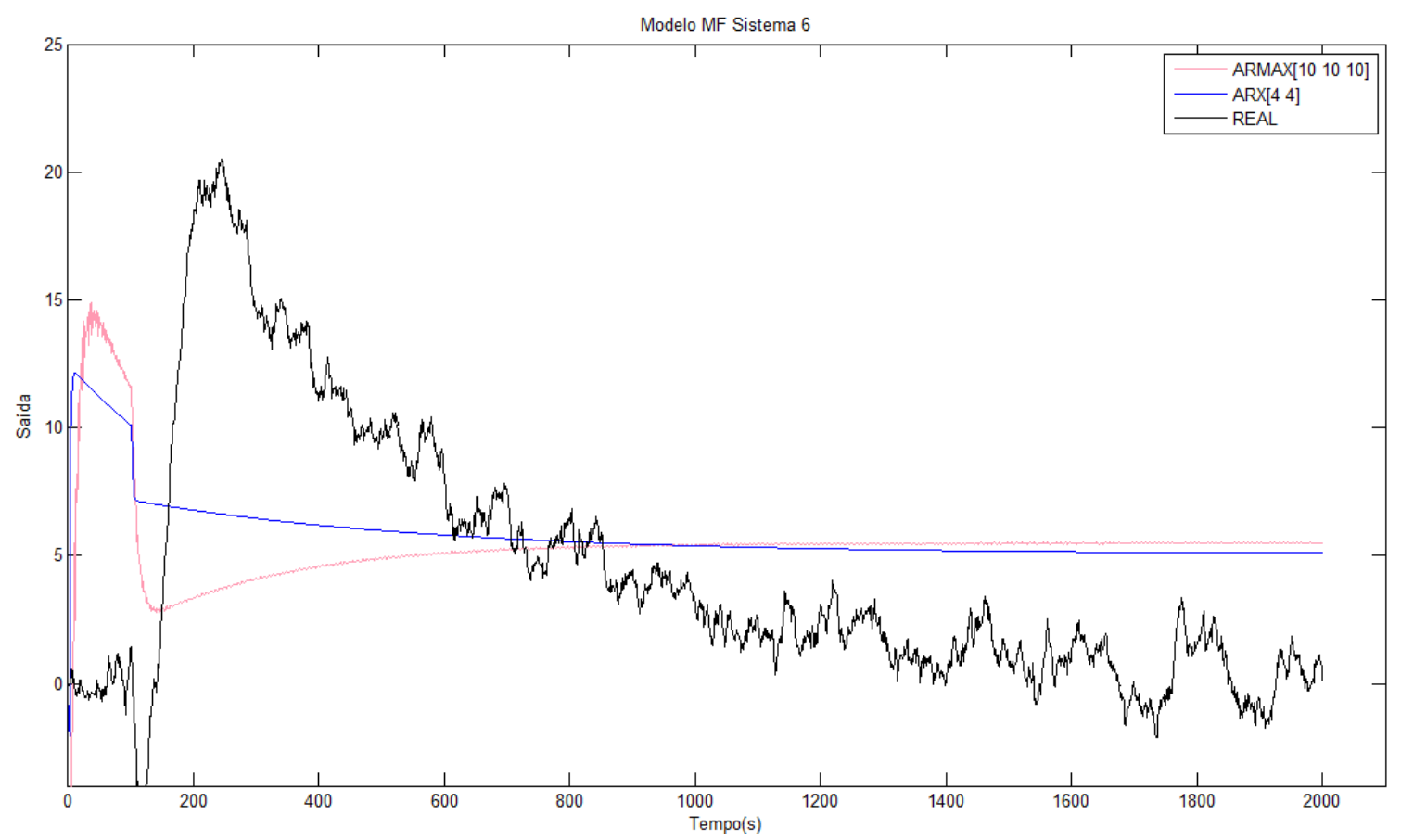

Figura 4.36: Resultado simulação do sistema 6, Malha Fechada, com densidade de potência do ruído branco igual a 0,05 .

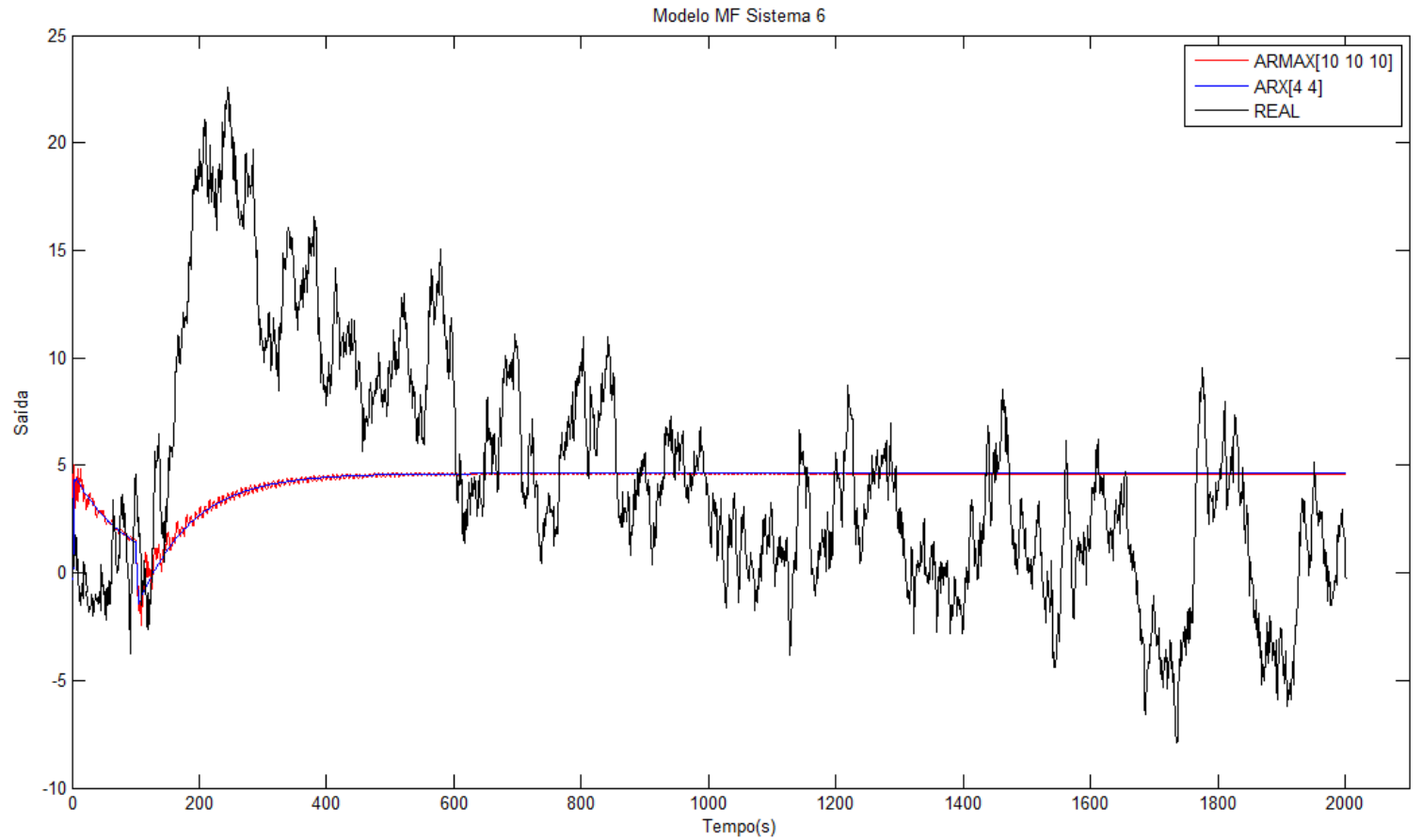

Figura 4.37: Resultado simulação do sistema 6, Malha Fechada, com densidade de potência do ruído branco igual a 0,5 . 
Como visto nas figuras 4.20 a 4.37, simulação com os sistemas em malha fechada, o modelo ARMAX também mostrou melhor resultado, quando comparado com modelo ARX, como mostra o índice FPE na tabela 4.3.

Tabela 4.3: Índice FPE, para os modelos ARX e ARMAX, dos sistemas simulados em Malha Fechada.

\begin{tabular}{|c|l|l|l|l|l|l|l|}
\hline $\begin{array}{c}\text { Densida de de } \\
\text { potência de Ruido }\end{array}$ & Modelo & Sistema 1 & Sistema 2 & Sistema 3 & Sistema 4 & Sistema 5 & Sistema 6 \\
\hline \multirow{3}{*}{0,005} & ARX & $1.29193 \mathrm{e}-6$ & $1.27864 \mathrm{e}-6$ & $1.42589 \mathrm{E}-5$ & $2.64696 \mathrm{E}-5$ & 0.00411689 & 0.0082856 \\
\cline { 2 - 8 } & ARMAX & $1.03343 \mathrm{e}-6$ & $1.04757 \mathrm{e}-6$ & $1.1705 \mathrm{E}-5$ & $2.19261 \mathrm{E}-5$ & 0.00356863 & 0.0071417 \\
\hline & ARX & $1.16893 \mathrm{e}-5$ & $1.6824 \mathrm{E}-5$ & 0.000123161 & 0.00023494 & 0.362268 & 0.0714332 \\
\cline { 2 - 8 } 0,05 & ARMAX & $1.00191 \mathrm{e}-5$ & $1.00569 \mathrm{E}-5$ & 0.000118613 & 0.000209076 & 0.349668 & 0.0706289 \\
\hline \multirow{3}{*}{0,5} & ARX & 0.000104665 & 0.000101749 & 0.00115804 & 0.00210007 & 0.347616 & 0.678576 \\
\cline { 2 - 8 } & ARMAX & 0.000100428 & $9.82505 \mathrm{E}-5$ & 0.00115396 & 0.00209556 & 0.346918 & 0.681603 \\
\hline
\end{tabular}

Contudo, nos gráficos das figuras 4.20 a 4.37, é notório que quanto maior a relação $(\theta / \tau)$, a curva do modelo acompanhou com menos precisão, ou não conseguiu acompanhar a curva do sinal do sistema "real"; principalmente com aumento da densidade de potência do sinal de ruído. Além disso, é importante notar também que alguns modelos identificados ( como o sistema 6, com densidade de ruído 0,5) o número de regressores para o modelo ARMAX foi de 10 regressores de saída, 10 de entrada e 10 regressores do sinal do erro o que equivale a uma representação matemática do sistema com equação de décima ordem. Estes modelos, com números elevados de regressores, possuem representações matemáticas que não são muito vistas nas práticas indústrias, pois segundo ASTRÖM e HÄNGGLUD (1995), grande parte das plantas industriais são representados por sistema de primeira e segunda ordem.

Após um melhor entendimento do uso dos modelo ARX e ARMAX, partiu-se, portanto, para os dados aferidos em planta industrial cujo controle preciso é essencial para seu funcionamento. Então, foram usados dados coletados na usina sucroalcooleira, em especial na produção de açúcar.

\subsubsection{Resultado da Identificação com dados reais da Usina Ipiranga}

Os testes de identificação foram feitos com dados oriundos do sistema supervisório da Usina Ipiranga, localizada em Descalvado - Sp. Vale salientar que os sinais foram coletados sem intervenção no processo natural da planta, ou seja, todos os sinais foram aferidos via supervisório com período de amostragem de um segundo. Outro ponto 
importante a ser destacado é que os dados coletados são de malha fechada, isto é, a planta já possui um controle prévio e a identificação será importante para auxiliar o ajuste ótimo aos parâmetros do controlador.

Dentre os dados obtidos e identificados tem-se os sinais referentes ao controle da temperatura do caldo de cana no processo de aquecimento, durante a etapa do tratamento do caldo, antes da decantação. Esta variável deve ser mantida em aproximadamente $107^{\circ} \mathrm{C}$, como pode ser observado na figura 4.38, dados de entrada (no gráfico inferior) e saída (no gráfico superior) do sistema de modelagem caixa preta.
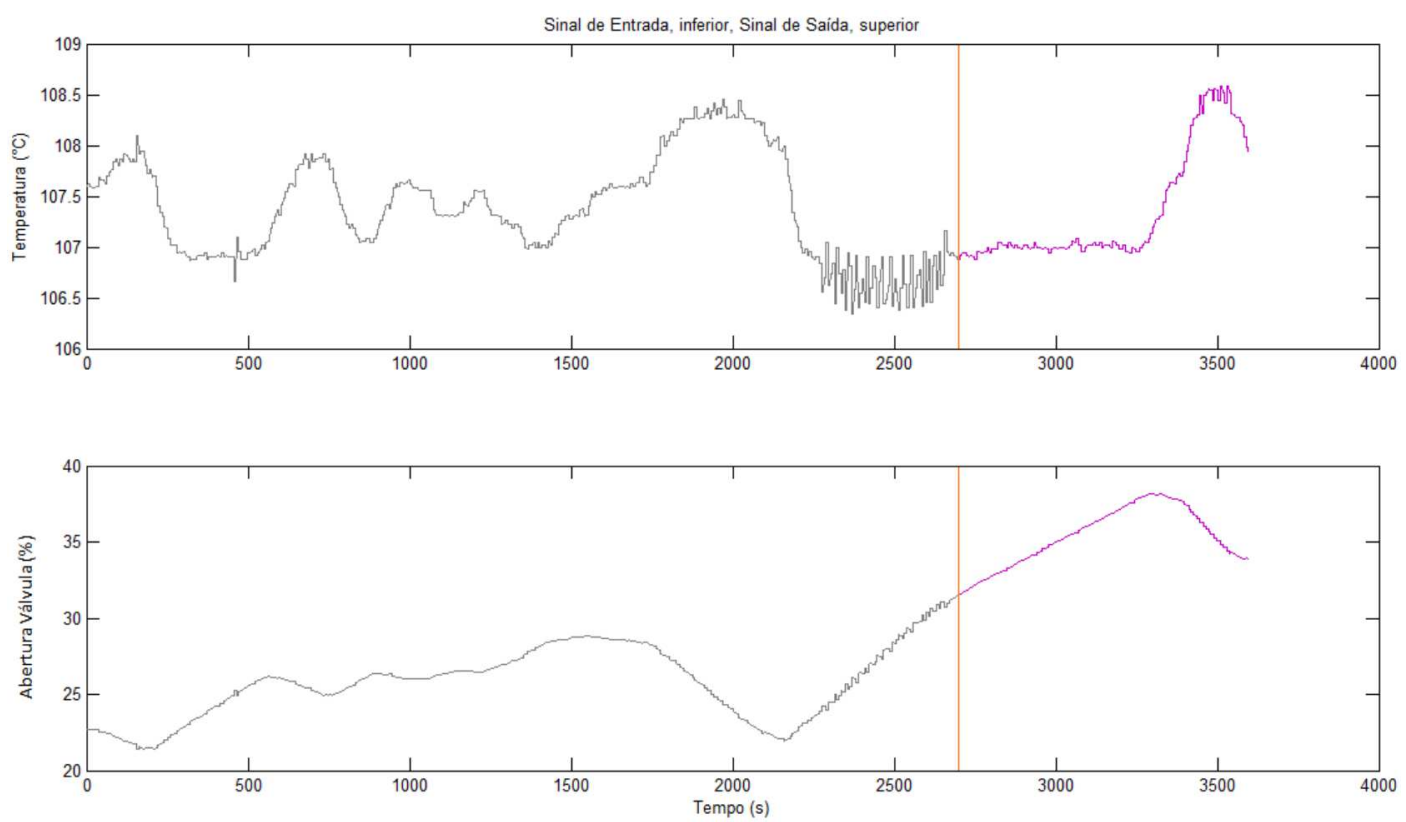

Figura 4.38: Conjunto de dados utilizado na identificação. Sinal de saída (superior) e entrada (inferior) de identificação referente à temperatura no processo de Aquecimento.

Vale salientar que a linha vermelha observada nos gráficos da figura 4.38, demarca o conjunto de dados utilizados na identificação e na validação.

Ao analisar os gráficos da figura 4.38, nota-se a presença de ruído, principalmente, no sinal de saída dos dados; bem como um comportamento atípico causado possivelmente por alguma irregularidade no controle ou no processo da planta, originado a partir de 2200 segundos.

De posse desses dados, foram realizados diferentes testes de identificação com diversas representações matemáticas e distintas estrutura de modelo, e então se estimou os parâmetros da equação que melhor representará o comportamento do sistema real. 
Os melhores resultados dos testes podem ser observado na firgua 4.39 .

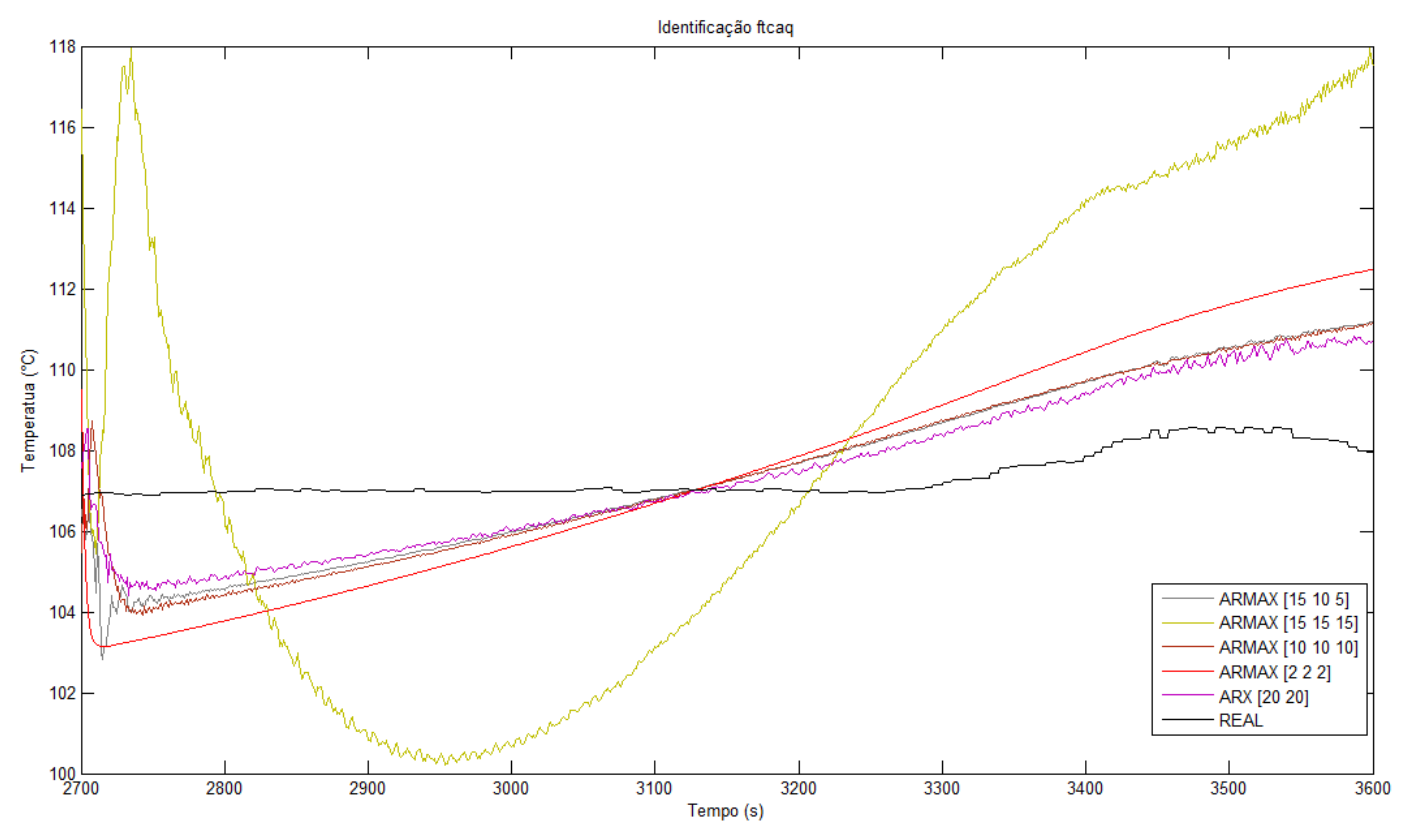

Figura 4.39: Gráfico Comparativo entre diferentes estruturas de modelo, referente à temperatura do caldo de cana no processo de Aquecimento.

Observa-se, a partir da figura 4.39, que os modelos reproduziram o comportamento do sistema ao longo do período de identificação. Isto pode ser notado ao observar o comportamento do sinal de entrada, figura 4.38, utilizado na modelagem, que até 1700 segundos, apresentou um comportamento crescente ao longo deste período que foi refletido pelo sinal modelado, entretanto em aproximadamente 1800 segundos o sinal de entrada inverteu e decresceu seu valor. Esta mudança de comportamento foi reproduzida já no conjunto de dados utilizado na validação em 2750 segundos. Em seguida, o sinal de entrada inverte novamente seu comportamento, voltando a crescer, tornando a ser representado no sinal identificado. Sendo assim, pode-se aferir que as representações matemáticas utilizadas nesta modelagem não conseguiram acompanhar com precisão a curva dos dados coletados. Isto pode ter ocorrido devido a inconsistência do comportamento do conjunto de dados ao longo dos 3600 segundos, ou seja, pelo conjunto de dados ser heterogêneo em um longo período. Além disso, a irregularidade ocorrida de, aproximadamente, 2200 a 2700 segundos, poder ter contribuído para o insucesso desta identificação.

A tabela 4.4 mostra o índice de FPE dos modelos simulados. Destes o que teve me- 
nor valor, e consequentemente representou melhor identificação, foi o modelo ARMAX com 15 regressores de saída, 15 regressores de entrada e 15 regressores de erro.

Tabela 4.4: Comparação dos índices FPE para diferentes representações matemáticas.

\begin{tabular}{|c|c|}
\hline $\begin{array}{c}\text { Modelo [ número de regressores do sinal de: } \\
\text { saida, entrada, erro] }\end{array}$ & FPE \\
\hline ARX [20 20] & 0,002356 \\
\hline ARMAX [2 2 2] & 0,002848 \\
\hline ARMAX [10 10 10] & 0,002389 \\
\hline ARMAX [15 15 15] & 0,002284 \\
\hline ARMAX [15 10 5] & 0,002425 \\
\hline
\end{tabular}

A partir dos resultados alcançados com os dados anteriores, na tentativa de melhorar a identificação, foi retirado da simulação os dados a partir de 2200 segundos, uma vez que este deve ter sido ocasinado por algum comportamento não característico do sistema. Assim, os dados de entrada, saída e os resultados estão expressos nas respectivas figuras 4.40 e 4.41 .
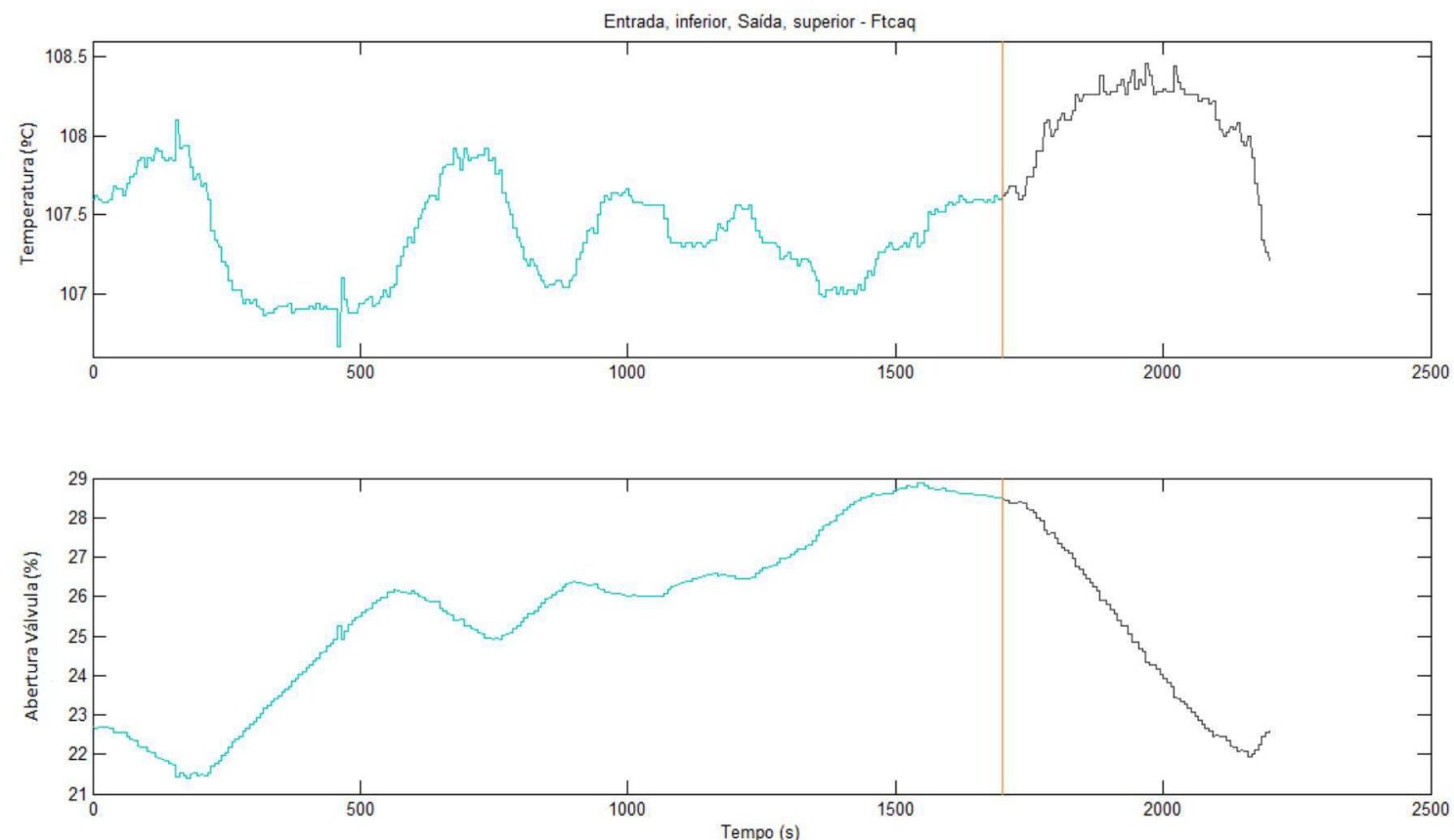

Figura 4.40: Conjunto de dados utilizado do sistema de identificação até 2200 segundos. 


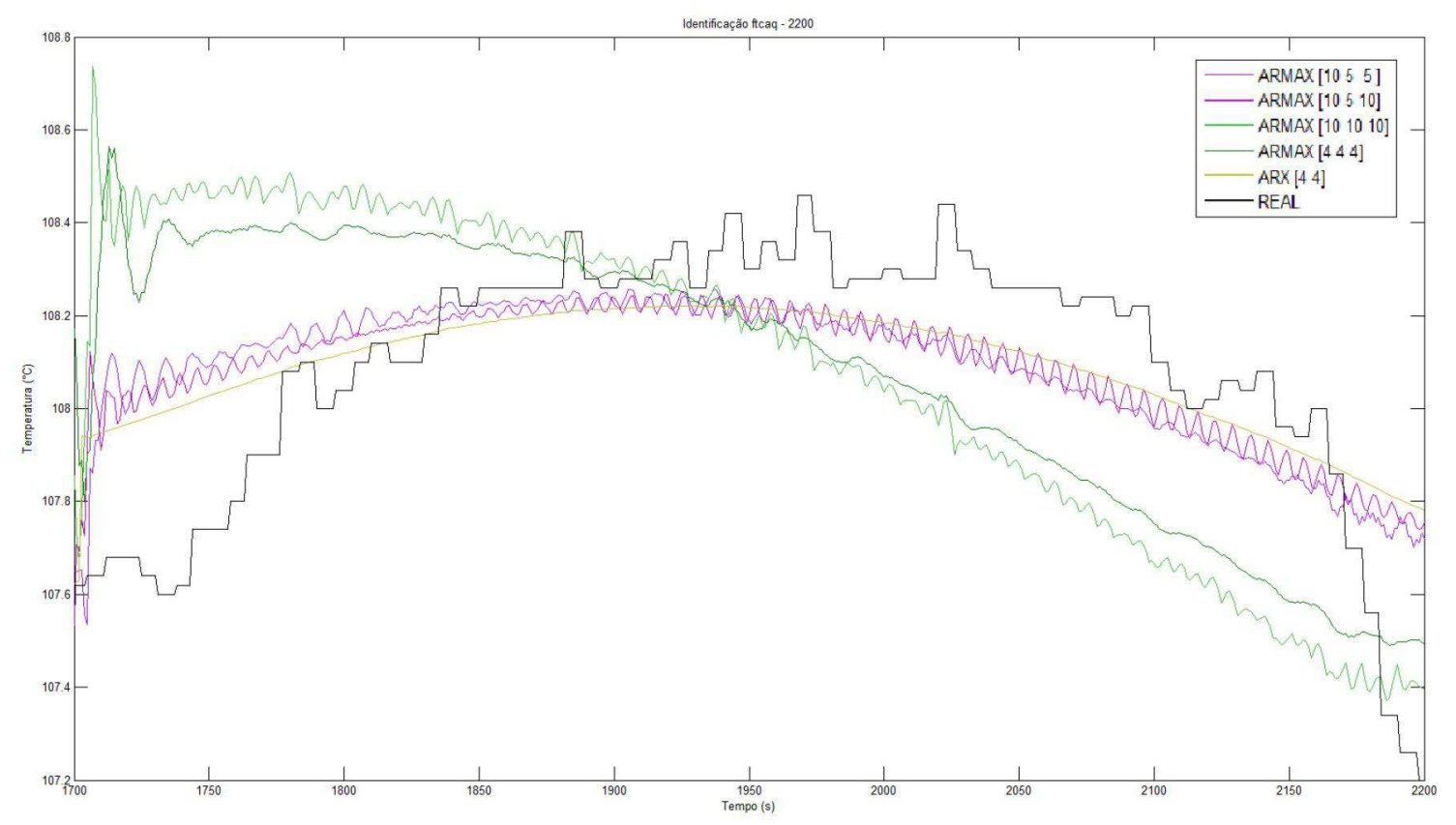

Figura 4.41: Resultado da Validação até 2200 segundos.

Verifica-se, ao observar a figura 4.41, que os modelos apresentaram valores alto de temperatura no início da validação, descrescendo seu valor ao longo deste período por refletir o comportamento do sinal de entrada, como já mencionado com conjunto de dados anterior, mesmo ao retirar os dados devido a irregularidade. Além disso, notase que alguns modelos conseguiram reproduzir a média do comportamento do sistema real, como os modelos ARMAX com 10 regressores de saída, 5 regressores de entrada e 5 regressores de erro, ARMAX com 10 regressores de saída, 5 regressores de entrada e 10 regressores de erro e ARX com 4 regressores de saída e 4 regressores de entrada. A tabela 4.5 mostra o índice FPE dos modelos simulados, deste o que teve menor valor, e consequentemente representou melhor idetificação foi o ARMAX com 10 regressores de saída, 5 regressores de entrada e 10 regressores de erro.

Tabela 4.5: Comparação dos índices FPE para diferentes representações matemáticas, referente à temperatura do caldo de cana no processo de Aquecimento com até 2200 segundos.

\begin{tabular}{|c|c|}
\hline $\begin{array}{c}\text { Modelo [ número de regressores do sinal de: } \\
\text { saida, entrada, erro] }\end{array}$ & FPE \\
\hline ARX [4 4] & 0,005934 \\
\hline ARMAX [4 4 4] & 0,005918 \\
\hline ARMAX [10 10 10] & 0,005713 \\
\hline ARMAX [10 5 5] & 0,005862 \\
\hline ARMAX [10 5 10] & 0,005634 \\
\hline
\end{tabular}


Ao comparar os gráficos de entrada e saída deste dados, figura 4.38 ou figura 4.40, infere-se que a relação $(\theta / \tau)$ é elevada, assim como o sistema 6 da tabela 4.1 do item 4.1. Isto pois ao abservar o sinal de entrada em aproximadamente 250 sengundos seu valor começar a aumentar; enquanto que o sinal de saída só responderá a esta ação em aproximadamente 600 segundos, ou seja, após uma variação no sinal de entrada o sinal de saída responde com um atraso de aproximadamente 350 segundos depois. Assim como nos testes com sinais simulados, o modelo que apresentou esta característica também não apresentou bons resultados de identificação com estas estruturas de modelagem.

Ainda na busca de melhoria dos resultados, foram filtrados o sinais de entrada e saída na tentativa de reduzir o efeito de ruído. Para isto foi utilizado o filtro passabaixa ou Butterworth de primeira e segunda ordem com frequência de corte 0,1 e 0,5. Os resultados da modelagem empírica desses "novos" sinais podem ser observados na figura 4.42 a 4.46 .
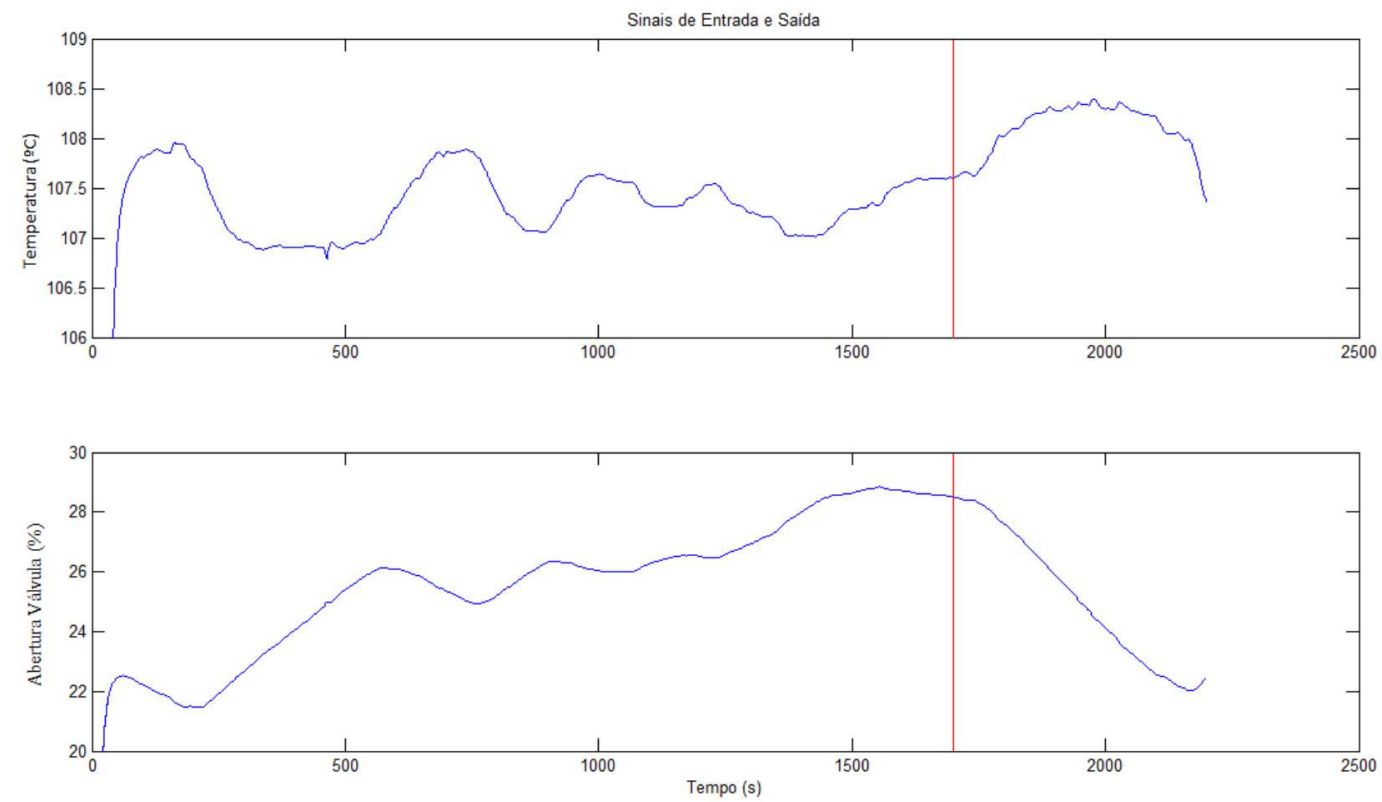

Figura 4.42: Conjunto de dados utilizado na identificação. Sinal de entrada, inferior, saída, superior, filtrados com Butterworth de primeira ordem e frequência de corte de 0,1 .

A linha vermelha, observada no gráfico da figura 4.42, delimita os dados utilizados na identificação e validação.

O resultado obtido com o filtro de ordem 1 e frequência de corte 0,1 pode ser 
observado na figura 4.43, e com frequência de corte 0,5 pode ser visto na figura 4.44.

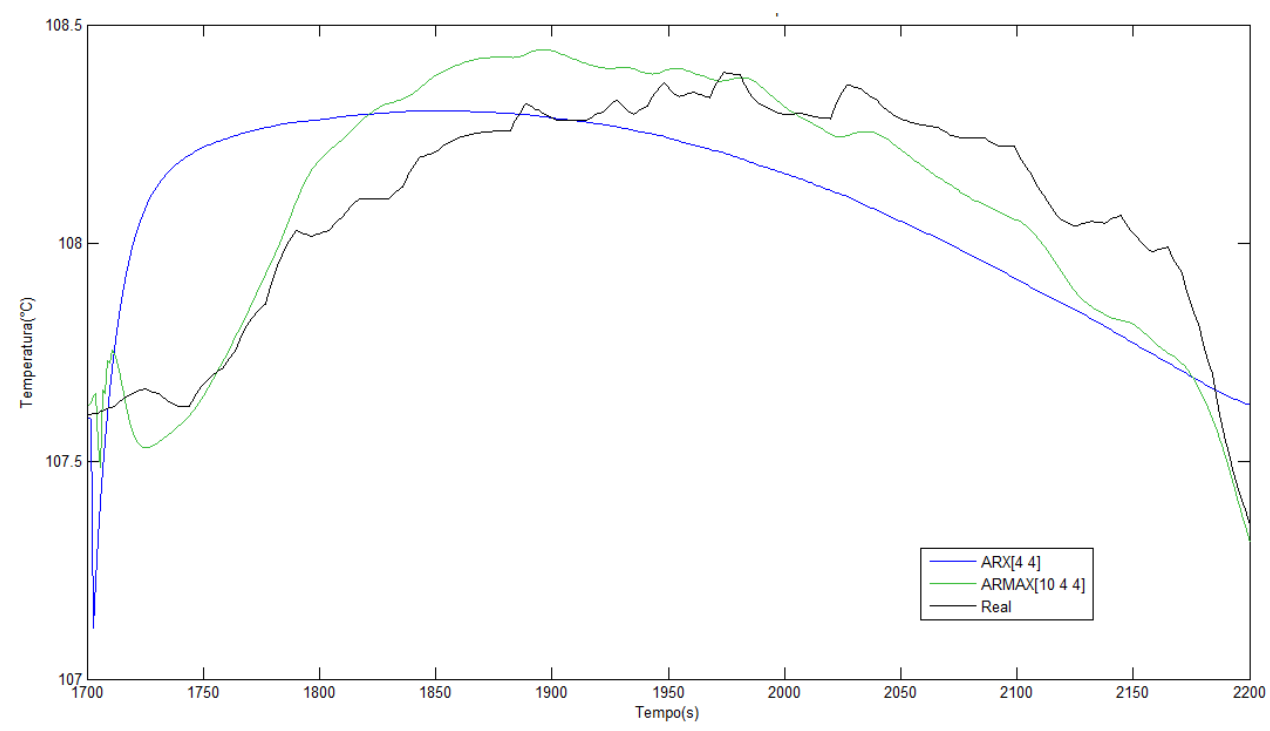

Figura 4.43: Sinais de validação da identificação com a utilização de filtro de primeira ordem e frequência de corte 0,1 .

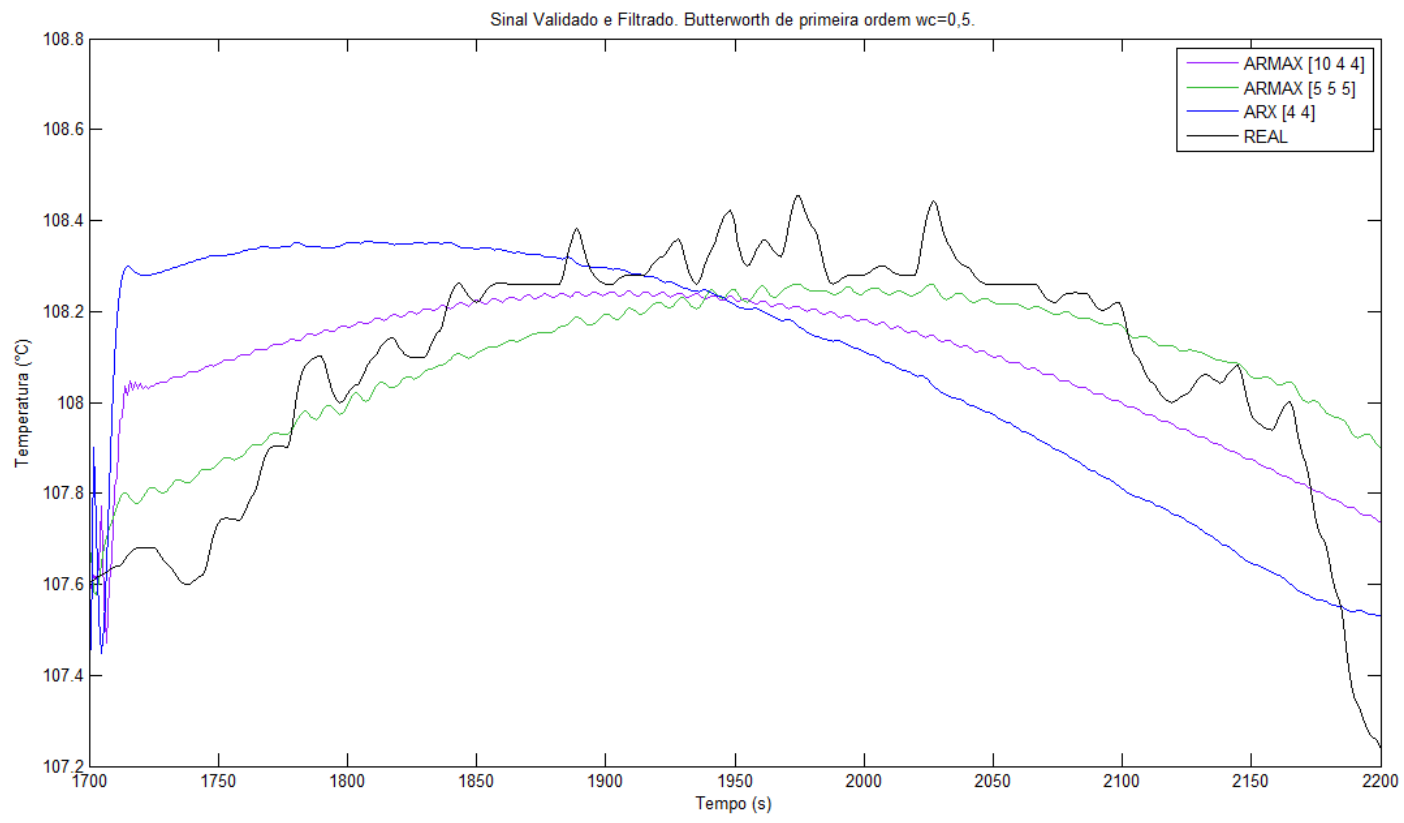

Figura 4.44: Sinais de validação da identificação com a utilização de filtro de primeira ordem e frequência de corte 0,5 .

O resultado obtido com o filtro de ordem 2 e frequência de corte 0,1 pode ser observado na figura 4.45, e com frequência de corte 0,5 pode ser visto na figura 4.46. 


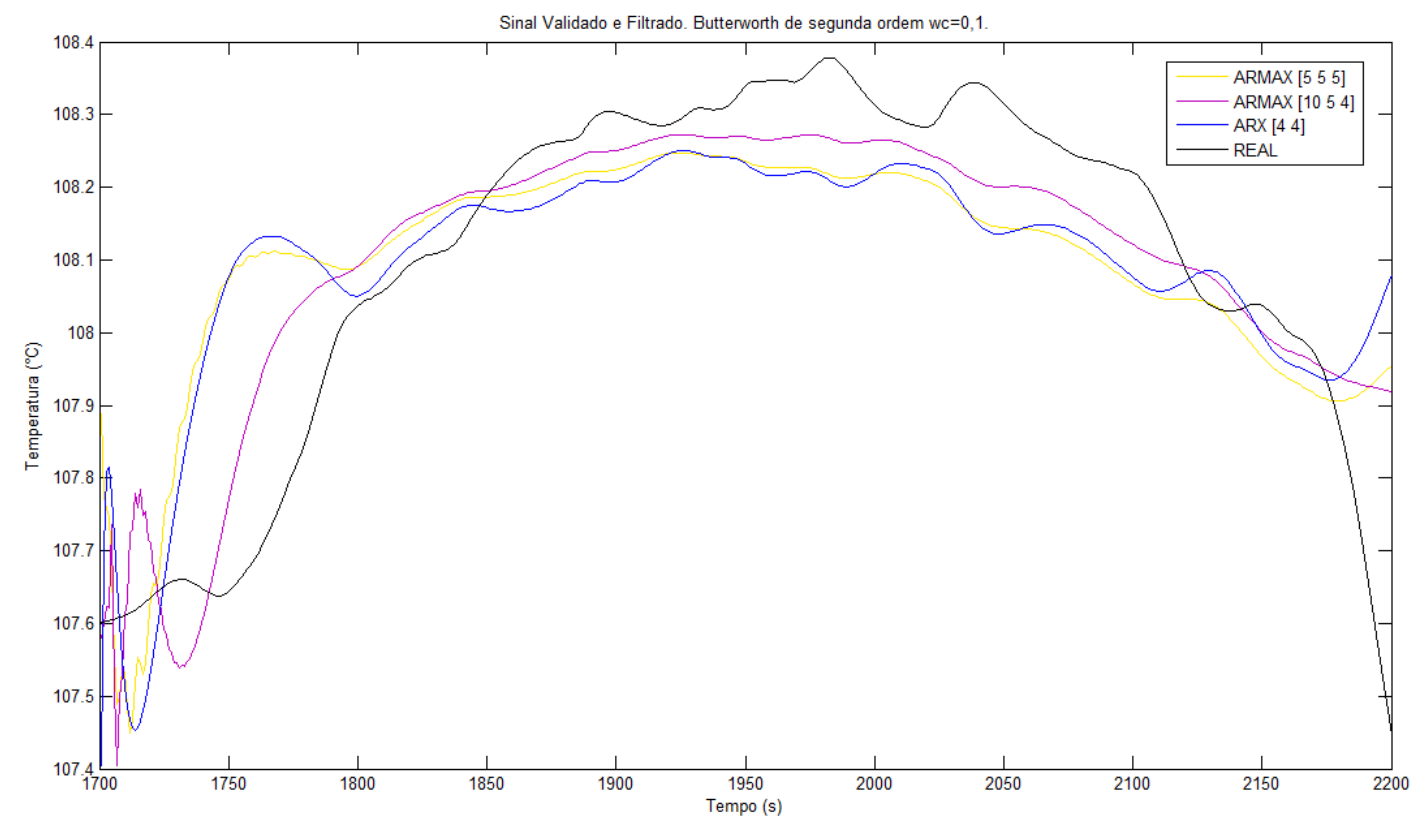

Figura 4.45: Sinais de validação da identificação com a utilização de filtro de segunda ordem e frequência de corte 0,1 .

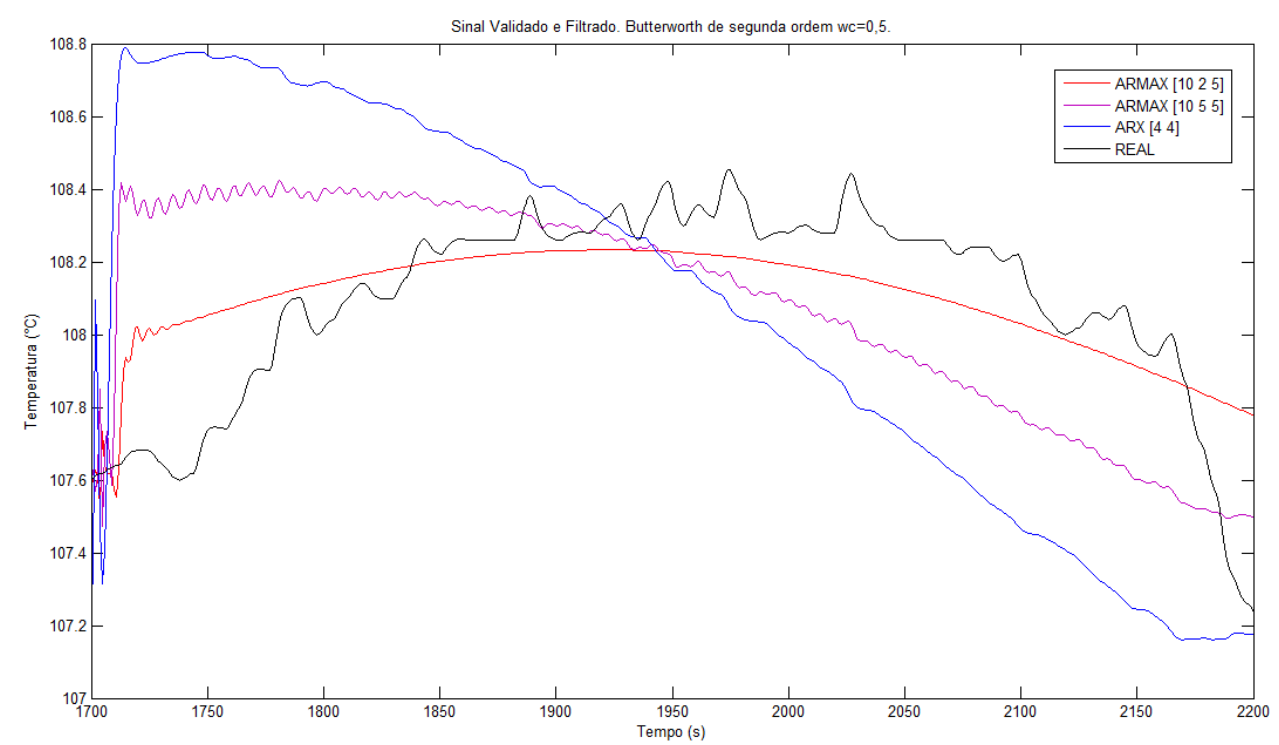

Figura 4.46: Sinais de validação da identificação com a utilização de filtro de segunda ordem e frequência de corte 0,5 .

Após analisar os gráficos com resultado dos sinais de identificação filtrados, figuras 4.42 a 4.46, infere-se que os modelos agora obtidos acompanharam com mais precisão e detalhes a média do comportamento da curva dos dados real, tentando reproduzir inclusive os pequenos picos de variação de temperatura. O modelo que teve menor 
índice de FPE foi o ARMAX com 5 regressores de saída, 5 regressores de entrada e 5 regressores de erro utilizado com filtro de segunda ordem e frequência de corte 0,1 como pode ser notado na tabela 4.6. Todavia deve citar também o modelo ARMAX com 10 regressores de saída, 4 regressores de entrada e 4 regressores de erro (filtro de primeira ordem e frequência de corte 0,1, figura 4.43) aproximou mais da curva do sistema real nos últimos minutos de dados validados. Isto nos ratifica da idéia de que o melhor modelo depende muito da utilidade do modelo a ser encontrado.

Tabela 4.6: Índices FPE de diferentes representações matemáticas, com a utilização de filtro Butterworth de primeira e segunda ordem.

\begin{tabular}{|c|c|c|c|}
\hline Ordem do Filtro & $\begin{array}{c}\text { Frequêencia de } \\
\text { Corte }\end{array}$ & $\begin{array}{l}\text { Modelo [ número de } \\
\text { regressores do sinal de: } \\
\text { saida, entrada, erro] }\end{array}$ & FPE \\
\hline \multirow{5}{*}{ PRIMEIRA ORDEM } & \multirow[b]{2}{*}{$W_{c}=0,1$} & $\operatorname{ARX}[44]$ & $5,2288 \mathrm{e}^{-4}$ \\
\hline & & ARMAX $[1044]$ & $5,3715 \mathrm{e}^{-3}$ \\
\hline & \multirow{3}{*}{$W_{c}=0,5$} & ARX [4 4] & $6,3115 \mathrm{e}^{-6}$ \\
\hline & & ARMAX [5 5.5] & $5,674 \mathrm{e}^{3}$ \\
\hline & & ARMAX $[1044]$ & $5,608 \mathrm{e}^{3}$ \\
\hline \multirow{6}{*}{ SEGUNDA ORDEM } & \multirow{3}{*}{$W_{c}=0,1$} & $\operatorname{ARX}[44]$ & $1,869 \mathrm{e}^{3}$ \\
\hline & & ARMAX [5 5.5] & $1,339 \mathrm{e}^{-8}$ \\
\hline & & ARMAX [1054] & 0,000191 \\
\hline & \multirow{3}{*}{$W_{c}=0,5$} & ARX [4 4] & $6,889 \mathrm{e}^{4}$ \\
\hline & & ARMAX [ 1025$]$ & $5,703 \mathrm{e}^{3}$ \\
\hline & & ARMAX $[1055]$ & $5,494 \mathrm{e}^{3}$ \\
\hline
\end{tabular}

Por fim, aumentou o conjunto de dados da validação com objetivo de analisar a curva do modelo por um maior período de tempo. Entretanto, para isto foi necessário diminiuir a quantidade de dados utilizados na modelagem. Deste modo, foi utilizado 1200 dados para modelagem e 1200 dados para validação. O resultado obtido não foi tão próximo a da curva real, quanto os resultados obtidos com os dados filtrados utilizando $70 \%$ para modelagem, como pode ser observado na figura 4.47 .

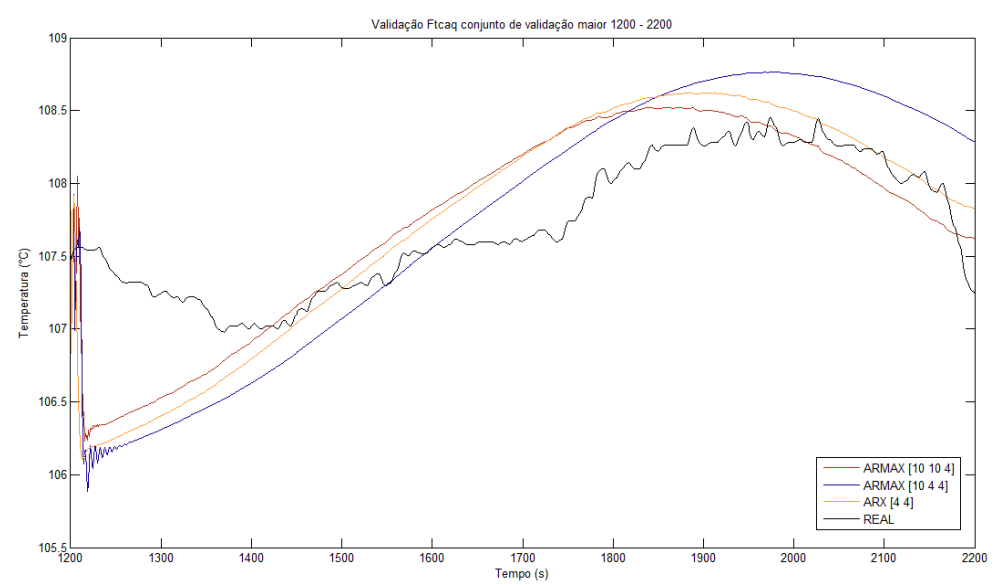

Figura 4.47: Sinais de validação da identificação com a utilização de filtro de segunda ordem e frequência de corte 0,5 . 
Outro conjunto de dados obtidos e identificado refere-se a temperatura do vapor de água utilizado para aquecer as linhas do caldo de cana. Estes tubos devem ser mantidos a uma temperatura próxima à $130^{\circ} \mathrm{C}$, evitando assim a cristalização do caldo e o entupimento dos canais de transporte. Os dados de temperatura, em graus Celsius, versus tempo, em segundos, de entrada e saída coletados podem ser analisados nos gráficos, inferior e superior respectivamente, da figura 4.48 .
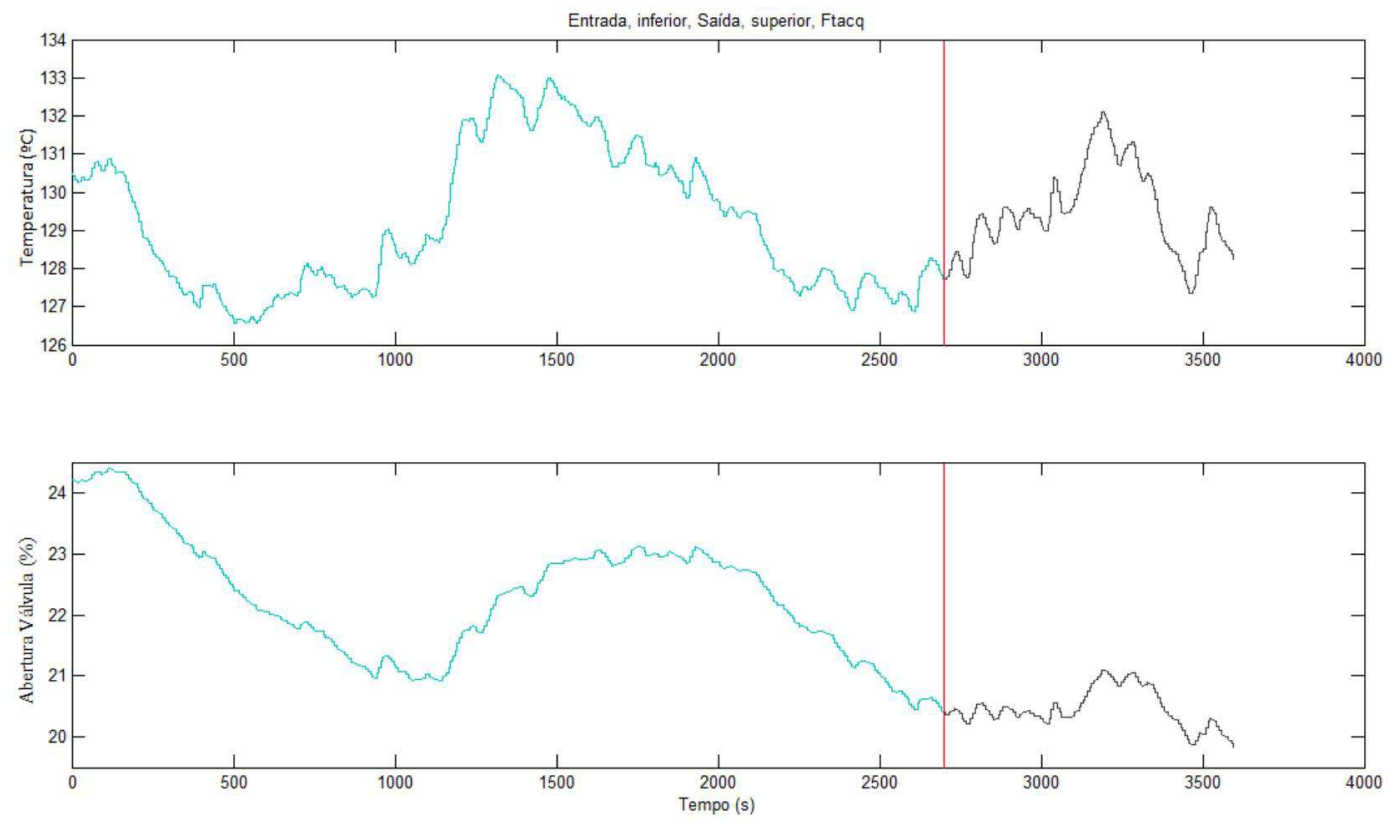

Figura 4.48: Conjunto de dados do sistema utilizados na identificação.

A linha vermelha, observada no gráfico da figura 4.48, delimita os dados utilizados na identificação e validação.

De posse desses sinais, foram realizados diferentes testes a partir de diversas representações matemáticas e distintas estrutura de modelo e, então, estimou-se os parâmetros. Dentre os testes realizados os mais expressivos foram com modelo ARMAX, com coeficientes de entrada, saída e de erro com 20 regressores cada, que pode ser comparado graficamente através da figura 4.49 . 


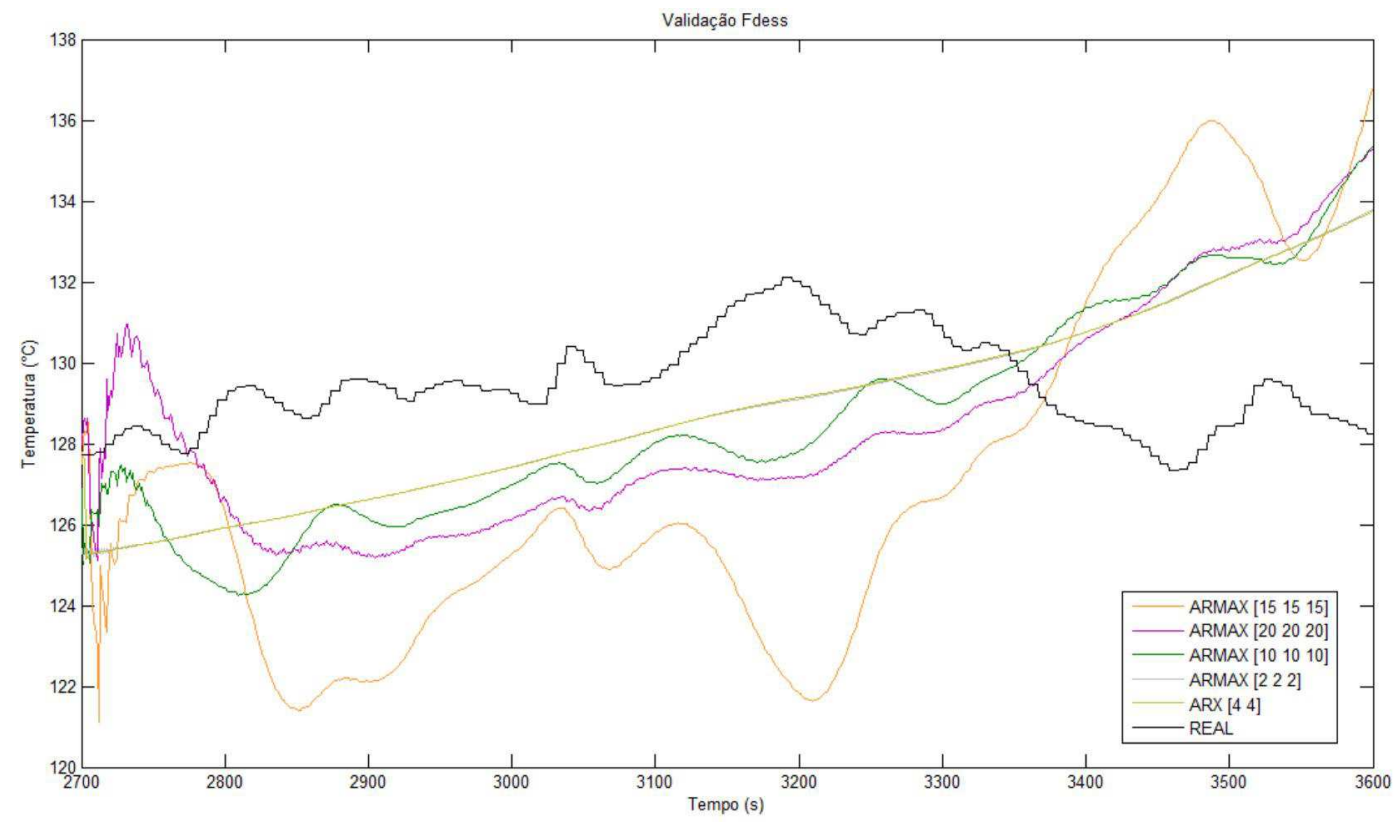

Figura 4.49: Gráfico Comparativo entre diferentes estruturas de modelo. Dado real aferido em preto, identificado com modelo ARMAX, em verde, e com modelo ARX, em laranja.

Na figura 4.49 faz-se notório, assim como observado conjunto de dados do sistema anterior, que as curvas dos resultados com o modelo ARMAX reproduziu o comportamento médio da curva do sistema real até a aproximadamente 3300 segundos, quando os sinais usados na modelagem empírica invertem seu valor, passa a crescer novamente, e os modelos identificados não conseguiram mais acompanhar. Isto possivelmente pode ter ocorrido por acúmulo do erro ao longo do processo. Vale ressaltar que o modelo ARX, que tem valor constante para os regressores do erro, não apresentou nem esta caracteristica, ficando com índice de FPE mais elevado, como observado na tabela 4.7.

Tabela 4.7: Comparação dos índices FPE para diferentes representações matemáticas.

\begin{tabular}{|c|c|}
\hline $\begin{array}{c}\text { Modelo [ número de regressores do sinal de: } \\
\text { saida, entrada, erro] }\end{array}$ & FPE \\
\hline ARX [4 4] & 0,002827 \\
\hline ARM AX [2 2 2] & 0,002799 \\
\hline ARMAX [10 10 10] & 0,002005 \\
\hline ARMAX [15 15 15] & 0,001903 \\
\hline ARMAX [20 20 20] & 0,001902 \\
\hline
\end{tabular}

Em seguida, utilizamos os mesmos filtros, passa-baixa, utilizados no conjunto de dados do sistema anterior, na tentativa de obter melhores modelos deste sistema. Os 
resultados obtidos para filtro de primeira ordem, frequência de corte 0,1 e 0,5 e segunda ordem, com mesmas frequências de corte, podem ser analisados respectivamente nas figuras de 4.50 a 4.53 .

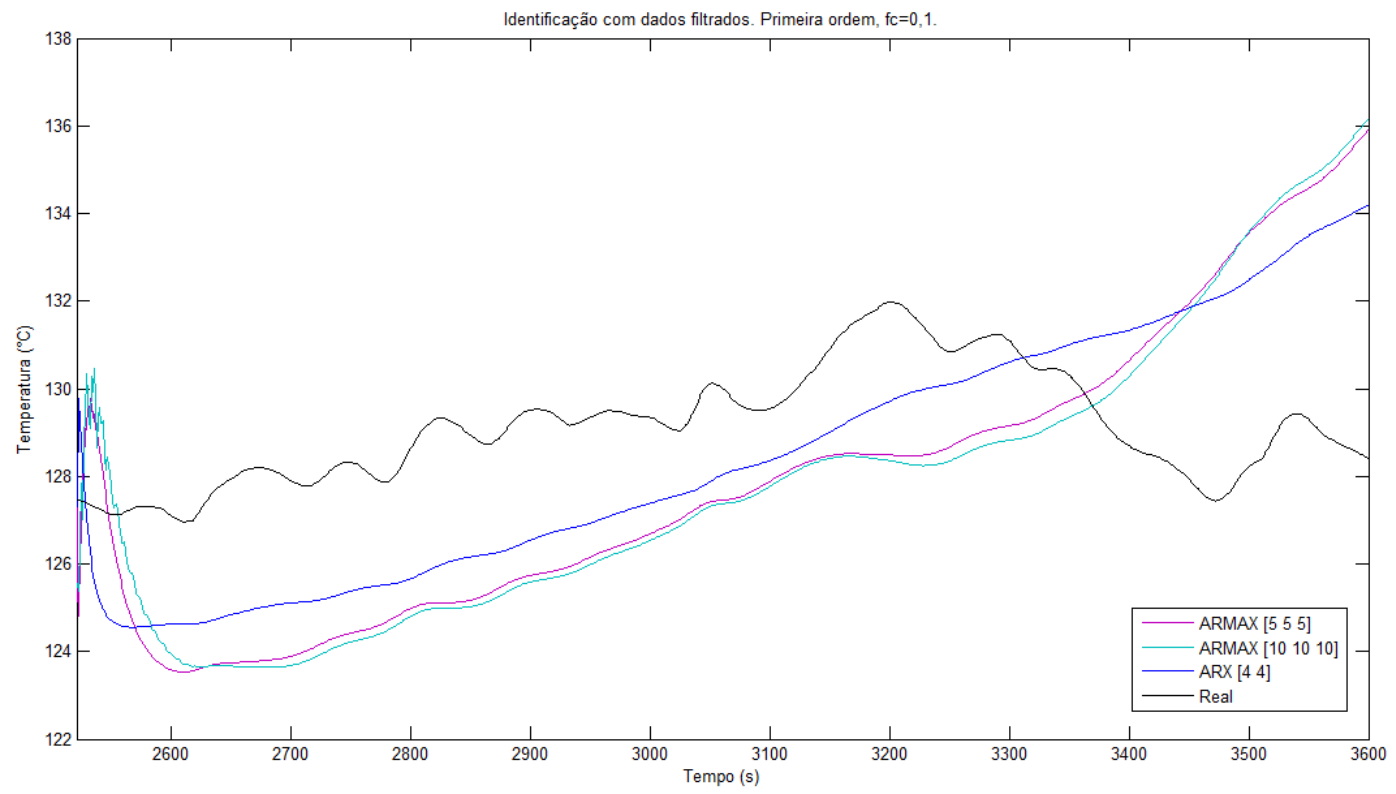

Figura 4.50: Gráfico Comparativo, entre diferentes estruturas de modelo, resultante da validação da modelagem utilizando filtro de primeira ordem e frequência de corte 0,1.

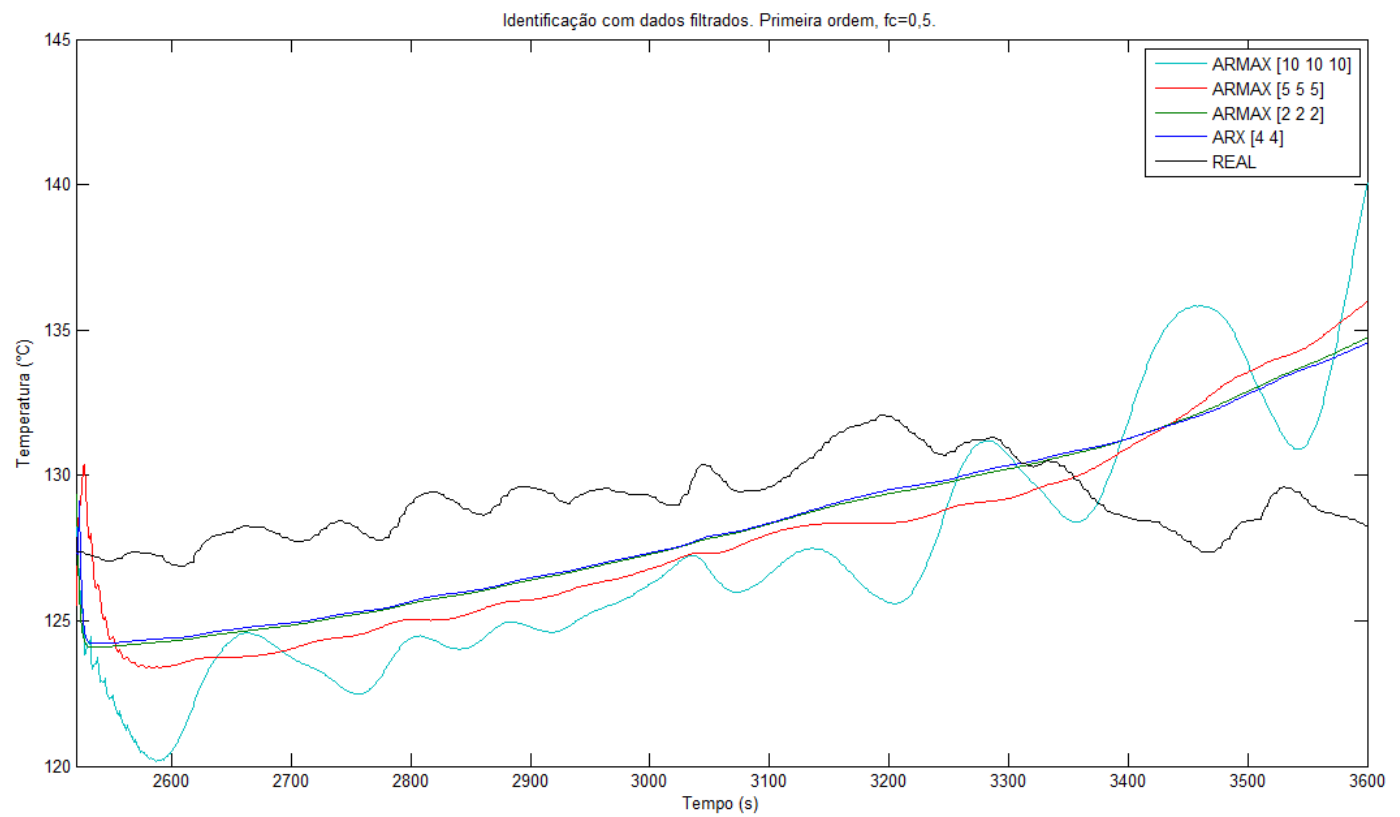

Figura 4.51: Gráfico Comparativo, entre diferentes estruturas de modelo, resultante da validação da modelagem utilizando filtro de primeira ordem e frequência de corte 0,5 . 


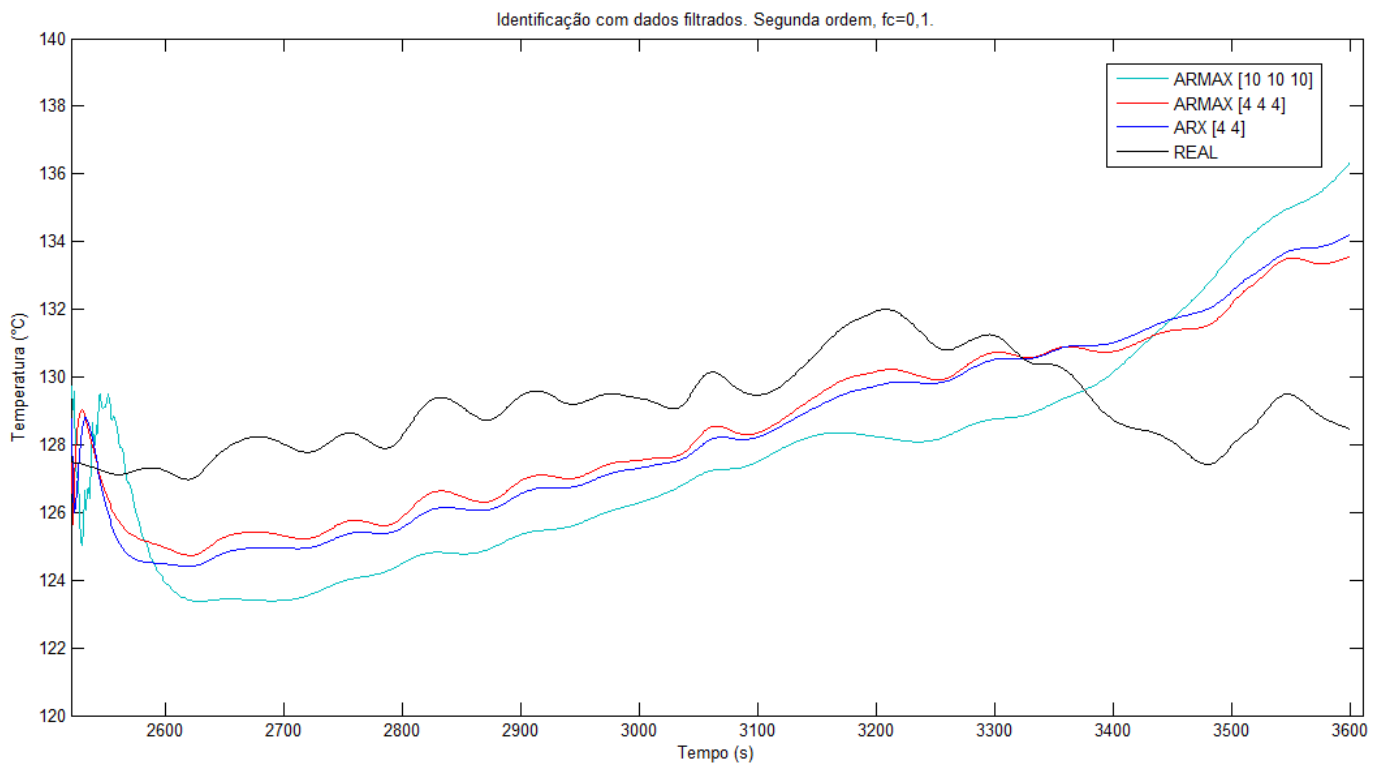

Figura 4.52: Gráfico Comparativo, entre diferentes estruturas de modelo, resultante da validação da modelagem utilizando filtro de segunda ordem e frequência de corte 0,1 .

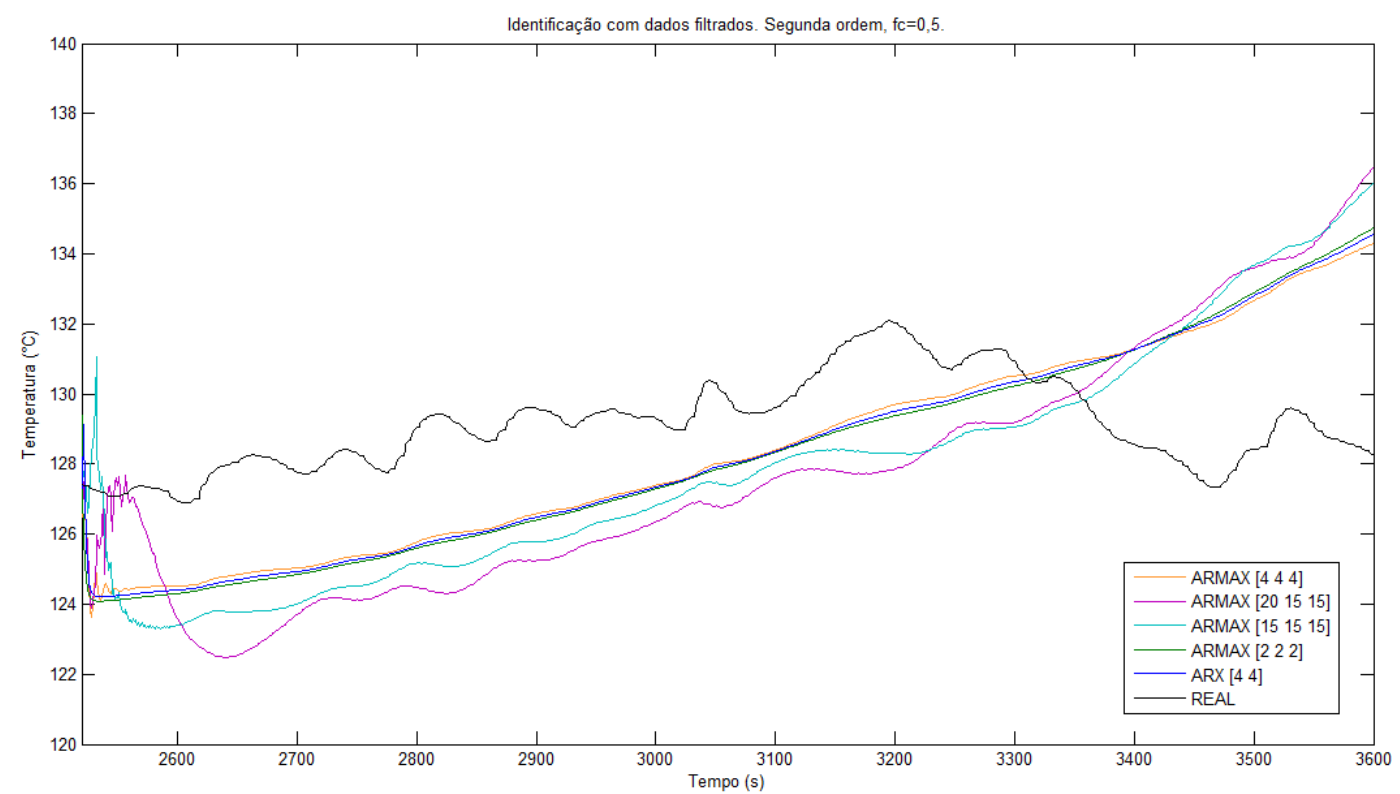

Figura 4.53: Gráfico Comparativo, entre diferentes estruturas de modelo, resultante da validação da modelagem utilizando filtro de segunda ordem e frequência de corte 0,5 .

Ao analisar as figuras 4.50 a 4.53, infere-se que a média do sinal de saída está abaixo da média do sinal utilizado para identificação, convergindo para a curva do sistema real até que a tendência do sinal de entrada se inverte. Após tal inversão o modelo acumula erros e não mais consegue acompanhar adequadamente a curva do 
sistema, devido possivelmente ao pouco tempo de simulação, como visto também antes do uso do filtro. Dentre os modelos identificados o que obteve menor índice de FPE foi o modelo ARMAX (com 10 regressores de saída, 10 de entrada e 10 regressores do erro) com filtro de segunda ordem com frequência de corte 0,1 , como pode ser confirmado na tabela 4.8 .

Tabela 4.8: Índices FPE de diferentes representações matemáticas, com a utilização de filtro Butterworth de primeira e segunda ordem.

\begin{tabular}{|c|c|c|c|}
\hline Ordem do Filtro & $\begin{array}{l}\text { Frequềncia de } \\
\text { Corte }\end{array}$ & $\begin{array}{l}\text { Madelo [ número de } \\
\text { regressores do sinal de: } \\
\text { saida, entrada, erro] }\end{array}$ & FPE \\
\hline \multirow{7}{*}{ PRIMEIRA ORDEM } & \multirow{3}{*}{$W_{c}=0,1$} & $\operatorname{ARX}[44]$ & $2,5303 \mathrm{e}^{-3}$ \\
\hline & & ARMAX $[55.5]$ & $2,2184 \mathrm{e}^{-3}$ \\
\hline & & ARMAX [ $\left[\begin{array}{lll}10 & 10 & 10\end{array}\right]$ & $1,7896 \mathrm{e}^{-3}$ \\
\hline & \multirow{4}{*}{$W_{c}=0,5$} & $A \mathrm{ARX}[44]$ & 0,0004334 \\
\hline & & ARMAX [2 22 2] & 0,0004333 \\
\hline & & ARMAX [ [ 5 5 5 5] & 0,0003374 \\
\hline & & ARMAX [ 101010$]$ & 0,0003071 \\
\hline \multirow{7}{*}{ SEGUNDA ORDEM } & \multirow{3}{*}{$W_{c}=0,1$} & ARX [4 4] & $9,1354 \mathrm{e}^{-3}$ \\
\hline & & ARMAX [4 44] & 0,0001558 \\
\hline & & ARMAX [ [ $\left.\begin{array}{lll}10 & 10 & 10\end{array}\right]$ & $4,5111 \mathrm{e}^{-4}$ \\
\hline & \multirow{4}{*}{$W_{c}=0,5$} & $\operatorname{ARX}[44]$ & 0,0004334 \\
\hline & & ARMAX [4 44] & 0,0003881 \\
\hline & & ARMAX [15 15 15] & 0,0002931 \\
\hline & & ARMAX [ $\left[\begin{array}{llll}20 & 15 & 15\end{array}\right]$ & 0,0002947 \\
\hline
\end{tabular}

Em seguida, alterou-se o conjunto de dados para modelagem tentando retirar a inversão do sinal de entrada. Sendo assim, reduziu-se o conjunto de teste de validação em até 944 segundos, como pode ser observado na figura 4.54, onde a mudança de cor separa o conjunto de dados usado na modelagem e na validação.
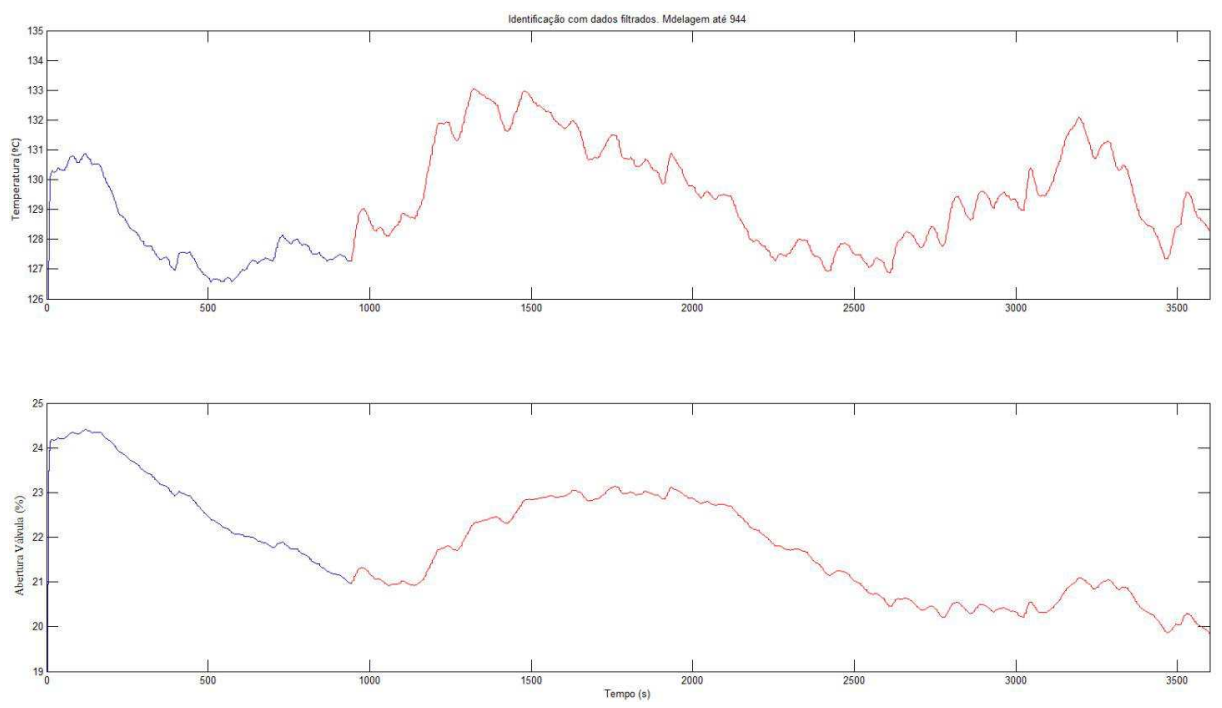

Figura 4.54: Conjunto de dados utilizados para identificação, com uso do filtro de segunda ordem e frequência de corte 0,5 . 
Os resultados obtidos com este conjunto reduzido de dados pode ser analisado na figura 4.55 .

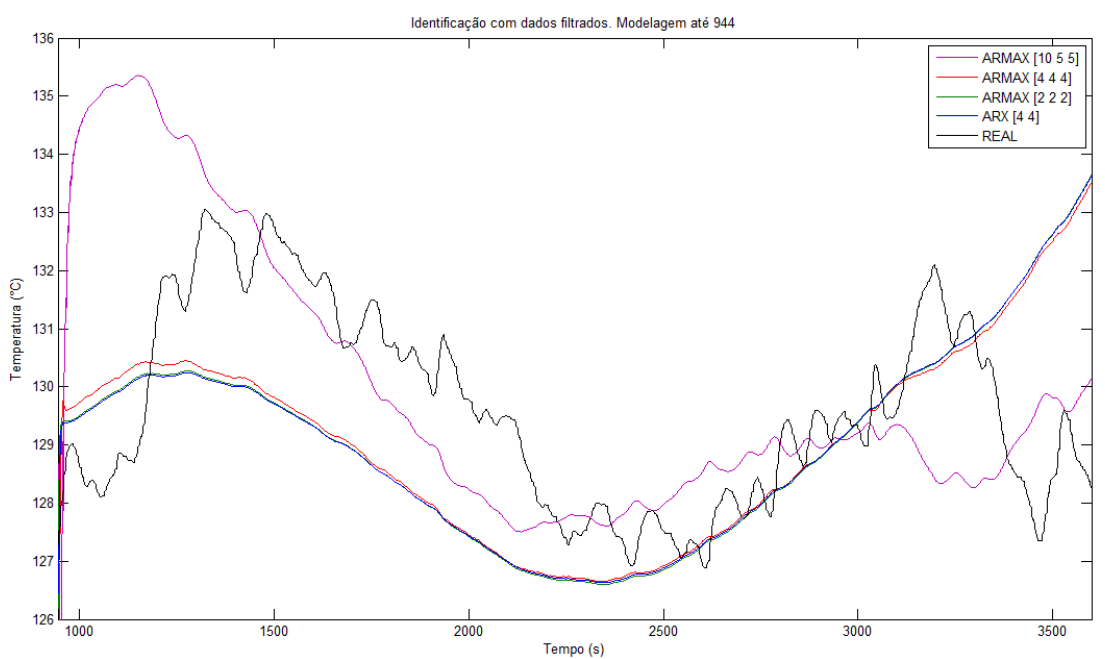

Figura 4.55: Gráfico Comparativo, entre diferentes estruturas de modelo, resultante da validação da modelagem utilizando filtro de segunda ordem e frequência de corte 0,5 e cojunto de dados de validação de 944 segundos.

Ao analisar os gráficos de resposta da identificação com a janela de dados de modelagem com 944 dados, percebe-se que as estruturas matemáticas com menor número de regressores acompanhou o comportamento da curva do sinal real, porém continuou a se "perder" quando houve a inversão do sinal de entrada, ao final dos dados; bem como no conjunto de dados anterior. Todavia, ao aumentar o número de regressores para o modelo ARMAX (10 regressores de saída, 5 regressores de entrada e 5 regressores de erro) nota-se que este modelo acompanhou a tendência do modelo da curva ao longo de todo o processo, entretanto com valores de pico mais distantes da curva do sistema real. Este resultado confirma, mais uma vez, que o melhor modelo depende do que o técnico quer representar com a identificação. Os valores do índice de FPE ratifica este modelo ARMAX com menor índice, tabela 4.9.

Tabela 4.9: Índices FPE de diferentes representações matemáticas, com conjunto de dados de modelagem reduzido para 944 dados.

\begin{tabular}{|c|c|}
\hline $\begin{array}{c}\text { Modelo [ número de regressores do sinal de: } \\
\text { saida, entrada, erro] }\end{array}$ & FPE \\
\hline ARX [4 4] & 0,0002609 \\
\hline ARMAX [4 4 4] & 0,0002452 \\
\hline ARMAX [2 2 2] & 0,0002605 \\
\hline ARM AX [10 5 5] & 0,0002213 \\
\hline
\end{tabular}




\section{Capítulo 5}

\section{Conclusão}

Com o objetivo de validar a técnica experimental de identificação em sistemas dinâmicos industriais ruídosos utilizando estruturas lineares como modelo ARX e ARMAX, foram realizados testes tanto com sinais simulados quanto com sinais adquiridos em sistemas supervisórios de processos reais.

Inicialmente foram realizados testes simulados para melhor entendimento dessas estruturas na presença do ruído. Assim, foram simulados em ambiente Simulink/Matlab seis sistemas com diferentes ordens, valores de tempo morto e constante de tempo, tanto em malha aberta como em malha fechada.

Dessa forma, infere-se que em sistemas de malha aberta tanto o modelo ARMAX quanto o modelo ARX apresentaram boa reprodução do comportamento dados. Deve ressaltar que a partir do sistema dois a curva do modelo ARMAX aproximou-se mais da curva do sistema real, chegando a sobrepor-se em certos momentos. Já nos sistemas de malha fechada, observou-se que o modelo ARMAX reproduziu com precisão a curva do sistema até o segundo sistema, ou seja, para sistemas de relação $(\theta / \tau)$ maior os modelos lineares utilizados não apresentaram tão bons resultados como em malhar aberta, principalmente com maior percentual de ruído.

De posse de um maior conhecimento das estruturas matemáticas ARX e ARMAX partiu-se para simulação com os dados reais de temperatura, coletados a partir do supervisório da Usina Ipiranga. Para estes dados foi necessária uma preparação dos sinais antes de serem utilizados na identificação, como redução do conjunto de dados e utilização de filtro para redução do efeito do ruído que contribuíram com a melhoria 
nos resultados simulados.

Com base nestes testes pôde-se concluir que os modelos, com estrutura ARMAX, acompanharam a média do comportamento do sistema real ao longo do tempo chegando a reproduzir um comportamento complexo do sistema real como os crescimentos e decrescimentos das curvas, melhor que o modelo ARX. Deve ressaltar que o curto tamanho do conjunto dos dados e a não manipulação dos dados de entrada limitou uma análise mais ampla dos modelos obtidos. Além disso, deve ser considerado que os sitemas reais apresentem não linearidades no comportamento da saída em relação a entrada que as estruturas lineares utilizadas não conseguiram reproduzir.

Sendo assim, como proposta de trabalhos futuros sugere-se melhoria na preparação dos dados, como uma análise no dominío da frequência dos dados e considerando a utilização espectro de frequencia dos sinais para uma melhor filtragem dos sinais. Além disso, o uso de estruturas não lineares como modelos NARMAX ou mesmo uso de redes neurais podem contribuir para melhor reprodução das caracteristicas dos sistemas. 


\section{Apêndice A}

\section{Modelo OSI}

Durante as últimas duas décadas houve um grande aumento na quantidade e no tamanho das redes. Várias redes proprietárias foram criadas através de implementações diferentes de hardware e de software. Como resultado muitas redes com diferentes especificações tornaram-se incompatíveis e inconunicavéis. Assim, para sanar esse problema a ISO reconheceu a necessidade e criou, em 1984, um padrão internacional de protocolos: o modelo de referência OSI; tornando, assim, as redes interoperáveis.

O modelo OSI é formado por sete camadas, conforme a Figura A.1. Esta estrutura multi-camadas facilita a compreensão de questões fundamentais sobre a rede.

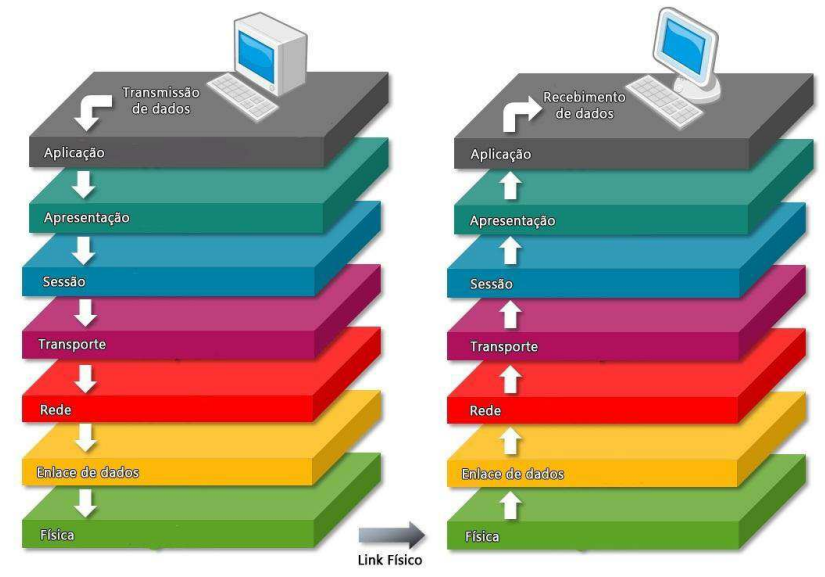

Figura A.1: Modelo de referência OSI.

O objetivo de cada camada é oferecer determinados serviços às camadas superiores, isolando estas camadas dos detalhes de implementação desses recursos. Uma determinada camada $\mathrm{N}$, de uma máquina (ou host), comunica-se com a camada $\mathrm{N}$ de outra 
máquina. As regras e conversões envolvidas na troca de informação formam o protocolo da camada $\mathrm{N}$.

Entre cada par de camadas adjacentes existe uma interface, que define claramente as regras de utilização dos serviços oferecidos pela camada inferior. O conjunto de camadas e protocolos definem a arquitetura da rede. Todavia, deve ressaltar que o modelo OSI não é uma arquitetura de rede, pois ele não especifica os serviços e os protocolos exatos que devem ser usados em cada camada. Esse modelo de referência apenas informa o que cada camada deve fazer.

As principais funções de cada camada são:

\section{Camada Física}

A camada física, responsável pela transferência de bits, define as especificações elétricas, mecânicas, funcionais e de procedimentos do meio de transmissão. Característica como nível de voltagem, taxas de dados físicos, conectores físicos e outros atributos similares são definidos pelas especificações da camada física (CARDOZO e MAGALHÃES, 2002).

\section{Camada Enlace de Dados}

A camada de enlace de dados assegura que o conteúdo da mensagem local de destino seja exatamente igual a origem, assim, a função desta camada é apresentar à camada superior a filtragem dos erros da camada física. Para isso, divide os dados de entrada em quadros (data frame) e os transmite seqüencialmente. Se o serviço for confiável, o receptor confirmará a recepção correta de cada quadro, enviando um quadro de confirmção. Outra função importante desempenhada por esta camada é o controle do fluxo de quadros, evitando que um transmissor envie quadros em uma taxa superior a que o receptor é capaz de processar.

3. Camada de Rede

A camada de rede controla a operação da sub-rede. Uma das suas funções principais é o roteamento de pacotes do transmissor ao receptor. O roteamento pode apresentar características dinâmicas, evitando gargalos em certos roteadores, ou estáticos, empregando-se sempre a mesma rota entre os comunicadores (CARDOZO e MAGALHÃES, 2002). 
Outra função desta camada é a fragmentação e a remontagem dos pacotes para atender a limites impostos por determinados segmentos da sub-rede de comunicação. Em sub-redes de difusão e redes locais esta camada é extremamente simples, dado que sua principal atribuição (roteamento) é inxistente.

4. Camada de Transporte

A camada de transporte tem como função principal receber dados da camada acima dela, camada sessão, dividi-los em unidades menores, caso necessário, repassar essas unidades à camada de rede e assegurar que todos os fragmentos chegarão corretamente à outra extremidade. Além disso, esta camada isola as camadas superiores das mudanças inevitáveis na tecnologia de hardware.

Outra característica desta camada é que ela também determina que tipo de serviço deve ser fornecido à camada de sessão e, em última análise, aos usuários da rede. Segundo TANENBAUM (2003), o tipo de conexão de transporte mais mais usado é um canal ponto a ponto livre de erros que entrega mensagens ou bytes na ordem em que eles foram enviados. Não obstante, outros tipos possíveis de serviços de transporte de mensagem são as mensagens isoladas sem nenhuma garantia de entrega; e a difusão de mensagens cuja mensagens são enviadas à muitos destinos. O tipo de serviço é determinado quando a conexão é estabelecida.

Vale salientar que a camada de transporte é a primeira camada fonte-destino, ou seja, um programa na máquina fonte, ou transmissora, "conversa" diretamente com o programa destino, ou seja, o receptor. Nas camadas inferiores, os protocolos são trocados entre cada uma das máquinas e seus vizinhos imediatos, e não entre máquina de origem e destino, que podem está separados por muitos roteadores. A diferença entre a camadas 1 a 3 (camada física, enlace de dados e rede), que são encandeadas, e as camadas de 4 a 7 (camada de transporte, sessão, apresentação e aplicação), que são camadas fim a fim, como pode ser observado na Figura A.2.

\section{Camada de Sessão}

A camada de sessão permite que usuários diferentes máquinas estabeleçam sessões entre elas, como por exemplo login, transferência de arquivos, etc.. Uma sessão oferece diversos serviços como controle de diálogo (mantendo o controle de quem deve transmitir em cada momento); gerenciamento de token (impedindo que duas partes tentem executar a mesma operação ao mesmo tempo) e a sicronização 


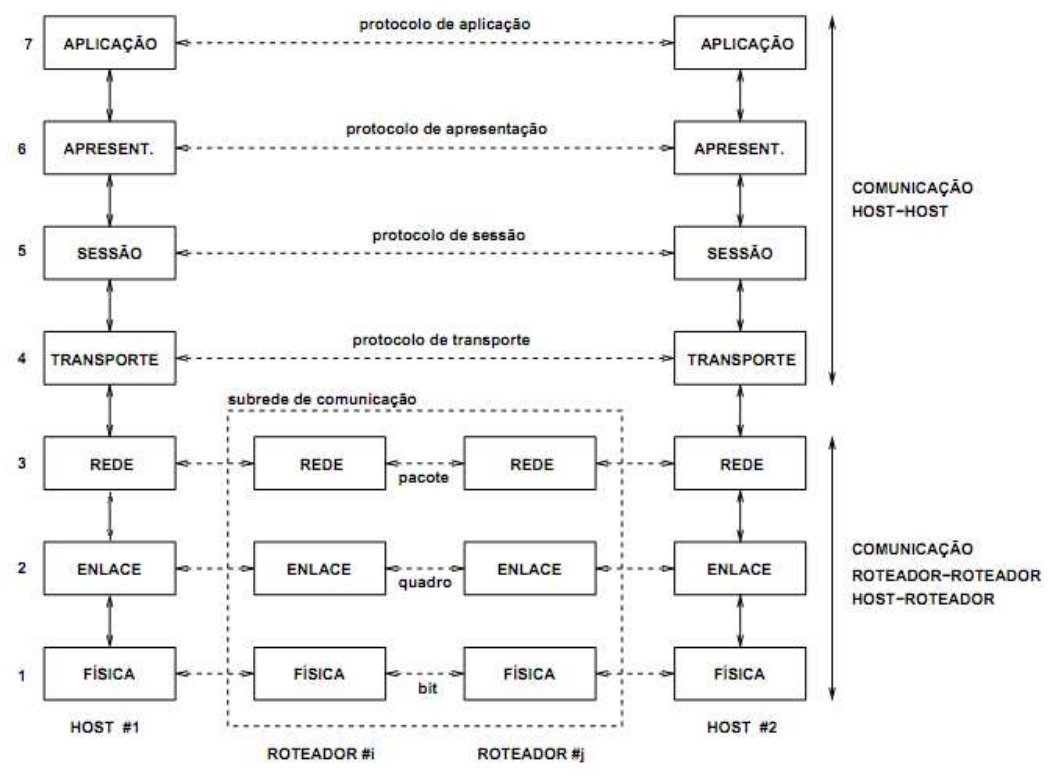

Figura A.2: Modelo detalhado OSI.

(realizando verificações períodicas de transmissão longa para possibilitar que elas continuem a partir do ponto que estavam ao ocorrer uma falha) (TANENBAUM, 2003).

6. Camada de Apresentação

Difere das camadas inferiores, que se preocupam com a movimentação de bits, por está realcionada à sintaxe e a semântica das informações transmitidas. Esta camada fornece serviços de compressão e criptografia de dados. A compressão de dados é útil para o envio de grandes massas de dados como imagens e textos. Já a criptografia é utilizada quando os dados transmitidos são confidenciais e visa evitar sua interceptação em trânsito por pessoas não autorizadas. Protocolos para estes serviços são também definidos nesta camada.

7. Camada de Aplicação

Esta camada dispõe uma série de serviços comumente necessários para os usuários. Um serviço muito utilizado é o Hyper Text Transfer Protocol (HTTP), que é a sabe para a World Wide Web (WWW). Outros protocolos de aplicação usados são transferência de arquivos, Correio eletrônico, login remoto e serviços de diretório são exemplos destes serviços. Essa camada caracteriza-se por ser controlada diretamente pelo usuário. 
Embora existam outros modelos, a maior parte dos fabricantes de rede, hoje, relaciona seus produtos ao modelo de referência OSI, especialmente quando desejam instruir os usuários ao uso dos produtos.

\section{A.1 Modelo OSI e as Redes Fieldbuses}

As redes Fieldbuses são baseadas no modelo de referência OSI/ISO, contudo estas redes não implementam as sete camadas. As redes de barramento de campo (fieldbuses) utilizam, normalmente, apenas três camadas: a física, a camada de enlace de dados e a camada de aplicação. Além dessas camadas, há também, eventualemnte, a presença da camada de usuário, como pode ser observado na Figura A.3.

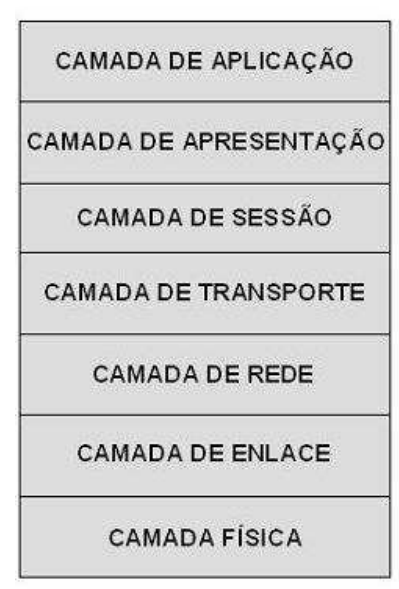

MODELO OSI

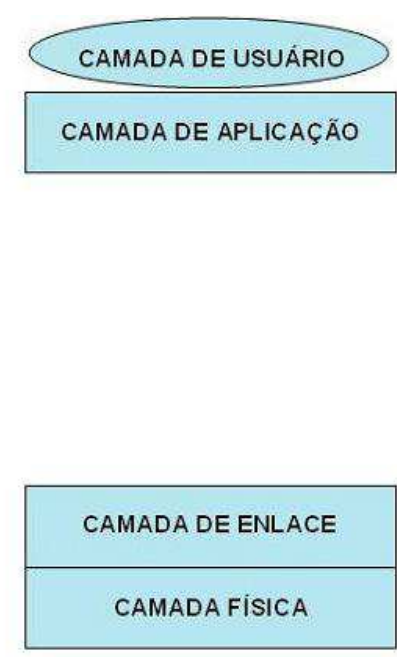

FIELDBUS

Figura A.3: Modelo OSI para Redes Fieldbuses.

A camada física corresponde a camada física do modelo OSI, como descrita anteriormente. Assim como as camadas de enlace de dados e aplicação que correspondem, respectivamente, as camdas de dados de enlace e aplicação como as do modelo de referência OSI.

Já a camada de usuário não é definida no modelo OSI. Na camada de usuário (User Application Layer) a verdadeira funcionalidade acontece, os transmissores medem, os posicionadores atuam e o usuário interagem com a rede; ou seja, é neste nível que os formatos de dados e suas semânticas são definidos e permitindo, assim, que os dispositivos de barramento de campo possam entender os dados e atuar de acordo com desejo 
da aplicação (CONCER, 2005).

Destarte, vale salientar que para realizar a comunicação entre diferentes tipos de instrumentos em uma rede de barramento de campo, faz-se necessário que todas as camadas, citadas, sejam implementadas da mesma maneira; permitindo portanto que os instrumentos sejam compatíveis entre si. 


\section{Apêndice B}

\section{Método de Ziegler e Nichols}

Ziegler e Nichols foram os pioneiros a propor uma método objetivo e simples para sintonia de controladores PID. Neles foram descritos dois métodos clássicos para determinar os parâmetros do controlador PID a partir de um processo com uma entrada e uma saída - Single input Single Output - Única Entrada e Única Saída (SISO) - que são amplamente utilizados tanto em seu formato original bem como em suas diversas modificações. O primeiro método é baseado na análise gráfica para sistemas de primeira ordem, com tempo morto e cuja entrada é um degrau unitário. Já o segundo, aplica-se a sistemas de malha fechada e deve ser considerado valores de ganho e período críticos obtidos experimentalmente a partir da estabilidade marginal quando aplicado uma entrada degrau.

A seguir será detalhado o primeiro método, foco deste trabalho. O segundo método pode ser melhor evidenciado em OGATA (2003), DORF e BISHOP (1998) e JÚNIOR (2009).

\section{B.1 Primeiro Método ZN - Método Gráfico}

Este método utiliza a resposta ao degrau unitário para gerar uma variação na saída de uma planta em malha aberta. Se a planta não possuir integradores e nem pólos complexos conjugados dominantes, então a curva de resposta a esta entrada pode ter aspecto de um S, como observado na figura B.1. 


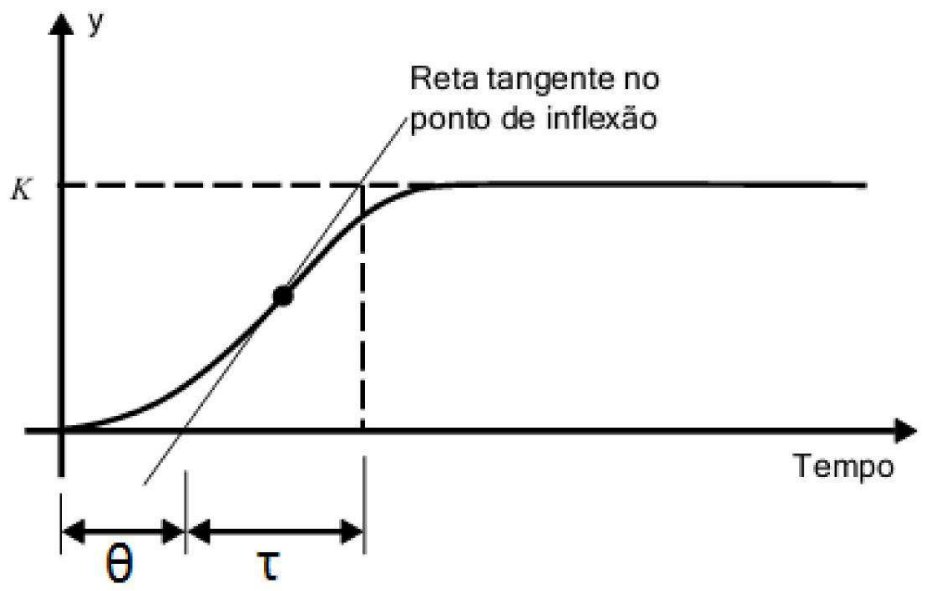

Figura B.1: Curva de resposta ao degrau em forma de S. (OGATA, 2003)

De posse do gráfico de resposta a entrada degrau do sistema para sistemas de primeira ordem, é possível determinar o atraso, ou tempo morto, $(\theta)$ e a constante de tempo $(\tau)$. Para isso, basta traçar uma reta tangente ao ponto de inflexão da curva com o formato de S, sendo $\theta$ determinado pela intersecção dessa reta com eixo horizontal. Já o valor de $\tau$ corresponde ao tempo que a reta tangente intercepta a reta $y(t)=K$, desconsiderando o valor do tempo morto.

Após a determinação dos valores de $\theta$ e $\tau$, ZN sugerem em seu método valores de $K_{p}, T_{i} e T_{d}$ de acordo com a fórmula da tabela B.1

Tabela B.1: Regra Sintonia de Ziegler e Nichols baseado na resposta ao degrau da planta - Primeiro Método. (OGATA, 2003)

\begin{tabular}{|c|c|c|c|}
\hline Controlador & $K_{p}$ & $T_{i}$ & $T_{d}$ \\
\hline \hline $\mathrm{P}$ & $\frac{\boldsymbol{\tau}}{\theta}$ & $\infty$ & 0 \\
\hline PI & $0.9 \frac{\mathbf{\tau}}{\theta}$ & $\frac{\theta}{0.3}$ & 0 \\
\hline PID & $1.2 \frac{\mathbf{\tau}}{\theta}$ & $2 \theta$ & $0.5 \theta$ \\
\hline
\end{tabular}




\section{Referências Bibliográficas}

AGUIRRE, L. A. Introdução a Identificação de Sistemas - Técnicas Lineares e Não lineares aplicadas a sistemas Reais Editora UFMG,(2 edição ed.), 2004.

AGUIRRE, L. A., G. G. RODRIGUES, e C. R. F. JÁCOME. Identificação de Sistemas Não-Lineares Utilizando Modelos Narmax Polinomiais - Uma Revisão e Novos Resultados. SBA Controle 6 A Automação, 1998, volume 9(2), 90-106p.

ALBUQUERQUE, P. U. B. d. e A. R. d. ALEXANDRIA. Redes Industriais. Ensino Profissional, 2009.

ANG, K. H., G. CHONG, e Y. LI. PID Control System Analysis, Design, and Technology. IEEE Transactions on Control Systems Technology, 2005, volume $13(4)$.

Arruda, G. H. M. d. e P. R. Barros. Estimação da função de Sensibilidade Baseada em Experimento com Relé em Malha Fechada. Revista Controle 64 Automação, 2003, volume 14(3).

ARRUDA, L. V. R. d., F. N. JR, M. C. S. SWLECH, e M. R. DELGADO. Um Método Evolucionário para Sintonia de Controladores PI/PID em Processos Multivariáveis. Revista Controle \&S Automação, 2008, volume 19(1).

ASTRÖM, K. J. e T. HÄNGGLUD. The future of PID Control. Control Engineering Pratice 9, 2001, 1163-1175.

BRANDÃO, D.. Ferramenta de Simulação para projeto, avaliação e ensino de redes fieldbus. Tese de Doutorado, EESC-USP, 2005. 
CARDOZO, E. e M. F. MAGALHÃES. Redes de Computadores: Modelo OSI. Dissertação de Mestrado, UNICAMP, 2002.

CARMO, M. J. d. Ambiente Educacional Multifincional Integrado para Sintonia e Avaliação do Desempenho de Malhas Industriais de Controle. Dissertação de Mestrado, UFJF, 2006.

COELHO, L. d. S. Tuning of PID controller for an automatic regulator voltage system using chaotic optimization approach. Chaos, Solitons \& Fractals, 2009, volume 39(4),1504-1514.

CONCER, G. M. Identificação de Processos Industriais utilizando Foudation Fieldbus. Dissertação de Mestrado, UFSC, 2005.

CUNHA, M. J. d. Desenvolvimento e implementação de uma Ferramenta Computacional Aplicada no Processo de Identificação de Sistemas em Ambiente FieldBus Foudation. Dissertação de Mestrado, EESC-USP, 2009.

DORF, R. C. e R. H. BISHOP. Sistemas de Controle Modernos, Editora LTC, (8 edição ed.), 1998.

FERNANDES, F. S. Identificação por Predição de Erro e Síntese de Controladores Robustos. Dissertação de Mestrado, UFMG, 2002.

FONSECA, M. d. O. Comunicação OPC - Uma abordagem prática. VI Seminário de Automação de Processos, Associação Brasileira de Metalugia e Materiais, 2002.

IWASE, M., H. IIKUBO, S. HATAKEYAMA, e K. FURUTA • An identification method for continuous-time transfer functions based on nonlinear optimization. IEEE, 2002.

JANKE, M. OPC - plug and play integration to legacy systems. IEEE CONF REC ANNU PULP PAP IND TECH CONF, 2000, 68-72.

JÚNIOR, M. L. d. L. e $\quad$ F. R. $\quad$ B. CARDOSO. Comparação das Tecnologias de Rede Fieldbus e Profibus. Disponível em: < ftp://users.dca.ufrn.br/DCA447/trabalho2/trabalho2_1.pdf > . (Acesso em 20 de outubro de 2010). 
JÚNIOR, R. F. F. Identificação Remota de Plantas Industriais Utilizando Tecnologias OPC e $\boldsymbol{C Y B E R O P C}$.Dissertação de Mestrado,EESC-USP, 2009.

JURIZATO, L. A. e P. S. R. PEREIRA. Sistemas Supervisórios. Network Technologies, Nova Odessa, 2003.

LIPTÁK, B. G.. Instrument Engineers' Handbook, Chilton Book Company, (3 edição ed.), 1995.

LJUNG, L. . System Identification - Theory for the User. Prentice Hall, 1999.

MAnnala, M. J. Projetos de Controle Convecional e Adaptativo aplicados ao Sistema Térmico de uma Bancada de Ensaios de Cabos e Condutores. Dissertação de Mestrado, PUC-PR, 2004.

NETO, A. F. d. S. e F. J. GOMES. Controladores PID: Introduzindo Inteligência Computacional no Controle Industrial. COBENGE, 2010.

NOGUEIRA, T. A. Redes de Comunicação para Sistemas de Automação insdustrial. Dissertação de Mestrado, UFOP, 2009.

OGATA, K. Engenharia de Controle Modernos, Editora Prentice Hall, (4 edição ed.), 2003.

OPCFOUDATION. Padronização da Comunicação através da Tecnologia OPC. Disponível em: < http://www.softbrasil.com.br/site/novidade/artigos/151/ >. (Acesso em 25 de junho de 2009).

OVIEDO, J. J. E., T. BOELEN, e P. V. OVERSCHEE. Robust Advanced PID Control(RAPID). IEEE Control Systems Magazine,2006.

PANTONI, R. P. Desenvolvimento e implementação de uma Descrição de Dispositivos Aberta e Não Proprietária para equipamentos FieldBus Foudation Baseada em XML. Dissertação de Mestrado, EESC-USP, 2006.

SANTOS, S. C. Identificação Multivariável Aplicada aos Processos Químicos. Dissertação de Mestrado, UFSC, 2000.

SILVA, A. P. G.and SALVADOR, M. O que são sistemas supervisórios, Elipse Knowledge Base. Brasil, 2005. 
SJOBERG, J., Z., QINGHUA, L. LJUNG, A. BENVENISTE, B. DEYLON, P. GLORENNEC, H. HJALMARSSON, e A. JUDITSKY. Nonlinear black-box modeling in system identification: a unified overview*. Automatica volume 31(12), 1691-1724p.

SMAR. Manual de Instruções dos Blocos de Função, 2002.

SMAR. O que é Profibus. Disponível em: < http://www.smar.com/brasil2/profibus.asp antenor >. (Acesso em 22 de janeiro de 2011).

SOUZA, A. J. d., R. H. FEIJÓ, C. G. BEZERRA, G. B. P. LEITÃO, W. L. S. d. ANDRADE, L. A. GUEDES, e A. A. D. MEDEIROS. Gerência de Informação de Processos Industriai: Um estudo de Caso na Produção de Petróleo e Gás. VII SBAI/II IEEE LARS, 2005.

TANENBAUM, A. S. Redes de Computadores, Campus,(4 edição ed.), 2003.

VIANA, D. e E. G. SILVEIRA. Automação Industrial: desafios e alternativas ao gerenciamento de projetos multidisciplinares. Congresso anual da $A B M$, 2005.

YU, C. C. Autotuning of PID Controllers - A Relay Feedback Approach,(2nd ed.), 2006.

ZEILMANN, R. P. Uma Estratégia para Controle e Supervisão de Processos Industriais via Internet. Dissertação de Mestrado, UFRGS, 2002.

ZHUANG, M.and ATHERTON, D.P. Automatic tunning of optimum PID controlles. Control Theory and Applications. IEEE Proceeedings D, May 1993, volume 140(2), 216-224p. 